\title{
HUMIC SUBSTANCES IN NATURAL WATERS AND THEIR COMPLEXATION WITH TRACE METALS AND RADIONUCLIDES: \\ A REVIEW
}

by

Sam Boggs, Jr., David Livermore, and Martin G. Seltz

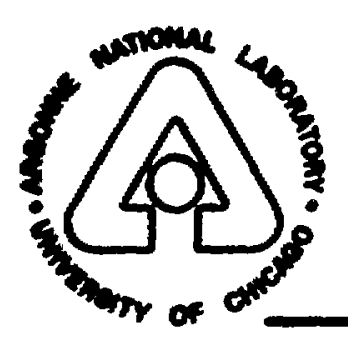

ARGONNE NATIONAL LABORATORY, ARGONNE, ILLINOIS Operated by THE UNIVERSITY OF CHICACO for tho U. S. DEPARTMENT DF ENEAGY undor Contract W-31-100-Engos6 

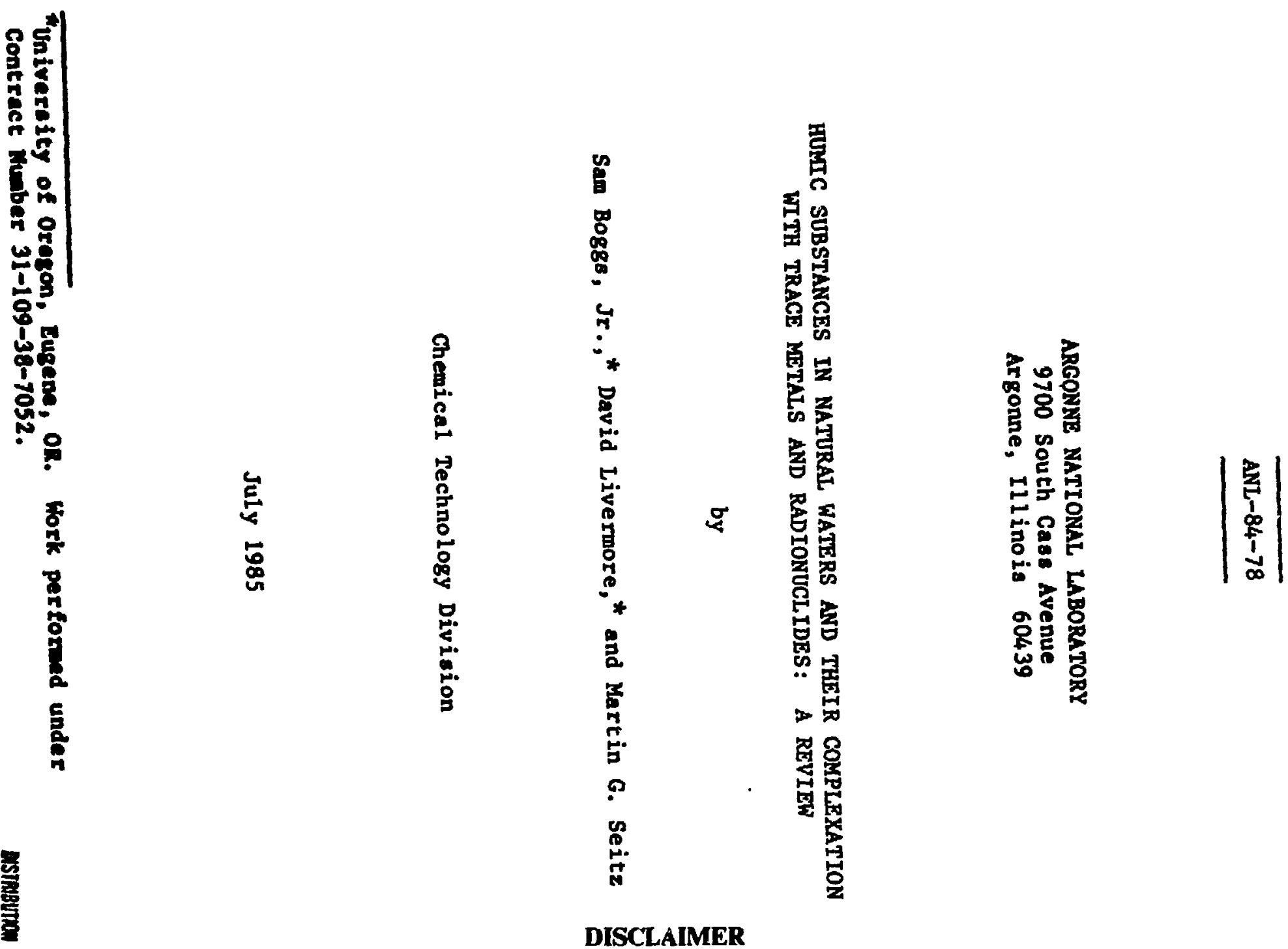
Government. Neither the United States Government nor any agency thereof, nor any of their employees, makes any warranty, express or implied, or assumes any legal liability or responsibility for the accuracy, completeness, or usefulneas of any information, apparatus, product, or procese discloned, or represents that its use would not infringe privately owned rights. Reference herein to any specific commercial product, process, of service by trade name, trademark. manufacturer, or otherwise does not necewarily constitute or imply its endorsement, recommendation, of favoring by the United Stutes Government or any agency thereof. The views and opinions of suthors exprewed herein do not necesurily state or reflect those of the United States Government or any avency thereof. 
ABSTRACT ............................ 1

I. INTRODUCTION

II. DISTRIBUTION AND CHARACTERIZATION OF DISSOLVED

HUMIC SUBSTANCES IN WATURAL WATERS . . . . . . . . . . . . 4

A. Dissolved Organic Carbon Content of Natural Waters . . . . 4

B. Types of Organic Carbon Compounds . . . . . . . . . . 5

C. General Characteristics of Humic Substances. . . . . . . 7

D. Chemical Composition and Structure of Humic

Substances ................... 8

1. Elemental Composition ................. 8

2. Oxygen-Containing Functional Groups ........... 9

3. Chemical structure .. . . . . . . . . . . . . 9

E. Origin of Humic Substances in Natural Waters

and Soils.................... 12

F. Methods for Isolating and Purifying Humic Substances . . . . 17

1. Extraction and Fractionation of Humic

Substances from Soils ................. 17

2. Purification of Soil-Derived Humic Substances . . . . . . 19

3. Extracting Humic Substances from Water . . . . . . . 19

G. Methods for Analyzing and Characterizing Humic

Substances . . . . . . . . . . . . . . . . 22

1. Spectrophotometry in the Ultraviolet and

Visible Regions... . . . . . . . . . . . . . . 23

2. Infrared Spectrophotometry ............... 24

3. Nuclear Magnetic Resonance Spectrometry . . . . . . . . . 24

4. Electron Spin Resonance Spectrometry . . . . . . . . . 24

5. X-Ray Analysis and Electron Microscopy .......... 24

6. Viscosity Measurements .............. 25

7. Surface Tension Measurements ............. 25

8. Molecular Weight Measurement B . . . . . . . . . 25

9. Degradation Methods . . . . . . . . . . . . . 26

III. INTERACTION OF HUMIC SUBSTANCES WITH METALS . . . . . . . . . . 27

A. General Concepts . . . . . . . . . . . . . 27

1. Metal Complexes . . . . . . . . . . . . . 27

2. Chelates ..................... 28

3. Types of Ligands . . . . . . . . . . . . . . 29 
B. Stabilitles of Metal Complexes and Chelates . . . . . . . 29

1. Stability Constants for Metal Chelates . . . . . . . . 29

2. The Importance of Stability Constants . . . . . . . . 34

3. Factors Influencing the Stability of Metal Complexes . . . . . . . . . . . . . . . 34

C. Types of Metal-0rganic Interactions . . . . . . . . . . . 37

D. Techniques for Studying Ketal-Organic Interactions . . . . 41

1. Potentiometric Titration . . . . . . . . . . 41

2. Ion-Exchange Equilibrium .............. . 41

3. Equilibrium Dialysis . . . . . . . . . . . . 42

4. Gel Filtration Chromatography . . . . . . . . . . 42

5. Ion-Selective Electrodes ................ 43

6. Calculation of Stability Constants from

Experimental Data . . . . . . . . . . . . . 43

E. Influences of Metal-Ligand Concentrations and

Environmental Variables on the Stability of

Metal-organic Complexes . . . . . . . . . . . . . 45

1. Influence of Metal Type . . . . . . . . . . . . 46

2. Type of Organic Matter ................. 47

3. Metal and Organic AcId Concentrations.......... 48

4. Effects of pH.... ................. 48

5. Effects of Ionic Strength ............. 49

IV. COMPLEXING OF RADIONUCLIDES BY ORGANIC SUBSTANCES . . • . . • . • 51

A. Introduction . . . . . . . . . . . . . . . . 51

B. Complexing of Radionuclides with Synthetic

Organic Compounds . . . . . . . . . . . . . . . 52

C. Complexing of Radionuclides with Humic Oiganic

Substance. . . . . . . . . . . . . . . . . . . 54

1. Complexirig of Soll Humic Substances with

Rad lonuclides . . . . . . . . . . . . . . . 54

2. Complexing of Radionuclides by Dissolved Humic

Substances in Surface Water 8 and Groundwater . . . . . 62

D. Diacussion: Factors Afiecting Radionuclide-organic

Conplexing . . . . . . . . . . . . . . . . . 76

1. Oxidation State of Actinide Elements . . . . . . . 78

2. Bffecta of pll . . . . . . . . . . . . . . . . 80

3. Effecte of Tenperature on Radionuclide Mobility In the Presence of Organic Complexante . . . . . . . 81

4. Effects of Ionic Strength ................. 82

5. Effecto of Conpeting LIgand. .............. 84 


\section{TABLE OF CONTENTS (contd)}

Page

6. Effects of Radionuclide Concentration . . . . . . . 86

7. Effects of Dissolved Organic Carbon Concentration . . . . . . . . . . . . . . 87

v. SURMARY AND CONCLUSIONS . . . . . . . . . . . . . . 90

A. Distribution and Characterization of Dissolved

Hunic Substances in Natural Waters . . . . . . . . 90

B. Interaction of Hunic Substances with Metals . . . . . . . 91

1. Type of Metal Ion ................... 91

2. Type of Organic Matter . . . . . . . . . . . . . 92

3. Metal and HA-FA Concentrations . . . . . . . . . . 92

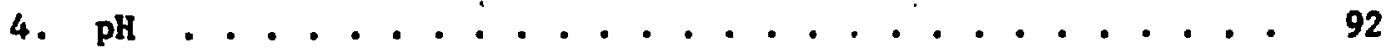

5. Ionic strength . . . . . . . . . . . . . . 92

c. Complexing of Radionuclides by Organic Substances . . . . . 92

1. Oxidation state................. 93

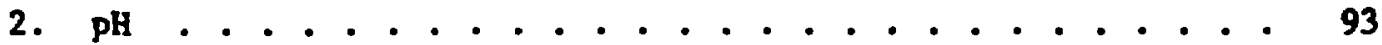

3. Temperature .................... 94

4. Ionic strength ... . . . . . . . . . . . . 94

5. Radionuclide Concentration ............ 95

6. Humic and Fulvic Acid Concentration.......... 95

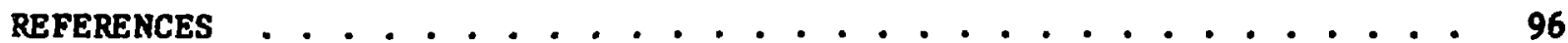




\section{LIST OF FIGURES}

No.

1. Chemical Structures for Fulvic and Humic Acids . . . . . . . 14

2. Proposed Pathway to Marine Humic and Fulvic Acids by Oxidative Crosslinking of Polyunsaturated Lipids Catalyzed by Ultraviolet Light and Transition Metals . . . . . .

3. Fractionation and Purification Procedures for Humic and Fulvic Acids.................... 18

4. Exampl es of Metal Complexes . . . . . . . . . . . . . 27

5. Structural Diagrams of Chelated Compounds Illustrating the Ring Structure of Chelates and the Manner in which the Ligand Ions "Grip" the Central Metal Ion .......... 29

6. Structural Diagram Illustrating how Fe is Sequestered and Chelated by Ethylenediaminetetraacetic Acid . . . . . . 31

7. Examples of Chelate Rings . . . . . . . . . . . . 35

8. Structure of Phthalic and Salicylic Acids . . . . . . . 38

9. Scatchard Plot for the Binding of Copper(II) by Fulvic Acid at $\mathrm{pH} 8.0$............... 45

10. P1ot of Bound $\mathrm{Cu}^{2+}$ vs. Total $\mathrm{Cu} 2+$ at Various Ionic Strengths as Derived from Ion-Selective Electrode Titration of the Fulvic Acid with $\mathrm{Cu}^{2+}$........... 50

11. Resin Extraction of Pu-Contaminated Soil . . . . . . . . . 55

12. Influence of Humic Acid on the Rate of Am(III) Transport in Groundwater . . . . . . . . . . . . . . . . . 59

13. Effect of pH on Extractability of 239pu . . . . . . . . . . 61

14. The Relationship of Distribution Coefficient and Concentration of Dissolved Organic Carbon ............

15. Variation of Distribution Ratio as a Function of Ambient Dissolved Organic Carbon Concentration for Several Natural Waters . . . . . . . . . . . . . .

16. Variations of Distribution Ratio as a Function of Dissolved Organic Carbon Concentration . . . . . . . . . .

17. Dialysis of an Aqueous Solution of Uraniva as a Function of $\mathrm{pH}$ in Humic Acid, Fulvic Acid, and Tannic Acid 
18. Dialyzable Uranium Concentration as a Function of Total Uranium Concentration at pH 6.0 in an Aqueous Solution Containing $20 \mathrm{mg} / \mathrm{L}$ of Humic Acld, Fulvic Acid, and Tannic Acid

19. Plot of Apparent $\mathrm{pK}_{\mathrm{a}}$ Values as a Function of Degree of Dissociation . . . . . . . . . . . . . . . . . 71

20. Variation of the Enthalpy of Protonation as a Function of the pH of the Measurement . . . . . . . . . . . 72

21. Variation of the Distribution Coefficient with humic and Fulvic Acid Concentration . . . . . . . . . . 73

22. Dependence of the Logarithmic Ratio of Bound to Free ${ }^{154} \mathrm{Eu}(\mathrm{III})$ on $\mathrm{pH}$...................... 77

23. Concentrations of U, Co, Sr, and Cs in Aqueous Systems Contalning Kaolinite, Illite, and Montmorillonite, Both with and without Oxalic Acid, as a Function of Temperature . . . . . . . . . . . . . . . . . . 83

24. Distribution Ratios for Americlum between Synthetic Groundwater and Granulated Pomona Basalt Reacted Seven Days in the Presence of Various Concentrations of Humic Acid

25. Distribution Ratios for Neptunium between Synthetic Groundwater and Granulated Pomona Basalt Reacted Seven Days in the Presence of Various Concentrations of Humic Ac1d 
1. Naturaliy Occurring Organic Substances . . . . . . . . . . 6

2. Elemental Composition of Humic Acids and Fulvic Acids Extracted by Alkall from Different Sol1s and Materials . . . . . 9

3. Elemental and Functional Group Analyses of Humic AcIds and Fulvic Acids...................... 10

4. Elemental Composition of Humic Concentrates from Selected Groundwaters . . . . . . . . . . . . . . . . . 11

5. Principal Functional Groups In Humic Substances . . . . . . . 12

6. Analysis of "Model" Humic and Fulv1c Acld . . . . . . . . . . 13

7. Kethods of Concentrating Humic Substances from Water . . . . . 20

8. Methods for Analysis and Characterization of thumic Substances . . . . . . . . . . . . . . . . . 23

9. Structural Types of Metal Complexes and Chelates . . . . . . . 30

10. Donor Atoms in Metal Complexes . . . . . . . . . . . . . 31

11. Some Common Types of UnIdentate LIgands . . . . . . . . . . . 32

12. The Effects of Steric Hindrance on Stability Constants, $18 \mathrm{~K}_{1} \mathrm{~K}_{2}$......................... 36

13. Factors Influencing Solution Stabilities of Complexes - . • - 39

14. Stability Constanta for Uranium-Organic Complexes . . . . . . 69

15. BInding Constants for Eu(III) and Am(III) with Fulvic and Humic Acids at pH 4.5 ............... 73

16. Binding Constants of Selected Radionuclides wth lumis Acld ......................... . 74

17. Binding Constants for Th(IV) to Humic and Fulvic Acids . . . . 74

18. Comparison of Oxidation States for the Actinide Blements in Solution . . . . . . . . . . . . . . . . . 78

19. Inf1uence of Carbonate, Blcarbonate, and Organic Meter on Solubilization of Pu in Filtered Seamater . . . . . . 
HUMIC SUBSTANCES IN MATURAL WATERS AND THEIR COMPLEXATION WITH TRACE METALS AND RADIONUCLIDES: A REVIEW

by

Sam Boggs, Jr., * David Livermore, * and Martin G. Seitz

\begin{abstract}
Dissolved humic substances (humic and fulvic acids) occur in surface waters and groundwaters in concentrations ranging from less than $1 \mathrm{mg}(\mathrm{C}) / \mathrm{L}$ to more than $100 \mathrm{mg}(\mathrm{C}) / \mathrm{L}$. Humic substances are strong complexing agents for many trace metals in the environment and are also capable of forming stable soluble complexes or chelates with radionuclides. Concentrations of humic materials as low as $1 \mathrm{mg}(C) / \mathrm{L}$ can produce $a$ detertable increase in the mobility of some actinide elements by forming soluble complexes that inhibit sorption of the radionuclides onto rock materials. The stability of trace metal- or radionuclide-organic complexes is commonly measured by an empirically determined conditional stability constant $\left(K^{\prime}\right)$, which is based on the ratio of complexed metal (radionuclide) in solution to the product concentration of uncomplexed metal and humic complexant. Larger values of stability constants indicate greater complex stability.
\end{abstract}

The stability of radionuclide-organic complexes is affected both by concentration variables and environmental factors. In general, complexing is favored by incieased concentration of humic or fulvic acid, decreased concentration of radionuclide, increased $\mathrm{pH}$, and decreased ionic strength. Actinide elexents are generally most soluble in their higher oxidation states. The presence of high concentrations of humic substances tends to reduce actinides to their less soluble state; however, competitive chelation by the humic substances acts in the opposite direction to increase solubility.

Radionuclides can also form atable, insoluble complexes with humic materials that tend to reduce radionuclide mobility. These insoluble complexes may be radionuclide-humate colloids that subsequently precipitate from solution, or complexes of radionuclides and humic substances that sorb to clay minerals or other soil particulates strongly enough to immobilize the radionuclides. Colloid formation appears to be favored by increased radionuclide concentration and lowered $\mathrm{pH}$; however, the conditions that favor formation of insoluble complexes that sorb to particulates are still poorly understood.

*Univeraity of Oregon, Eugene, $O R$. 


\section{INTRODUCTION}

High molecular weight compounds of humic and fulvis acids occur in small concentrations in natural surface waters and groundwaters. These humic substances are the major organic constituents of soils and sediments. They are described, generally, as polymers with molecular weights from 300 to 30,000 . The humic substances form through the breakdown of plant and animal tissues by chemical and biological processes that tend to produce complex chemical structures that are more stable than the original material from which they were derived [SCHNITZER-1978]. One of the more important characteristics of humic substances is their ability to form water-soluble and water-insoluble complexes with metal ions and hydrous oxides and to interact with clay minerals and various organic compounds such as alkanes, fatty acids, and toxic organic substances such as pesticides. The characteristics of natural humic materials, their origin, and their complexes with naturally present metals have recently been reviewed [BOGGS-1985].

The formation of water-soluble complexes of humic substances with metal ions is of particular interest because complexing can increase concentrations of these ions in natural waters far above the concentrations that could be expected based on the solubilities of inorganic species. The metals may be transported in flowing groundwaters, followed by destruction of the meta1humic substance bond at elevated temperature, and this is thought to give rise to the formation of ore deposits. In any case, the solubilities of simple ore minerals have long been recugnized to be inadequate to form some ores [BARNES]. Apparently aqueous complexes are responsible for forming these ores, with organic humic and fulvic acids being one group of ligands important in the formation of some ores [SAXBY]. Many low-temperature deposits of sulfide minerals have associated organic solids and aqueous species. However, little has been done to date to characterize these materials. Responsible scientists must be concerned about the possibility that complexing of disposed metal-containing wastes by humic substances may enhance the mobility of these metals and promote their entry into the biosphere. This potential problem has special pertinence to the siting of radioactive waste repositories where the complexed metals may be radioactive. Therefore, for $a$ better understanding of both the occurrence of nur natural resources and the possible dispersion of disposed waste, it is important that we develop a fuller understanding of the ability of dissolved humic substances to form complexes with dangerous metals. We may then be able to assess our natural mineral resources more accurately and to take adequate precautions to prevent the dispersal of disposed radionuclides.

Section II presents the origin and characteristics of humic materials as we understand them today and outilines the methods that have been used to separate and analyze these aubstances.

Section III focuses on the genersl problem of metal-organic interactions and treats some of the factors that are important in chelating and complexing of wetal ions by humic subatances.

Section IV deals specifically with the complexing of radionuclidee by organic substances, treated from the standpoint of both eapirical and experimental studies. 
Because the complexing of radionuclides by organic subetances is the oubject of our ongoing work, we attempted to be comprehensive in the final part of the review by considering all recent relevant publications. They were identified from computer-stored and -retrieved data files. In addition, oubject and author indexea of major chemical and geochemical journa is were searched for relevant publications. Finally, indexes of citations to major works in this oubject were examined to reveal relevant publications that were missed in the other searches. As a result of this effort, we feel we have identified a reasonably comprehenoive list of publications (several hundred) for developing the review, and many of the se publications have been cited herein. 


\section{DISTRIBUTION AND CHARACTERIZATION OF DISSOZVED HUAIC SUBSTANCES IN NATURAL WATERS}

\section{A. Dissolved Organic Carbon Content of Natural waters}

Most natural waters contain some dissolved organic carbon (DOC); however, surprisingly few measurements of the organic carbon content of natural waters have beel made. This scarcity of data is apparentiy because most scientists have been primarily concerned with the inorganic composition of natural waters and, until recently, have had little interest in the dissolved organic constituents. The lack of a simple, inexpensive method for determining the organic carbon content of waters, particularly those with low DOC levels, has probably also hampered collection of DOC data.

Stumm and Morgan [STUMM] suggest that concentrations of DOC in natural waters range from about $0.1 \mathrm{mg} / \mathrm{L}$ in seawater and some unpolluted and nonproductive fresh waters to $10 \mathrm{mg} / \mathrm{h}$ in lakes, streams, and estuaries; however, the value of $10 \mathrm{mg} / \mathrm{L}$ is clearly too low as an upper range for DOC concentrations in lakes and streams because much higher values have been reported. For example, Malcolm and Durum [MALCOLM] report an average value of $27 \mathrm{mg} / \mathrm{L}$ DOC in the Sopchoppy River in Florida, and Thurman [THURMAN-1979] reports $32 \mathrm{mg} / \mathrm{L}$ in the Suwannee River of Georgia. Reuter and Perdue [REUTER-1977] indicate that rivers draining the coastal plains of the southeastern United States in regions of abundant swamps contain concentrations of humic substances as high as $100 \mathrm{mg}(\mathrm{C}) / \mathrm{L}$ with a mean value of about $45 \mathrm{mg}(\mathrm{C}) / \mathrm{L}$; however, these values may also include particulate carbon $(>0.45 \mathrm{~mm})$. Thus the DOC content of these waters is probably lower than the total organic carbon (TOC) content reported. (Most investigators arbitrarily place the particle size boundary between "dissolved" organic carbon and particulate organic carbon at $0.45 \mathrm{~m}$. Thus, all organic carbon that passes through a $0.45-\mu m$ filter is considered DOC). Christman and Gjessing [CHRISTMAN-1983B] point out that DOC values in streams vary considerably with climatic zones, ranging from $3 \mathrm{mg} / \mathrm{L}$ in temperate and arid zones to $6 \mathrm{mg} / \mathrm{L}$ in tropical zones and $10 \mathrm{mg} / \mathrm{L}$ in subarctic zones. Meybeck [MEYBECK] reported a stream volume weighted world average of $5.75 \mathrm{mg}(\mathrm{DOC}) / \mathrm{L}$. Values of $\mathrm{DOC}$ as high as $115 \mathrm{mg} / \mathrm{L}$ have been found in some high pH, alkaline lakes [WAHLGREN-1982].

Ocean water appears to have a lower DOC content than most lakes and otreams. Williems [WILLIAMS] reports that the average concentration of DOC in the oceans from depths of $0-300 \mathrm{~m}$ is $1.0 \mathrm{mg} / \mathrm{L}$ and from 300-3800 a is $0.5 \mathrm{mg} / \mathrm{L}$; however, values as high as $3 \mathrm{mg} / \mathrm{L}$ have been found in sowe parts of the Gulf of Mexico [HARVEY].

Published data on the DOC content of groundwaters are sparse. Means [MEANS-1982A] reports the DOC values of waters from nine deep wells in granitic and basaltic rocks in Washington and sweden range from less than $1 \mathrm{mg} / \mathrm{L}$ to se wuch ss $20 \mathrm{mg} / \mathrm{L}$. Leenheer and Bagby [LEENELER-1982] sapled waters from 77 wells (at depths ranging to $210 \mathrm{~m}$ ) from basaltic and volcanic rocks and interbedded sediments at the Idaho Mational Engineering Laboratory and measured DOC values ranging from 1.6 to $18.0 \mathrm{mg} / \mathrm{L}$ (average, $6.1 \mathrm{mg} / \mathrm{L}$ ). Values of DOC as high a 18 to $20 \mathrm{~m} / \mathrm{L}$ are not typical, however, and mat groundwaters appear to contain only a fow $\mathrm{n} / \mathrm{L}$ DOC. In fact, Leenheer et $\mathrm{i}$. [LEENHER-1974] found that the wan DoC concentration of 100 sroundwaters 
in sandstones, 1 inestones, and crystalline rocks from various locations (10-400 deep) was $1.2 \mathrm{mg} / \mathrm{L}$. Grigoropoul os and Smith [GRIGOROPOULOS] measured the organic carbon content of 13 wells and springs in Missouri and found that the DOC content ranged from 0.003 to $0.3 \mathrm{mg} / \mathrm{L}$ in 8 prings and from 1.0 to $5.5 \mathrm{mg} / \mathrm{L}$ in shallow groundwaters. Robinson et al. [ROBINSON] examined the organic carbon in groundwaters from five sms 11 towns in Illinois and reported DOC values ranging from 1.5 to $7.2 \mathrm{mg} / \mathrm{L}$. Thurman [THURMAN-1979] measured the DOC in the groundwaters of five aquifers from various parts of the United States and obtained values ranging from 0.2 to $13 \mathrm{mg} / \mathrm{L}$.

Much higher values of DOC are found in some deep formation waters (many of wich are brines) associated with oil and gas fields. Carothers and Kharaka [CAROTHERS] found concentrations of organic acids (mainly short-chain fatty acids ranging from acetic acid to butric acid) in formation waters in California and Texas that ranged from $50 \mathrm{mg}(\mathrm{C}) / \mathrm{L}$ for low temperature waters (1ess than about $80^{\circ} \mathrm{C}$ ) to $4900 \mathrm{mg}(\mathrm{C}) / \mathrm{L}$ for higher temperature waters (80$200^{\circ} \mathrm{C}$ ). Means [MEANS-1982B] reports values of 12.8 to $76.5 \mathrm{mg} / \mathrm{L} \mathrm{DOC}$ in formation waters from deep wells in some petrcleum-producing basins such as the Paradox Basin in Utah and the Permian Basin of New Mexico and Texas.

\section{B. Types of Organic Carbon Compounds}

The dissolved organic substances in natural waters encompass a wide range of compounds from $\mathrm{CH}_{4}$ to high molecular weight polymers, and include functional groups* ranging from hydrocarbons to complex multifunctional compounds [FAULKNER]. These organic compounds are derived by biological and biochemical degradation of organic life substances. Table 1 shows a greatly simplified list of these substances that have been reported in natural waters. Note that the organic decomposition products include both humic substances (humic and fulvic acids) and large numbers of non-humic substances such as amino acids, fatty acids, phenols, sterols, natural sugars, hydrocarbons, urea, and porphyrins. Many organic compounds in natural waters are complex polymers that consist of large molecules made up of many repeating subunits (monomers). If these polymeric organic substances contain a sufficient number of polar or hydrophilic functional groups such as $-\mathrm{COO}^{-},-\mathrm{NH}_{2}, \mathrm{R}_{2} \mathrm{NH},-\mathrm{RS}^{-}, \mathrm{ROH}$, and $\mathrm{RO}^{-}$, they will remain in solution despite their large molecular size [STUMM]. These large polymers include polypeptides, certain lipids, polysaccharides, and huric suostances.

\footnotetext{
*The term "functional group" refers to the molecules of compounds in a particular family of organic compounds such as alkanes, alcohols, or esters that are characterized by the presence of a certain arrangement of atoms; e.g., the - $\mathrm{COOH}$ carboxyl functional group. The functional group is that part of the molecule where wost of its chemical reactions occur and is the part that effectively determines the compound's chemical properties. The properties of functional group are very similar whether it appears in a simple compound or a complex molecule.
} 
Table 1. Whtally Occurring Organic Substances.a Copyright 1981 John wiley \& Sons. Reprinted by permission [STUMM] .

\begin{tabular}{|c|c|c|}
\hline Life Substances & Decomposition Intermediales & $\begin{array}{l}\text { Intermediates and Products Typically Found } \\
\text { in Nonpolluted Natural Waters }\end{array}$ \\
\hline Proteins & 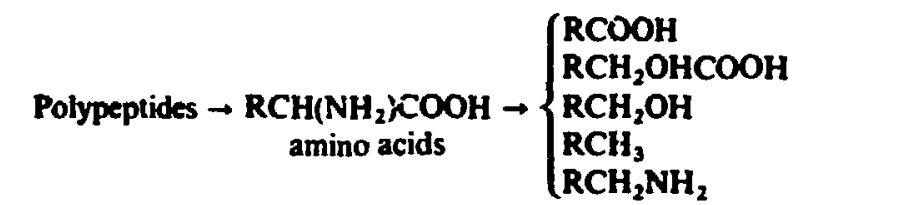 & $\begin{array}{l}\mathrm{NH}_{A}^{+}, \mathrm{CO}_{2}, \mathrm{HS}^{-}, \mathrm{CH}_{4}, \mathrm{HPO} 2_{4}^{--} \text {, peptides. } \\
\text { smino acids, uren, phenols, indole, fatty } \\
\text { acids, mercaptans }\end{array}$ \\
\hline $\begin{array}{l}\text { Polynucieotides } \\
\text { Lipids }\end{array}$ & Nucleotides $\rightarrow$ purine and pyrimidine bases & \\
\hline $\left.\begin{array}{l}\text { Fats } \\
\text { Waxes } \\
\text { Oils }\end{array}\right\}$ & $\underset{\text { fatty acids }}{\mathrm{CH}_{2} \mathrm{CH}_{2} \mathrm{COOH}}+\underset{\text { glycerol }}{\mathrm{CH}_{2} \mathrm{OHCHOHCH}{ }_{2} \mathrm{OH}} \rightarrow\left\{\begin{array}{l}\mathrm{RCH}_{2} \mathrm{OH} \\
\mathrm{RCOOH}^{2} \\
\text { shorter chain acids } \\
\mathrm{RCH}_{3} \\
\mathrm{RH}^{2}\end{array}\right.$ & $\begin{array}{l}\mathrm{CO}_{2}, \mathrm{CH}_{4} \text {. aliphatic acids, acetic, lactic, citric, } \\
\text { slycolic, malic. palmitic. stearic, oleic acids. } \\
\text { carbohydrates, hydrocarbons }\end{array}$ \\
\hline $\left.\begin{array}{l}\text { Corbohydates } \\
\text { Cellulose } \\
\text { Surch } \\
\text { Hemicellulose }\end{array}\right\}$ & $\mathrm{C}_{\mathbf{x}}\left(\mathrm{H}_{2} \mathrm{O}\right)_{y} \rightarrow\left\{\begin{array}{l}\text { monosaccharides } \\
\text { oligosaccharides } \\
\text { chitin }\end{array}\right\} \rightarrow\left\{\begin{array}{l}\text { hexoses } \\
\text { pentoses } \\
\text { glucosamine }\end{array}\right\}$ & $\begin{array}{l}\mathrm{HPO}_{4}^{2-}, \mathrm{CO}_{2}, \mathrm{CH}_{4} \text {. glucose, fructose. } \\
\text { galactose, arabinose, ribose, xylose }\end{array}$ \\
\hline Lignin & $\begin{array}{r}\left(\mathrm{C}_{2} \mathrm{H}_{2} \mathrm{O}\right)_{x} \rightarrow \text { unsaturated aromatic alcohols } \rightarrow \\
\text { polyhydroxy carboxylic acids }\end{array}$ & \\
\hline $\left.\begin{array}{l}\text { Porphyrins and Ph } \\
\text { Cblorophyll } \\
\text { Hemin } \\
\text { Carotenes and } \\
\text { Xantophylls }\end{array}\right\}$ & Chlorin $\rightarrow$ pheophytin $\rightarrow$ hydrocarbons & $\begin{array}{l}\text { Phyrane } \\
\text { Pristane, carotenoids } \\
\text { lsoprenoid, alcohols, ketones, acids } \\
\text { Porphyrins }\end{array}$ \\
\hline Comptex Substan & $\begin{array}{l}\text { ormed from Breakdown Imermediales, e.g. } \\
\text { Phenols + quinones }+ \text { amino compounds } \\
\text { Amino compounds + breakdown products of }\end{array}$ & $\begin{array}{l}\text { Melanins, melanoidin, gelbstofie } \\
\text { Humic acids, fulvic acids. "tannic" sul }\end{array}$ \\
\hline
\end{tabular}

IR 1s the aymbol used to represent any alkyl group $\left[\mathrm{CH}_{3}^{-}\right.$(nethyl); $\mathrm{CH}_{3} \mathrm{CH}_{2}^{-}$(ethyl); $\mathrm{CH}_{3} \mathrm{CH}_{2} \mathrm{CH}_{2}{ }^{-}$(propy1); $\mathrm{CH}_{3} \mathrm{CHCH}_{3}$ (180propy1)] - 
The organic fractions of groundwaters are found associated with inorganic anion and cation fractions of groundwaters that can be fractionated by filtration. Uaing filters characterized as allowing nolecules amaller than 1000 molecular weight to pase ( $1000 \mathrm{~mol}$ wt cutoff filters), Boggs et al. [BOGGS1984B] found that about $20 \%$ of the $\mathrm{Mg}, \mathrm{Ca}, \mathrm{Sr}$, and $\mathrm{Ba}$ and much of the oul fate ( $800 \%$ ) in groundwaters from basaltic rock remajned associated with the water fractions enriched in organic molecules a. $12 \ldots$ c.tion. These results suggest that complexes of inorganic-organic molecules can constitute a substantial fraction of the total anount of some elements in groundwaters.

Humic substances make up a high percentage of the total DoC in natural waters, and appear to be the single most abundant organic constituents of these waters; however, wide variations in the humic content of natural waters appear to exist. Reuter and Perdue [REUTER-1977] report that, on the average, humic materials constitute 60 to $80 \%$ of the total DOC in surface waters. Christman and Gjessing [CHRISTMAN-1983A] discuss data ind icating that $48 \%$ of the organic carbon in North Carolina terrestrial waters is humic/fulvic material. Thurman, in Christman and Gjessing [CHRISTMAN-1983A], suggest that about $10 \%$ of the DOC in streams consists of identifiable compounds such as amino acids, carbohydrates, and volatile fatty acids. The balance consists of carbon in polymeric form ( $90 \%$ of DOC), about $50 \%$ of which is humic in nat ure. Harvey et al. [HARVEY] report that humic and fulvic acids make up 50 to $98 \%$ of the DOC in Mississippi River outflow water and from 10 to $50 \%$ in other parts of the Gulf of Mexico. Few data are available on the relative fraction of the total DOC in groundwaters that consists of humic substances. Thurman [THURMAN-1979] examined groundwaters from five aquifers in various areas in the United States and determined that humic substances make uf from 5 to $33 \%$ of the total $D O C$ in four of the aquifers and $66 \%$ in the remaining aquifer. he concluded from his data that groundwaters are depleted in humic substances relative to surface waters.

Humic substances are also the major organic constituents of soils and sediments. They are widely distributed over the earth's surface in both terrestrial and aquatic environments, and they have received far more study than other species of dissolved organic compounds. They also appear to be the most important type of organic compounds with respect to their ability to form stable complexes with metal ions. Because of their potential for complexing radionuclides and their abundance in some natural waters, humic substances are of great interest and concern in the disposal of radioactive wastes. The remainder of this report is devoted to discussion of the characteristics of these humic substances and their interactions with metal ions and radionuclides.

\section{c. General Characteristics of Humic Substances}

Humic substances differ from other organic substances found in soils and natural waters because they no longer possess the specific physical and cheaical properties that characterize well-defined organic compounds. They are dark-colored, acidic, predominantly aromatic [containing one or more benzene ringe $\left(\mathrm{C}_{6} \mathrm{H}_{6}\right)$ ], hydrophilic (polar molecules with an affinity for water), chemically complex, polyelectrolyte-like materials that range in molecular weight from a few hundred to several thousands [SCHNITZER-1978]. Stum and 
Morgan [STUM] describe humic substances as polyners ( 300 to 30,000 mol vt) containing phenolic $\mathrm{OH}$ and carboxylic groups with a lower number of aliphatic OH groups."

Humic substances are comonly divided into three fractions based on their solubility in acid and alkaline solutions: (1) humic acid, which is soluble in alkaline solutions but is precipitated by acidification; (2) fulvic acid, Wich is the humic fraction that remains in the aqueous acidified solutions and is soluble in both acid and base; and (3) humin, the insoluble humic fraction of soils that cannot be extracted by either acid or base.

Although the chemical structure of humic substances is not well $\mathrm{known}$, the three humic fractions are believed to be atructurally oimilar. Fulvic acid appears in general to have a lower molecular weight than humic acid, but with wore hydrophilic functional groups than humic acid or humin [ScHsITzeR1972]. In a otudy of fulvic and humic acid fractions extracted from anrine clays, Rashid and Ring [RASHID-1969-1971] found that the molecul ar weight of fulvic acid ranges from less than 700 to 10,000 , with about $32 \%$ by weight of the fulvic acid in the molecular weight group less than $700,20 \%$ from 700 to 5000, and 477 from 5000 to 10,000. Humic acid fractions showed a much wider range of values, extending from less than 700 to more than 2,000,000. Iohiwatari [ISHIWATARI] reported similar ranges of molecular weights; however, Schnitzer and Rhan [SCHNITZER-1978] suggest that some of these molecular weights may be excessively high.

\section{Chemical Composition and Structure of Humic Substances}

\section{Elemental Composition}

Humic substances are composed predominantly of carbon, oxygen, hydrogen, and nitrogen, and contain omall amounts of oulfur. Table 2 shows that the carbon composition of humic acids derived from selected soil. ranges from about 51 to $62 \%$. The carbon composition of fulvic acids is somewhat lower, ranging from 43 to $47 \%$. Oxygen leve1s are correspondingly lower in humic acid ( 31 to $36 \%$ ) than in fulvic acid ( 45 to 49\%). In general, soil humic acids contain about $10 \%$ more carbon and $10 \%$ less oxygen than fulvic acids. Humic substances in soils also contain about 1 to $7 \%$ nitrogen and 0.1 to $1.5 \%$ sulfur (not hown in Table 2). Plechanov et al. [PLECHANOW] invest igated the elemental coaposition of several river waters (Table 3 ). They report carbon values ranging from 53 to $56 \%$ for humic acid and 41 to $53 \%$ for fulvic acid. These data suggest that humic acids in rivers may be slightly depleted in carbon relative to soils. Gjessing [GJESSING] also found that huic substances in aurface waters contain somewhat less carbon and nitrogen than soil huic compounds; hovever, Thuran [THURMA1-1979] observed that the carbon levels in the groundwaters of five selected aqui fers were richer in carbon than soil humic substances (Table 4) but were generally somewhat depleted in oxygen and nitrogen.

\footnotetext{
*Phenols are compounds that have a hydroxyl (OH) group attached directly to an aromatic ring; i.e., a benzene ring. Carboxyl groups contain the univalent organic redical (-COOH). Aliphatic groupe are etraight or branched, open-chain hydrocarbone having the expirical formula $\mathrm{C}_{n} \mathrm{H} 2 \mathrm{n}+2$; e.8., alkanes, alkenes, and alkynes.
} 
Table 2. Blementel Composition of Humic Acids (HA) and Fulvic Acids (FA) Extracted by Alkali from Different Soils and Materials. Copyright 1978 John Wiley 6 Sons. Reprinted by permission [HAYES].

\begin{tabular}{|c|c|c|c|c|c|c|c|c|}
\hline \multirow[b]{2}{*}{ Saple } & \multicolumn{2}{|c|}{$7 \mathrm{c}$} & \multicolumn{2}{|c|}{70} & \multicolumn{2}{|c|}{$\mathbf{7 n}$} & \multicolumn{2}{|c|}{$7 \mathrm{~N}$} \\
\hline & $\mathbf{H A}$ & FA & HA & FA & $\mathbf{H A}$ & FA & HA & FA \\
\hline Sod podzolic & 57.6 & 42.6 & 35.3 & 44.6 & 5.2 & 5.0 & 4.8 & 4.1 \\
\hline Chernorem & 62.1 & 44.8 & 31.4 & 49.4 & 2.9 & 3.4 & 3.6 & 2.3 \\
\hline $\begin{array}{l}\text { Incept isol } \\
\text { (our face) }\end{array}$ & 34.5 & 42.8 & 34.1 & 47.7 & 5,3 & 3.8 & 5.5 & 2.0 \\
\hline $\begin{array}{l}\text { Inceptisol } \\
\text { (aubour face) }\end{array}$ & 51.4 & 46.9 & 36.0 & 44.6 & 6.7 & 4.5 & 4.9 & 2.3 \\
\hline Brown coal & 63.1 & & $(32.7)^{a}$ & & 2.8 & & 1.4 & \\
\hline Brown $\cos 1^{b}$ & 65.4 & & & & 4.0 & & & \\
\hline S. chartarum & 57.3 & & 27.7 & & 7.0 & & 6.8 & \\
\hline S. atra & 53.1 & & 34.8 & & 5.7 & & 5.4 & \\
\hline
\end{tabular}

${ }^{a}$ The parenthetical entry was determined by subtracting the weights of the other constituents from $100 \%$.

bsecond source.

2. Oxygen-Containing Functional Groups

Hayes and Swift [HAYES] suggest that carboxyl, phenolic hydroxyl, alcoholic hydroxyl, carbonyl, and possibly quinone and methoxyl groups are the principal functional groups in humic substances. Ether, ester, and ketcre groups may also be present ( Table 5). The means of ranges in acidity of selected functional groups (in meq/g) are given in Table 6. Total acidity in Table 6 refers to the sum of the $\mathrm{CO}_{2} \mathrm{H}+$ phenolic OH groups. Note that the total acidity and especially the $\mathrm{CO}_{2} \mathrm{H}$ content of fulvic acids are considerably higher than those of humic acids. Both contain about the same concentrations of phenolic $\mathrm{OH}, \mathrm{C}=\mathrm{O}$, and $\mathrm{OCH}_{3}$ groups per unit weight, but the fulvic acids are richer in alcoholic oH groups [SCHNITZER-1978].

\section{Chemical Structure}

The chemical structure of humic substances is still incompletely known; however, new analytical advances hold hope for eventually characterizing the tructure of humic substances. Most of our knowledge of the chenical structure of humic materials comes from degradativa studies in which the more complex humic substances are broken down into simpler ubstances that can be characterized. Degradation products of humic and fulvic acids are minly phenolic and benzene carboxylic acids; however, owing to the degradative wethods used in isolating these compounds, it is not known if they could have originated from more complex aronatic structures or could have occurred in the initial huaic material in essentially the wae form in wich they were isolated but held together by relatively weak bonding [SCHNITZER-1978]. 
Table 3. Elemental and Functional Group Analyses of Humic Acids and Fulvic Acide. a [PLECHANOV].

\begin{tabular}{|c|c|c|c|c|c|c|c|c|}
\hline semple & $7 \mathrm{c}$ & $X \mathbf{H}$ & $7 \mathrm{~N}$ & 70 & 75 & X Ash & $\mathrm{x}-\mathrm{OCH}_{3}$ & $\frac{-\mathrm{COOH}}{(\mathrm{meqv} / \mathrm{g})^{\mathrm{b}}}$ \\
\hline FA-O & 51.96 & 4.32 & 1.04 & 39.80 & 3.05 & $<0.02$ & 6.5 & 4.25 \\
\hline FA-1 & 53.32 & 4.51 & 1.20 & 38.90 & 1.77 & 0.03 & 8.2 & 4.00 \\
\hline$H A-1$ & 56.00 & 4.51 & 1.36 & 37.25 & 0.72 & 0.37 & 6.0 & 4.25 \\
\hline$F A-2$ & 53.15 & 4.76 & 1.04 & 37.59 & 2.60 & 1.02 & 7.7 & 3.95 \\
\hline $\mathrm{HA}-2$ & 55.29 & 4.53 & 1.26 & 37.08 & 1.78 & 0.25 & 6.1 & 4.15 \\
\hline FA-3 & 51.47 & 4.51 & 1.63 & 40.78 & 1.14 & 0.34 & 1.9 & 3.80 \\
\hline$M A-3$ & 55.00 & 4.30 & 2.10 & n.d.c & 0.8 & n.d. & n.d. & 3.33 \\
\hline FA-RTd & 41.4 & 5.1 & 2.8 & 49.5 & n.d. & 1.18 & n.d. & 4.31 \\
\hline FA-ORe & 51.1 & 3.62 & 1.13 & n.d. & n.d. & 1.0 & n.d. & 6.8 \\
\hline HA-ORe & 53.4 & 3.73 & 2.10 & n.d. & n.d. & 4.3 & n.d. & 4.5 \\
\hline
\end{tabular}

alemental, ash, and methoxyl analyses were carried out by Prof. Dipl. Ing., Dr. H. Malisoa, G. Reuter Analytische Laboratorien, Elbach (Germany) and by the Analytical Laboratory, Studavik Energiteknik AB (Sweden).

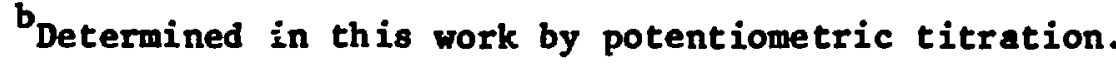

$c_{\text {n.d. }}$ - not determined.

dFulvic acids from River Tamar.

Fulvic and humic acids from Oyster River.

Liao et al. [LIAO] found in a study of aquatic humic material that only 12 to 17 wt $\%$ of the starting material remained after NaOH hydrolysis and 22 to 25 wt $\mathrm{z}$ after $\mathrm{KMnO}_{4}$ oxidation. Thus, lese than one-third of the original aterial was accounted for anong the structural categories that could be characterized after degradation-making it difficult to generalize about the original acromolecular atructure of aquatic fulvic and huric acid. The organic compounds that were identified by Lieo et al. [LIAO] in 'ise degradative products included (1) benzene carboxylic acid nethyl esters ( 29 compounda), (2) furan carboxylic acid methyl esters (5 compounds), (3) aliphatic monobasic acid wethyl esters (14 conpounds), (4) aliphatic dibasic acid nethyl esters (14 compounds), (5) aliphatic tribasic acid methyl eaters (5 compounds), and (6) (carboxyphenyl)glyoxylic acid wethyl ester. (8 compounds). The results indicate that aquatic huic substances contain both aromatic and aliphatic compounds. Liao et al. [LIAO] state that "the aromatic rings contain aninly three to eix alkyl subetituente, and polynuclear aroutic and fused-rins 
Table 4. Elemental Composition of Humic Concentrates from Selected Groundwaters. Reprinted by permisaion [THURMAN].

\begin{tabular}{|c|c|c|c|c|c|c|c|c|}
\hline & \multicolumn{6}{|c|}{ Ash-free and moisture-free basis } & \multirow{2}{*}{$\begin{array}{c}\% \\
\text { Ash }\end{array}$} & \multirow{2}{*}{$\begin{array}{c}\% \\
\text { Moisture }\end{array}$} \\
\hline & C & H & N & 0 & $\mathbf{P}$ & $\mathbf{S}$ & & \\
\hline $\begin{array}{l}\text { Laramie-Fox Hills } \\
\text { fulvic acid }\end{array}$ & 62.67 & 6.61 & 0.42 & 29.14 & 0.2 & 0.44 & 1.09 & 2.58 \\
\hline $\begin{array}{l}\text { Laramie-Fox Hills } \\
\text { humic acid }\end{array}$ & 62.05 & 4.92 & $3 . \therefore$ & 23.45 & 0.46 & 0.96 & 5.12 & 8.47 \\
\hline $\begin{array}{l}\text { Biscayne fulvic } \\
\text { acid }\end{array}$ & 55.44 & 4.17 & 1.77 & 35.39 & 0.2 & 1.06 & 0.43 & 6.75 \\
\hline $\begin{array}{l}\text { Biscayne humic } \\
\text { acid }\end{array}$ & 58.28 & 3.39 & 5.84 & 30.14 & 0.22 & 1.43 & 0.1 & 10.38 \\
\hline St. Peter whole & 62.33 & 6.32 & 0.53 & 30.20 & 0.47 & 0.45 & 2.16 & 5.41 \\
\hline $\begin{array}{l}\text { Suwannee fulv : } \\
\text { acid }\end{array}$ & 54.65 & 3.71 & 0.47 & 39.28 & 0.2 & 0.5 & 0.95 & 7.65 \\
\hline $\begin{array}{l}\text { Suwannee humic } \\
\text { acid }\end{array}$ & 57.24 & 3.94 & 1.08 & 39.13 & 0.2 & 0.63 & 0.56 & 10.15 \\
\hline Madison whole & 56.5 & 5.84 & & & & & & \\
\hline Red River whole & 61.68 & 6.78 & & & & & & \\
\hline
\end{tabular}

structures may also be present. The data suggest that the principal aliphatic segments of the original natural product are composed of relatively short saturated chains (two to four methylene units), and branched structures are apparently present."

The shapes and sizes of humic and fulvic acid particles are known to vary with $\mathrm{pH}$. They tend to aggregate into long fibers or bundles of fibers at low $\mathrm{pH}$, but at high $\mathrm{pH}$ they digperse and the molecular arrangement becomes smaller but better oriented. Scanning electron micrographs show that fulvic acid prepared at $\mathrm{pH}$ 2-3 and then dried occurs mainly as elongated bundles of fibers. With increase in $\mathrm{pH}$ to about 7 , the fibers tend to mesh into a finely woven network with a sponge-1ike structure. For fulvic acid prepared at about pH 8 the structure changes to sheets and at pH 10 homogeneous grains are visible. According to Schnitzer and Khan [SCHNITZER-1978], "one deals here not with chemical structures largely or exclusively composed of condensed ringa, but there must be present numerous linkages about which relatively free rotation can occur...humic substances are not single molecules but rather associations of molecules of microbiological, polyphenolic, 1 ignin and condensed lignin origins." Thun, they believe that fulvic acid is made up of phenolic and benzene carboxylic acids joined by hydrogen bonds to form a polymeric etructure of considerable stability. 
Table 5. Principal Functional Groups in Humic Substances

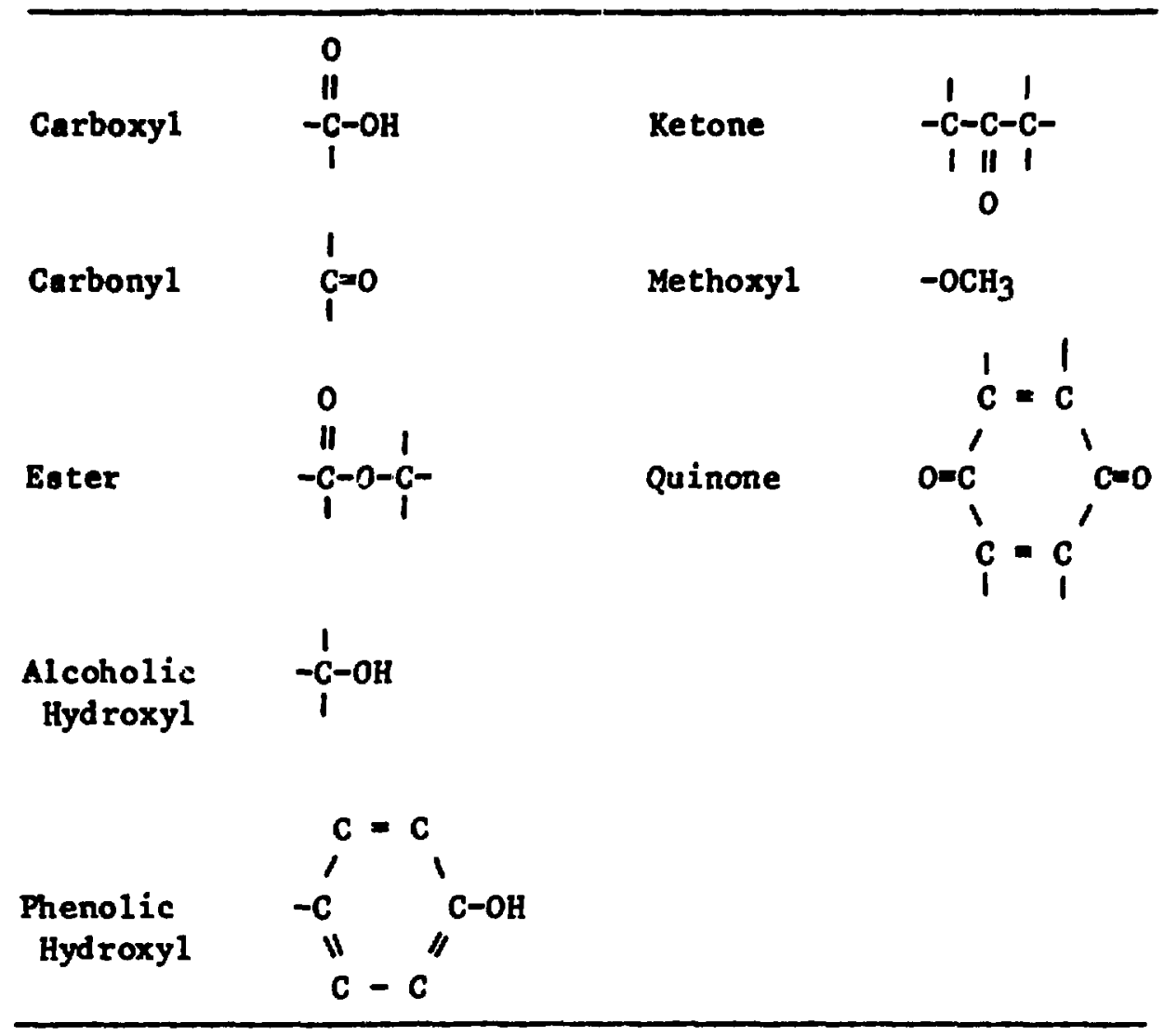

Chemical structures of fulvic and humic acids are depicted in Fig. 1. $X$-ray analyois and electron microscopy reveal that fulvic acid has a relatively open, flexible structure perforated by voids of varying dimensions that can trap or fix organic and inorganic compounds that fit into the voids, provided that the charges are complementary (Fig. la). A suggested structure for humic acid is shown in Fig. 1b. The structures of fulvic and humic acids apparently differ depending upon whether they are derived from marine or terrestrial organic matter. Stuermer and Payne [STUERMER-1976] show that marine fulvic acids are less aromatic and more aliphat ic in character and have lower molecular weights than terrestrial fulvic acids. Harvey et al. [HARVEY] propose that marine fulvic and humic acido are crosslinked, autoxidized, polyuneaturated fatty acids (Fig. 2). However, precautions must be taken in observations using electron beem instruments were the humic materials are subjected to high vacuum, anhydrou conditions. Characteristics observed under these conditiono any not be appropriate to the natural wet enviroments to which the observations should be applied.

E. Origin of Humic Substances in Natural Waters and Soils

As indicated in Section II.B, the composition of total DOC in aurface waters that is composed of humic substances ranges from about 60 to $80 \%$ and that in groundwaters ranges from as little as $5 \%$ to as much as 65\%. These dissolved humic substances are mixtures of humic and fulvic acid. Only a 
Table 6. Analysis of "Model" Humic

and Fulvic Acid (from

means of all data). Copy-

right 1978 Elsevier

Sclence Publishers.

Reprinted by permission

[SCHNITZ ER-1 978].

\begin{tabular}{crr}
\hline Element (\%) & \multicolumn{1}{c}{ HA } & FA \\
\hline $\mathrm{C}$ & 56.2 & 45.7 \\
$\mathrm{H}$ & 4.7 & 5.4 \\
$\mathrm{~S}$ & 3.2 & 2.1 \\
$\mathrm{O}$ & 0.8 & 1.9 \\
& 35.5 & 44.8 \\
\cline { 2 - 3 } & 100.4 & 99.7 \\
\hline Functional Groups & & \\
(meq/8) & $\mathrm{HA}$ & $\mathrm{FA}$ \\
\hline Total acidity & 6.7 & 10.3 \\
Co ${ }_{2}^{\mathrm{H}}$ & 3.6 & 8.2 \\
Phenolic OH & 3.9 & 3.0 \\
Alcoholic OH & 2.6 & 6.1 \\
Quinonoid C=0 & 2.9 & 2.7 \\
Ketonic C=0 & 0.6 & 0.8 \\
OCH $_{3}$ & 4.8 & 9.6 \\
E $_{4} /$ E $_{6}$ & & \\
\hline
\end{tabular}

few data seem to be available on the relative proportions of humic acid to fulvic acid in humic substances, although it appears that fulvic acid is the dominant humic species. Thurman [THURMAN-1979] found in one study, for example, that the humic substances in the groundwaters of five aquifers were composed of 60 to $97 \%$ fulvic acid, with means of $84 \%$ fulvic acid and $16 \%$ humic acid. Harvey et al. [HARVEY] report that marine humic substances in the Gulf of Mexico consist of 62 to $98 \%$ fulvic acid.

The character of humic substances in groundwaters is different from that In so1ls and surface waters [THURMAN-1979]. Groundwater humic substances are more allphatic in nature, less aromatic, less humifled, and of lower molecular weight than those in 80118 and surface waters. They are also enriched in carbon and depleted in oxygen and nitrogen compared to soil humic substances. These differences raise questions about the origin of the dissolved humic substances in groundwaters. Are they derived from terrestrial sources in soils, like the humic substances in surface waters, or do they originate by leaching of particulate humic organic material that is present in groundwater equifers?

The origin of humic substances in soils is described by Felbeck [FBLBECK], who list the following four hypotheses for the formation of these materials: 
(a)

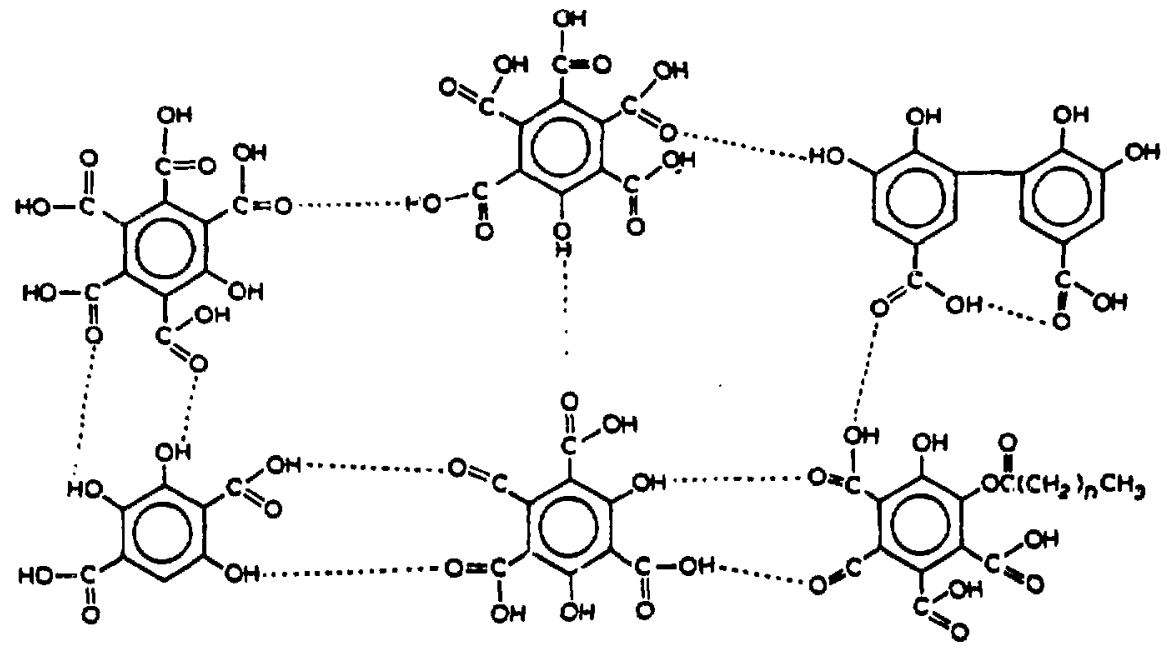

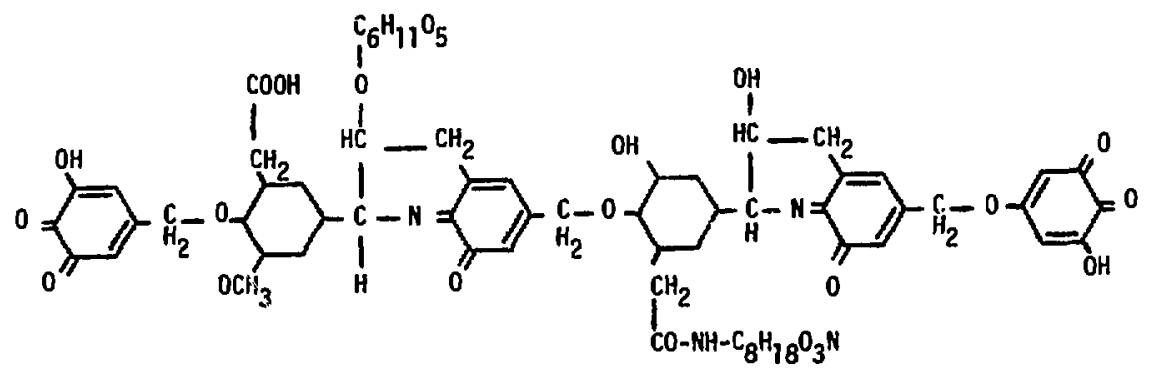

(b)

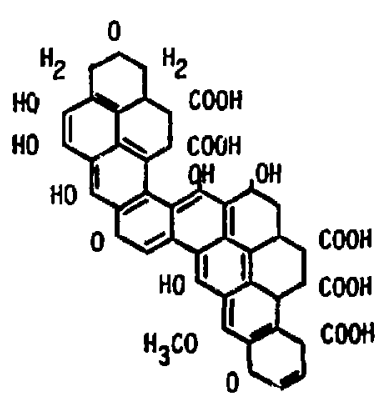

Fig. 1. Chemical structures for Fulvic and Humic Acida. (a) A partial structure for fulvic acid. Copyright 1978 Elsevier Science Publishers.

Reprinted by permission [SCHNITZER-1978].

(b) A suggested structure for humic acid.

Copyright 1983 SKBF/KBS. Reprinted by permission [OLOFSSON]. 
Fig. 2.

Proposed Pathway to Marine Humic and Fulvic Acids by Oxidative Crosolinking of Polyunsaturated Lipids Catalyzed by UItraviolet Light and Transition Metals. Copyright 1983 Elsevier Science Publishers. Reprinted by permission [HARVEY].

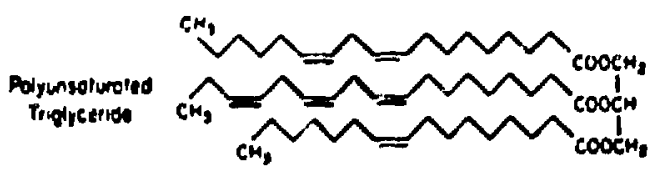

$\left.\underset{\text { SEVERAL }}{\text { STEPS }}\right|_{2, C N, * U, H, O}$

Moring

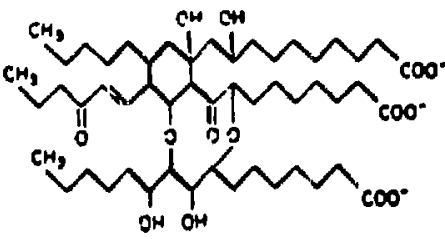

LETC

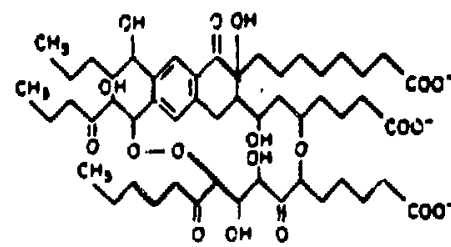

(1) The plant alteration hypothesis. Fractions of plant tissues that are resistant to microbial degradation, such as lignified tissues, are altered only superficially in the soil to form humic substances. The nature of the humic substances formed is strongly influenced by the nature of the original plant material. During the first stages of humification, high molecular weight humic acids and hunins are formed. These are subsequently degraded to fulvic acids and ultimately to carbon dioxide and water.

(2) The chemical polymerization hypothesis. Plant materials are degraded by microbes to small molecules that are then used by microbes as carbon and energy sources. The microbes synthesize phenols and amino acids, which are secreted into the surrounding environment where they are oxidized and polymerized to humic substances. The nature of the origimal plant material has little or no effect on the type of humic substance that is formed.

(3) The cell autolysis hypothesis. Humic substances are products of the autolysis ("self digestion" or chemical breakdown) of $\mathrm{plant}$ and microbial cells after their death. The resulting cellular debris (ougars, amino acids, phenols, and other aromatic compounds) condenses* and polymerizes by free radicals.

\footnotetext{
"Condensation is an organic chemical reaction in which monomeric polywer subunits are joined through intermolecular elimination of mall wolecules such as water or alcohols.
} 
(4) The microbial syntheais hypothesis. Microbes use plant tissue as carbon and energy sources to synthesize intercellularly high molecular weight humic materials. Aftex the microbes die, these substances are released into the soil. Thus, high molecular weight substances represent the first stages of humification, followed by extracellular microbial degradation to humic acid, fulvic acid, and ultimately to carbon dioxide and water.

The common element in all these hypotheses is the suggestion that humic substances in soils start as more complex, high molecular weight organic compounds that are then degraded, probably oxidatively, into lower molecular weight substances, with humic acid forming first and then degrading further to fulvic acid. The differences in groundwater and soil humic substances mentioned above indicate that additional changes in the character of the humic materials must occur either before humic substances get into groundwaters or with in the aquifer itself.

One hypothesis to explain the origin of dissolved humic substances in groundwaters is that rainfall percolating through soils leaches and solubilizes humic substances and transports them to the groundwater system. There they presumably undergo further chemical changes with in the reducing environment of the aquifer, which may include (1) oxygen depletion by chemical reduction of oxygen-bearing functional groups and (2) removal of oxygen by bacterial degradation [TlUURMAN-1979]. These changes account for the differences between soil and groundwater humic substances.

A second hypothesis suggests that the humic substances in groundwaters are leached from organic materiais that were deposited concirrently with deposition of the sediment making up the aquifer rock. Thurman [THURMAN-1979] offers as possible support for this hypothesis the fact that the humic materials of groundwaters tend to be more aliphatic in character than surface waters or soil humic matter. The more aliphatic character of marine humic substances versus terrestrial humic substances has been established by several investigators [RASHID-1970, STUERAER]. Thurman's reasoning is that because many groundwater aquifers are marine sedimentary rocks, they contain fine particles of marine organic matter trapped among sediment particles; therefore, leaching of marine particulate humic material should result in more dissolved aliphatic organic substances in the groundwaters. One weakness of this argument $1 i e s$ in the fact that terrigenou organic watter can be transported from the land and deposited in marine sediments; thus, the particulate organic matter in marine sediments is not necessarily all of marine origin.

In support of the hypethesis that the DOC of groundwaters may originate by leaching of particulate organic atter with in aquifers, Thurman [THURMN1979] points out that the carbon and oxygen content of groundwater hunic substances is similar to that of kerogen, which now makes up nost of the particulate organic matter in sedimentary rocks. Kerogen is disseninated organic anter that originated through complex processes of polymerisation and condensation during burial and diagenesis of sediments. Thurman neglects to point out, however, that kerogen is insoluble in nonoxidising acida, bases, and organic solvents. Presumably, kerogen is alıo largely insoluble in formation waters becsuse it has survived in sedinentary rocks for hundreds of millions of years in constant contect with formation pore waters. Therefore, 
It seens doubtful that the dissolved organic content of groundwater could have criginated by solution of kerogen, though it may have orlginated by solubilization of ocher types of organic substances in shallow aquifers. The fact that unusually high concentrations of dissolved aliphatic acld anions occur in deep formation watero in association with petroleum accumulations has been attributed to chernocatalytic degradation of kerogen [CAROTHERS]; however, these reactions occur at temperatures between 80 and $200^{\circ} \mathrm{C}$ and could not account for formation of aliphatic organic substances in shallow aquifers where temperatures are below $80^{\circ} \mathrm{C}$, unless high-temperature waters have moved from deepex formations to shallow aquifers.

The hypothesis that $\mathrm{DOC}$ in groundwaters originates by solution of organic matter within aquifers also has another weakness. It cannot account directly for the dissolved organic content of groundwaters in volcanic and crystalline igneous rocks that contain no Indigenous organic matter. Humic substances dissolved in groundwaters in ad jacent sedimentary formations could, of course, migrate into Agneous aquifers.

In any case, relatively 11ttle work has been done to study the origin of humic substances in groundwaters. Additional research 18 obviously needed to provide more definitive data on this problem.

\section{F. Methods for Isolating and Purifying Humic Substances}

Before humic substances can be effectively studied, they must be separated from the bulk of other organic and inorganic constituents and concentrated. Methods for concentrating humic substances vary depending upon whether they are being extracted from soils or water. Although our primary Interest in this report is in the humic substances in natural waters, specifically in groundwaters, we are including for completeness a short discussion of methods for extracting and purifying humic substances from both solls and waters.

\section{Extraction and Fractionation of Humic Substances from Soils}

The first isolation of individizal oryanic compounds from soils was done about 1910 and required extraction of several kilograms of soil to obtain sufficlent quantities of organic material for identification [PIERCE]. Since that time, numerous methods for extracting soil organic matter have been introduced. Detalls of many of these methods are summarized by Schnitzer and Khan [SCHNITZER-1972 -1978]. Other summaries are provided by Dormaar, Felbeck, and Plerce and Felbeck [DORMAAR, FELBECK, PIERCE]. Methods for separating humic substances have included extraction with dilute $\mathrm{NaOH}$, dilute $\mathrm{Na}_{4} \mathrm{P}_{2} \mathrm{O}_{7}$, neutral salts of mineral and organic acids such as Na-pyrophosphate, organic solvents such as acetyl acetone, treatment with chelating (Ion-exchange) resins, and ultrasonic dispersion. The method for extracting humic materials by solution in dilute $(0.1-0.5 \mathrm{~N}) \mathrm{NaOH}$ is the nost widely used technique and was first developed by Oden in 1919 [PIERCE]. Varlous modifications of the original technique have since been introduced in an attempt to increase the yield and decrease the extent of alteration of the organic natter.

After separation of humic substances from other soll constituents, they are fractionated by various nethods into huaic acid, fulvic acid, and humin. The bastc process for fractionation 1s shom in F18. 3. Extraction 


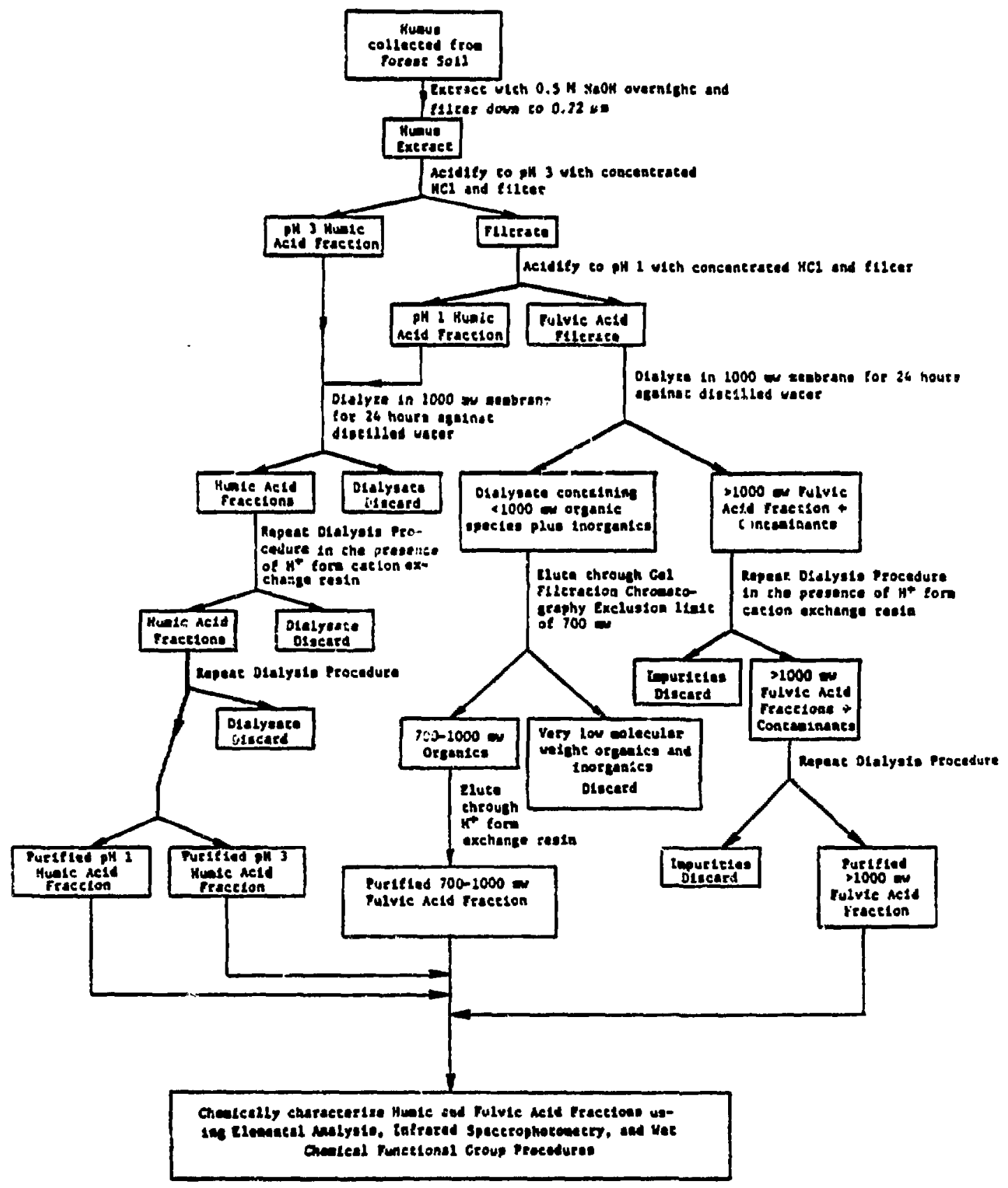

Fig. 3. Fractionation and Purification Procedures for Humic and Fulvic Acids. [MEANS-1982B].

of organic aaterial from soil by treatment with dilute NaOH yields an insoluble humin fraction and a soluble fraction consisting of humic and fulvic acid. This soluble fraction is separated further by acidifying to $\mathrm{pH} 1$, which causes the humic acid to precipitate. The humic acid precipitate can then be washad, purified, and dried to yield a powder of dried humic acid. Dried fulvic acid can be obtained from the remaining ooluble fraction by rotoevaporation or 
freese drying. If desired, the humic acid fraction can be broken down further by extraction with alcohol. Wre elaborate modifications of this basic extraction and fractionation process that presumably yleld better fractionation are described by Plerce and Felbeck [PIERCE] -

Other fractionation methods that have been tried include treatment with tetrahydrofuran contalning increasing percentuges of water, mixtures of dinethylformanide and water, salting out with ammonlum sulfate, varying the lonic strength and pH of pyrophosphate and sodium hydroxide extracting solutions, adding lncreasing volumes of ethanol to alkaline solutions containing huic acids, electrophoresis, and gel filtration chromatography

[SCENITZER-1978].

\section{Purification of So11-Derived Humic Substances}

Humic materials separated from soll or sediment may require fur ther treatment to remove remaining inorganic constituents and metal ions that may be complexed wth the humic subetances. Inorganic constituents can be effectively iemoved by shaking at room temperature with a dilute solution of HC1-HF (0.5 mL concentrated $\mathrm{HCl}+0.5 \mathrm{~mL} 48 \% \mathrm{HF}+99$ mL $\left.\mathrm{H}_{2} \mathrm{O}\right)$. After shaking for 24 to 48 hours, the acid mixture is removed by filtration and the residue washed with distilled water until free of $\mathrm{Cl}$. Ions and then dried. Ash content can be reduced in this manner to less than 1.0\% [SCHNITZER-1978].

Dialysis has also been used as a method for purifying humic substances. In this process, the dissolved humic material is placed inside a dialyols bag or membrane having a specific molecular weight cutoff, such as 1000. Organic compounds with molecular weights 8 reater than the cutoff value of the membrane remain inside the bag, whereas salts and lower molecular weight ccmpounds are removed. Bound metal ions and salts can also be removed from humic substances by passage over ion exchange resins such as Dcwex-50 [NASH-1980].

\section{Extracting Humic Substances from Water}

The methods for lsolating humic substances from ter were first developed for concentrating trace amounts of organic substances in seawater. Recause of the 10w concentrations of DOC in seawater and many other natural waters, large quantities of ter may have to be processed to obtain desired concentration levels of DOC for analytical purposes. Several methods for extracting humic subatances from water have been tried, including freeze concentration and freeze drying, liquid extraction, coprecipitation with varlous alts, anion exchange, ultrafiltration, and adsorption methods using either charcoal or organic, nonionic resins such as experimental adsorbent (XAD) reulns as an adsorbent. The advantages and disadvantages of thece different nethods of concentration have been sumarized by Thuraan [THUDMN-1979] and are presented in Table 7.

Because of 1t: ease, speed of application, and high recovery of husic subetances, the edeorption method using synthetic nonionic polyners (XUD resins) appears to be the nost efficient method for ceparating discolved bulc substances ftom smter. Inge volunes of meter can be proceseed quickly 
Table 7. Methods of Concentrating Humic Substances from Water. Reprinted by permiseion [THURMAN].

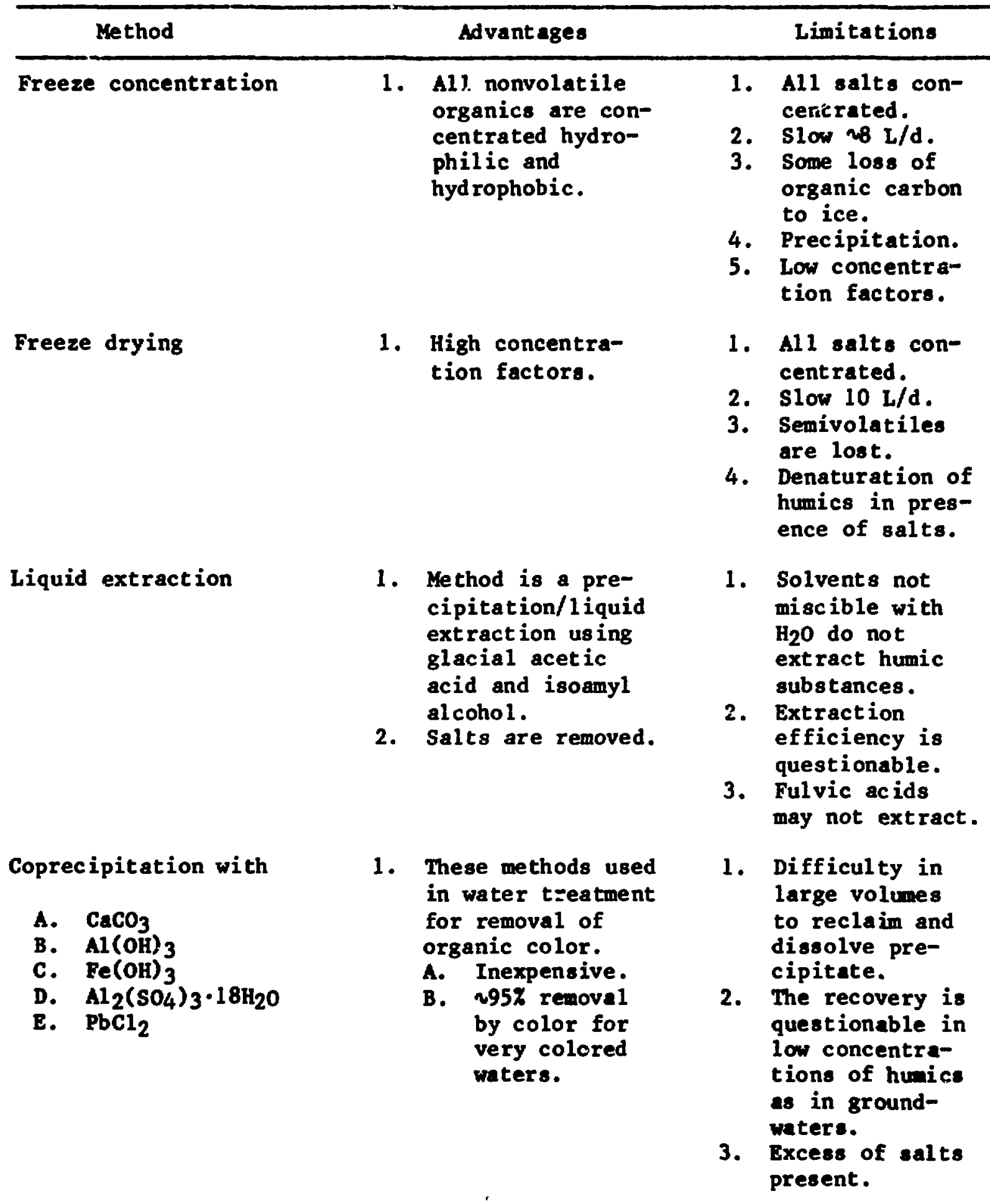

(contd) 
Table 7. (contd)

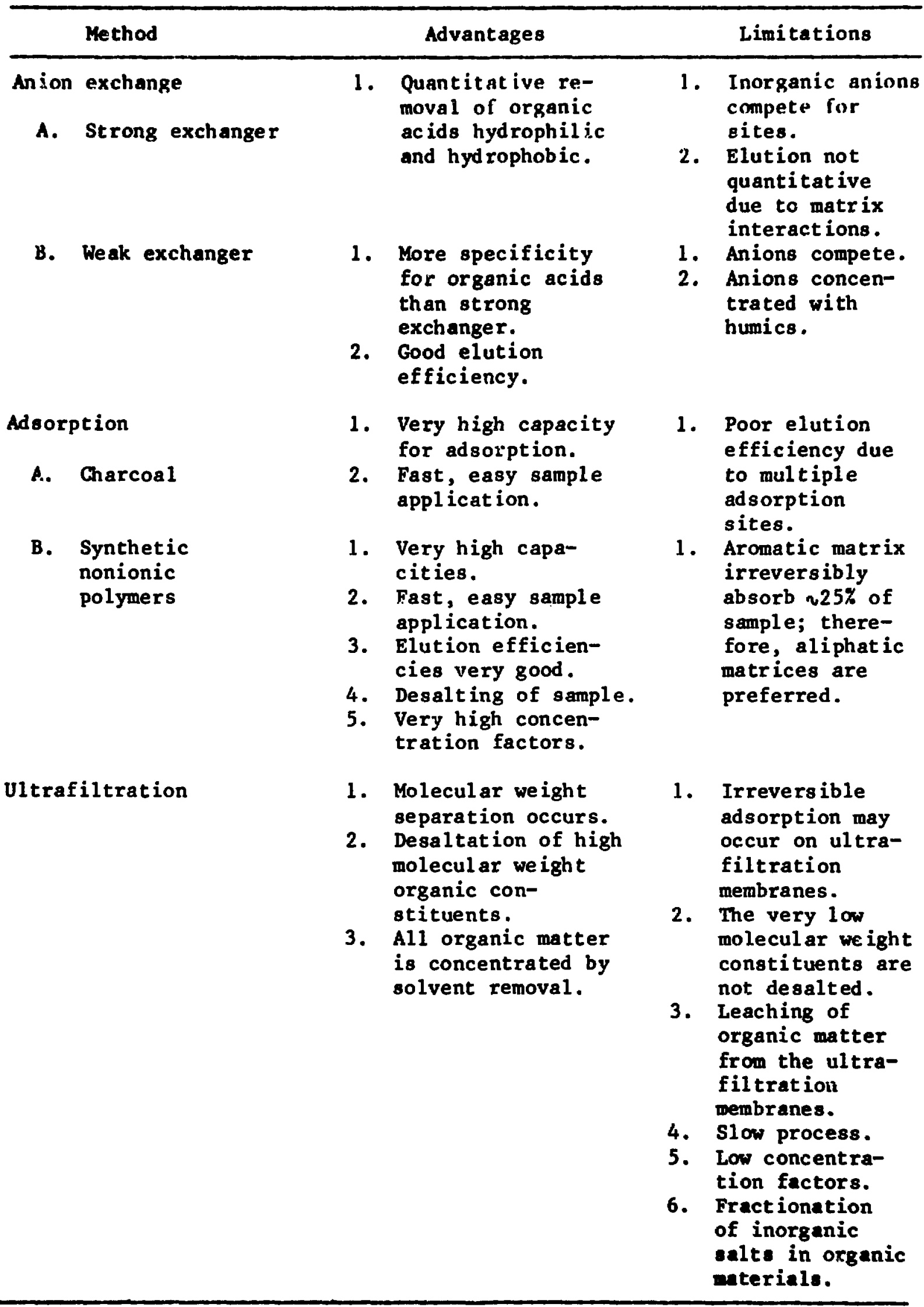


and recoveries up to $95 \%$ of the humic acid and $75 \%$ of the fulvic acid have been reported. The separation of humic substances from water using XaD resins involves two steps:

(1) Adsorption. Water is passed through a column packed with a suitable XAD resin. Humic and fulvic acids are adsorbed onto the resin as the water passes through the column. The XAD resins are nonionic, macroporous organic adsorbents. They are formed by copolymerization and consist of a styrene-divinylbenzene or methyl methacrylate matrix. The pore size and surface area of the resins are a function of the extent of the crosslinking agent. The beads formed consist of many microbeads with pore sizes of about 50 to 250 [SIMPSON]. The resins do not contain functional groups and ion exchange does not occur. Trapping or retention of organic solutes on these resin adsorbents occurs by low-energy (1-5 kcal/mol) physical adsorption processes such as hydrogen bonding, van der Waals forces, and dipoledipole interactions [GUSTAFSON, SIMPSON]. The efficiency of adsorption is influenced by $\mathrm{pH}$ and rate of flow of water through the column. Mantoura and Riley [MANTOURA-1975] found that greater efficiency of adsorption occurs at a pH of 1 ess than 2.2 and a flow rate of less than 35 bed volumes (column volumes) per hour.

(2) Desorption. Aqueous or organic media are passed through the column to desorb the humic acid and fulvic acid and elute them from the column. Mantoura and Riley [MANTOURA-1975] report that maximum recovery was achieved with $0.2 M$ sodium hydroxide as an eluant; how ever, a number of other substances can also be used including sodium chloride, amionium hydroxide, and methanol-ammonia. After the concentrated humic substances are eluted from the column, they must undergo additional treatment to remove the inorganic salts or organic reagents used as eluants and to separate humic acid from fulvic acid.

\section{G. Methoda for Analyzing and Characterizing Humic Substances}

Dissolved humic substances can be characterized by both chemical and physical methods. Chemical methods yield data on elemental composition and the composition of oxygen-containing functional groups, and include determination of total carbon, hydrogen, nitrogen, oxygen, sulfur, active hydrogen and total acidity, and acidity of functional groups expressed in meq/g of humic preparation. Specific methods for determining total acidity and the composition of major oxygen-containing functional groups in humic substances are described by Schnitzer and Khan [SCHNITZER-1972]. Schnitzer and Khan [SCHNITZER-1972 -1978] also describe more than 20 physical nondegradative and degradative methodo for characterizing humic oubstances (Table 8). Nondegradative physical methods provide insight into such properties of humic substances as viscosity, ultraviolet and infrared absorbance, shapes of humic acid and fulvic acid nolecules, and the chemical structure of humic substances. Degradative methode use oxidative, reductive, therma1, or other degradative techniques to break down the complex structure of humic and fulvic acids into inpler compounds that can be identified and whose chemical structures can then be related to those of the starting materials. Details of these techniques are given by Schnitzer and Khan [SCHNITZER-1972 -1978] and in several 
Taile 8. Methods for Analyois and Characterization of Humic Substances

Nondegradative Methods

Spectrophotometry in the UV and Visible Region; Spectrofluorometry Infrared (IR) Spectrophotometry

Nuclear Magnetic Resonance (MMR) Spectrometry

Electron Spin Resonance (ESR) Spectrometry

$X$-Ray Analysis

Electron Microscopy and Electron Diffraction

Viscosity Measurements

Surface Tension Measurement 8

Molecular Weight Measurements

Vapor Pressure Osmometry

U1tracentrifugation

Gel Filtration

Electrometric Titration

Degradative Methods

Oxidative Degradation

Reductive Degradation

Hydrolysis Degradation

Thermal Degradation

Pyrolysis - Gas Chromatography

Radiochemical Degradation

Biological Degradation

papers that appear in a symposium volume dealing with aquatic and terrestrial humic materials edited by Christman and Gjessing [CHRISTMAN-1983A]. Only a brief summary of some of the more useful techniques is given here.

1. Spectrophotometry in the U1traviolet (UV) and Visible Regions

The Beer-Lambert law relating to light absorption states that when monochromatic light traverses a solution, the fraction of the incident light absorbed is proportional to the number of molecules in the light path. Light absorption by a dissolved material is thus proportional to its molecular concentration. The Beer-Lambert law is expressed as

absorbance (or extinction or optical density) $=\log _{10}$ Io/I = ECL

where Io = intensity of the incident light,

$I$ - intensity of transmitted light,

$\mathrm{E}=$ extinction coefficient,

$C=$ concentration of the substance being investigated, and

$L$ - path length or thicksess of the cell that contains the solution.

The value of $E$ is numerically equal to optical denoity if $C$ is $1 \mathrm{~mol} / \mathrm{L}$ and I is $1 \mathrm{~cm}$. Therefore, $\mathrm{E}$ is a messure of the intensity of absorption at a siven wavelength. 
Hunic subetances generally yleld uncharacteristic absorption spectra In the UV and visible regions; however, the ratios at specific wavelengthe of optical densities or absorbances of dilute aqueous humic and fulvic acid solutions can be used to characterize humic substances. Soll sclentists commonly use the ratio of optical densities or absorbances at 465 and $665 \mathrm{~mm}$ for characterization. This ratio is referred to as the $E_{4} / E_{6}$ ratio, and 18 reported to be Independent of the concentration of humic substances but to vary for humic substances derived from different types of solls.

\section{Infrared (IR) Spectrophotometry}

The vibrations of organic molecules Interact with electromagnetic energy to absorb and radiate in the IR regton of the electromagnetic spectrum. The main infrared absorption bands of humlc substances range from 1050 to $3400 \mathrm{~cm}^{-1}$. The IR spectra provide valuable information on oxygen-containing functional groups and are particularly useful for gross characterization of humic substances of diverse origins. The IR spectra are also useful for detecting changes in the chemical structure of humic substances after various types of degradative treatments.

\section{Nuclear Magnetic Resonance (NMR) Spectrometry}

Nuclear magnetic resonance is the selective absorption of electromagnetic radiation at the approprlate resonant frequency by nuclel undergoing precession in a strong magnetic fleld. Thus, NMR spectrometry involves use of an appropriate spectrometer to scan and measure the MR spectrum of nucle1. The frequency of resonant photons varles slightly for hydrogen in different molecules, and hydrogen in the same molecule in different enviroments; thus, hydrogen bonded differently can be distingulshed in an MR spectrum. According to Schnitzer and Khan [SCHNITZER-1978], proton-NMR has so far provided relatively little information on the chemical structure of humic materials, but has the potential to provide very useful structural information.

\section{Electron Spin Resonance (ESR) Spectrometry}

Electron spin resonance is resonance that occurs when electrons that are undergoing transitions between energy levels in a substance are irradiated w th electromagnetic energy of a proper frequency to produce maximum absorption. In ESR spectrometry, unpaired or "odd" electrons in paramagnetic substances (substances having a small positive magnetic susceptibility) are measured. Paramagnetic organic compounds, commonly calleri free radicals, are present in relatively high concentrations in humic substances and may play important roles in polymerization-depolymerization redctions [SCHMITZER-1972]. Therefore, the principal application of ESR spectrometry in the study of humic substances is in studying the nature and reaction of stable free radicals.

\section{X-Ray Analys18 and Electron Microscopy}

llaturally occurring humlc substances are largely noncrystalline; however, diffraction patterns of humic acids comonly show atonfe spacings of $3.5 \mathrm{~A}$ and those of fulvic acids show spacings of 4.1 to $4.7 \mathrm{~A}$, Indicating the presence of some ordered materials. Electron diffraction also indicates 
the presence of crystalline materials in humic substances. Crystallinity in humic substances can be detected only at $p H$ values lower than 2.5 , and the dspacings of these materials resemble those of disordered carbon. Small angle $X$-ray scattering has also been used to measure the particle sizes of humate materials saturated with sodium.

Electron microscopy permits observations of the shapes and sizes of humic and fulvic acid particles. It has been used to study the atructure of these substances and to explore the effects of $\mathrm{pH}$ on shape, size, and degree of aggregation of humic acid and fulvic acid particles. A difficulty with using the results of this technique is that the particles are separated from aqueous solution and dried.

\section{Viscosity Measurements}

Viscosity measurements of macromolecules in aqueous solutions can provide information about particle sizes or volumes, particle weights, and polyelectrolyte behavior; however, conflicting results have been reported by different workers in applying viscosity measurements to humic substances. The shapes of humic acid particles, for example, have variously been reported to be globular, spherical, elongated ellipses, mixtures of linear and spherical particles, and rod-shaped particles. These different results appear to be caused by investigators using widely differing methods of extraction, separation, and purification of humic materials. If the problem of standardizing techniques can be solved, viscosity measurements offer significant potential for determining some of the important characteristics of humic substances.

\section{Surface Tension Measurements}

Humic and fulvic acids are predominantly hydrophilic, but they also contain substantial concentrations of aromatic rings, fatty acid esters, aliphatic hydrocarbons, and other hydrophobic substances. Together, these hydrophilic and hydrophobic substances in humic and fulvic acids cause them to be surface active [SCHNITZER-1978]. Both humic and fulvic acids cause a decrease in the surface tension of waters as $\mathrm{pH}$ and concentrations of humic materials increase, and it is thought that hydrophilic oxygen-containing functional groups $\left(\mathrm{CO}_{2} \mathrm{H}, \mathrm{OH}, \mathrm{C}=\mathrm{H}\right)$ in the humic substances play significant roles in lowering surface tension of waters and in increasing soil wetability.

\section{Molecular Weight Measurements}

Schnitzer and Khan [SCHNITZER-1972 -1978] group the various methods for measuring the molecular weights of humic substances into three classes: (1) those methods measuring number-average molecular weights (such as osmotic pressure methods and dialysis), (2) those determining weight-average molecular weights (viscosity measurements, gel filtration), and (3) those measuring z-average molecular weigt.ts (sedimentation; e.g., ultracentrifugation). As might be expected, the different methods yield different results for the same materials.

Gel filtration chromatography is the simplest and most convenient method available for determining molecular weight of humic materials, and for these reasons it has been very widely used. Gel filtration involves use of a 
long column (a common size is $24 \mathrm{~cm} \times 2.5 \mathrm{~cm}$ ) packed with an organic gel that has the ability to exclude organic particles larger than a specified molecular weight. A commonly used gel is Sephadex (Pharmacia, Inc.), which is a beadformed gel prepared by cross-linking dextran with epichlorohydrin. Gels are available in a wide range of exclusion limits or molecular weight cutoffs such as $700,1500,100-5000,500-10,000$, and 1000-200,000.

The technique for determining molecular weight by gel filtration requires that a column first be packed with a suitable gel. The solution containing the dissolved humic substances is then passed down the column, which is usually connected to a peristaltic pump. As the solution moves down the column, humic materials are fractionated by molecular weight. A description from the Pharmacia Fine Chemicals Handbook is as follows: "As a solute passes down a chromatographic bed its movement depends upon the bulk flow of the mobile phase and upon the Brownian motion of the solute molecules which causes their diffusion both into and out of the stationary phase. The separation in gel filtration depends on the different abilities of the various sample molecules to enter pores which contain the stationary phase. Very large molecules which never enter the stationary phase, move through the chromatographic bed fastest. Smaller molecules, which can enter the gel pores, move more slowly through the column, since they spend a proportion of their $t$ ime in the stationary phase. Molecules are, therefore, eluted in order of decreasing molecular size."

The eluant from the column is commonly passed through an inline UV-visible spectrophotometer that continuously monitors the absorbance of the effluent at a wave length (usually $250-420 \mathrm{~nm}$ ) appropriate to the concentration of fulvic or humic acid expected in the eluant. The eluant then moves on into a fraction collector. The results of gel filtration are generally expressed as an elution diagram that shows the variation of solute concentration in the eluant with the volume of the eluant passed through the column. Comparison of the elution diagram with diagrams obtained with a series of appropriate calibration standards permits determination of the molecular weight ranges of humic and fulvic acids in the sample.

\section{Degradation Methods}

Degratation methods break down complex humic substances into simpler compourds that can be more easily identified and characterized than the original humic materials. The expectation is that these simpler organic compounds can then be related to the starting humic substances and thus shed light on their structure and composition. Degradation methods include oxidation in alkaline and acidic solutions, reduction, hydrolysis, and thermal, radiochemical, and biological degradation. Degradation products may be further separated and identified by gas chromatography/mass spectrometric techniques [MEANS-1982A -1982B] or other suitable analytical methods. Details of these methods are given by De Haan, Reuter et al., Schnitzer and Khan, and Thurman and Malcolm [De HAAN, REUTER-1983, SCHNITZER-1972 -1978, THURMAN-19831. 
III. INTERACTION OF HUMIC SUBSTANCES WITH METALS

\section{A. General Concepts}

\section{Metal Coapjexes}

Metal-organic interactions have been studied for several decades; however, interest in the complexing of metals with humic substances has intensified since the early 1970s. An extensive literature now exists on this general subject. We make no attempt here to review this large body of published material in its entirety. Rather, we intend simply to abstract and synthesize some fundamental concepts of metal-organic complexing to develop the general background needed to examine the more specific problem of radionuclide-organic complexing. The concept of chemical "complexes" was conceived by the German chemist Alfred Werner in 1893 [MELLOR]. Werner introduced the idea of a metalcentered octahedral chemical structure and wrote, "If we think of the metal as the center of the whole system, then we can most simply place the molecules bound to it at the corners of an octahedron." This concept led to the realization that the valence of an atom and the number of bonds it can form may be different, and that an atom can have both primary and auxiliary valences. The primary valence is now called the oxidation state or oxidation number of the metal; that is, the stoichiometric valence of the element. The auxiliary valence represents the number of atoms bound directly to the central metal atom--called the coordination number. For many metals in the lower oxidation state $(+1,+2$, or +3$)$, the coordination number is commonly 4 or 6 ; more rarely it can be $2,3,5,7,8,9,10$, or 12 . For example, in the hexammine cobalt (III) complex shown in Fig. 4, cobalt has an oxidation number of +3 and a coordination number of 6 ; in the tetrammine-Cu(II) complex, copper has an oxidation number of +2 and a coordination number of 4 .

Fig. 4.

Examples of Metal Complexes.

(a) A coordination number of 6 .

(b) A coordination number of 4 .

Copyright 1959 John Wiley \& Sons.

Reprinted by permission [CHABEREK]<smiles>NN(C(N)(N)N)C(N)(N)N</smiles>

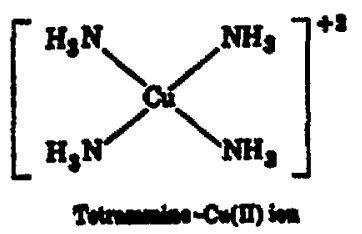

(b) 
A metal complex is a chemical specles that contains a metal atom or fion bonded to a greater number of lons or molecules than would be expected from simple valency considerations. The lons or moiacules bonded or coordinated with the metal ior are called ligands. A ligand is any negative fon or polar molecule bound to a metal atom. The actual atom through which a ligand is bonded to a metal is called the ligand atom. Depending upon the charge carried by the metal and Its ligands, a metal complex can be neutral, cationic, or anfonic. In the metal-11gand bond, the ligand 18 treated as an electronpair donor and the metal as an electron-pair acceptor. Two types of bonding are recognized between 1 igands and metals: (1) covalent bonds in which each of the joined atoms supplies one of the two binding electrons and (2) coord1nate bonds in which the metal atom accepts an electron-pair from each nonmetal atom; 1.e., the donor atom furnishes both electrons.

Werner also Introduced the convention of usirsg square brackets to indicate the entity that functions as a complex. The procedure for writing the formula of a metal complex has now been standardized by an international commission. The symbol for the central metal atom is placed first, followed by formulas of anionic and neutral ligands in that order. The formula for the entire complex or entity (molecule or lon) is enclosed in square brackets, e.8., $\left[\mathrm{Cu}\left(\mathrm{NH}_{2} \cdot \mathrm{CH}_{2} \cdot \mathrm{COO}\right)_{2}\right]$.

\section{Chelates}

Chelates are a special type of metal complex in which the ligands are bonded to the metal through two or more different ligand atoms and, thus, form part of heterocyclic rings in which the metal is one of the members. The word chelate is derived from the Greek chele, meaning claw, in reference to the fact that the 11gand lons appear to grip the central lon like a claw (Fig. 5). Metal chelates are defined simply as complexes in which the donor atoms are attached to each other as well as to the central metal ions, forming ring structures. (Note: covalent compounds in which a metal is directly bound to carbon are called organometallic compounds. Organometallic compounds have properties widely different from those of metal somplexes and chelates and are not considered further in this report.)

A molecule that acts as a chelating agent must possess at least two appropriate functional groups. The donor atoms of these functional groups must be capable of combining with a metal atom by donating a pair of electrons, which may be contributed by a basic coordinating group such as $\mathrm{NH}_{2}$ or acidic groups that have lost a proton. Furthermore, these functional groups must be so situated in the molecule that they allow formation of a ring with a metal atom as the closing member. Chelated molecules are more stable than nonchelated metal complexes because the metal ion is gripped more firmly; 1.e., the metal atom is more prone to unite with two donor atoms in a ring-forming nolecule than with the same atoms in two separate molecules.

The sinplest type of chelating molecules are attached to the metal aton by two donor or ligand atoms. Such molecules are called bidentate chelating nolecules. That 1e, a chelating agent that supplies two donor atoms to the metal to form a single chelate ring is bidentate. There are, however, many molecules wh three or aore donor atoms capable of combining wth metal atons and forming interlocking chelate rings. Based on the number 


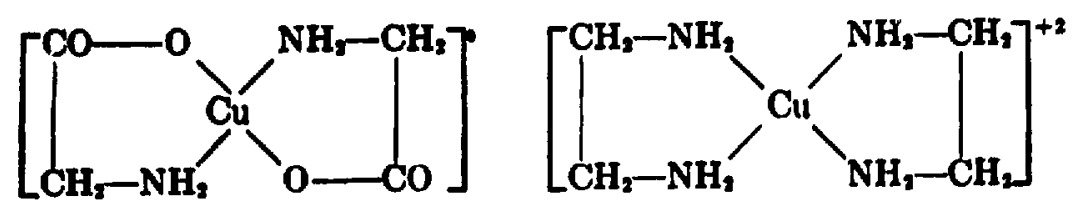

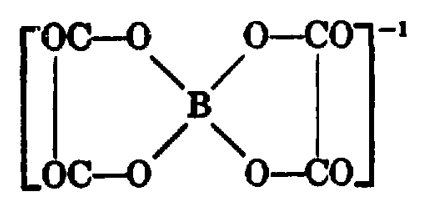

Fig. 5. Structural Diagrams of Chelated Compounds Illustrating the Ring Structure of Chelates and the Manner in which the Ligand Ions "Grip" the Central Metal Ion. [MARTELL-1952].

of donor atoms capable of combining with a metal atom, these molecules are called tridentate (or terdentate), quadridentate, quinquedentate, sexadentate, and octadentate molecules. The coordination number of the retal ion usually defines the maximum number of groups that can be bound together simultaneously to the metal ion ( $T a b l e$ 9). Atoms known to function as donors in metal complexes are shown in Table 10. Note that simple metal complexes can be joined ty unidentate bonds; however, a chelate cannot be unidentate.

\section{Types of Ligands}

Numerous types of both inorganic and organic compounds can act as ligands to form metal complexes. Common examples of inorganic ligands include the complex anions $\mathrm{SO}_{4}{ }^{2-}, \mathrm{HCO}_{3}{ }^{-}, \mathrm{OH}^{-}, \mathrm{CrO}_{4}{ }^{2-}$, and $\mathrm{MnO}_{4}{ }^{2-}$. Some of the common types of ligands important in organic chemistry are shown in Table 11 . We are primarily concerned in this report with or panic ligands that are capable of complexing with trace metals and radionuclides. These organic ligands include synthetic organic chelating agents, such as ethylenediaminetetraacetic acid (EDTA) (Fig. 6) and nitrilotriacetic acid (NTA), that are used routinely in radioactive cleanup and decontamination operations, as well as natural organic substances that occur in surface waters and groundwaters. The most important natural chelates are humic and fulvic acid, but organic acids such as citric, malic, lactic, and tartaric acids may also act as chelating agents.

\section{B. Stabilities of Metal Complexes and Chelates}

1 Stability Constants for Metal Chelates

The tandency toward formation of metal chelate compounds in an aqueous solution is measured by the chelate formation constant or stability constant. The magnitude of the stability constant gives a quantitative indication of the relative stabilities of various metal chelates, and may be used in conjunction with other data to predict whether or not a metal chelate compound is likely to form under a given set of conditions. 
Table 9. Structural Types of Metal Complexes and Chelates. Copyright 1959 John Wiley \& Sons. Reprinted by permission [CHABEREK].

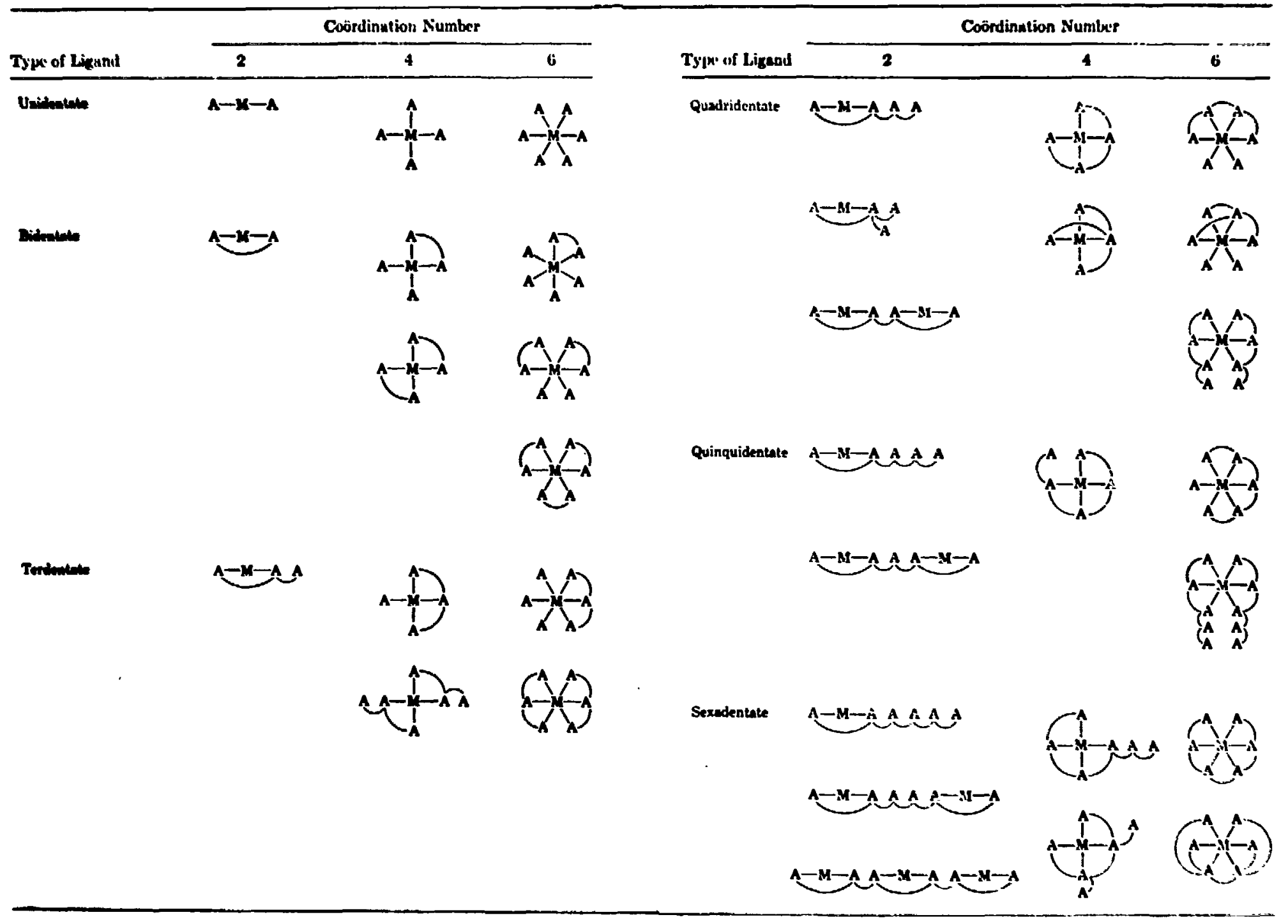


Table 10. Donor Atoms in Metal Complezes. Copyright 1964 Academic Press. Reprinted by permission [MELLOR].

\begin{tabular}{llll}
\hline & & & H \\
& N & O & F \\
& P & S & C1 \\
& As & $\mathrm{Se}$ & $\mathrm{Br}$ \\
$\mathrm{Sb}$ & $\mathrm{Te}$ & $\mathrm{I}$ \\
\hline
\end{tabular}

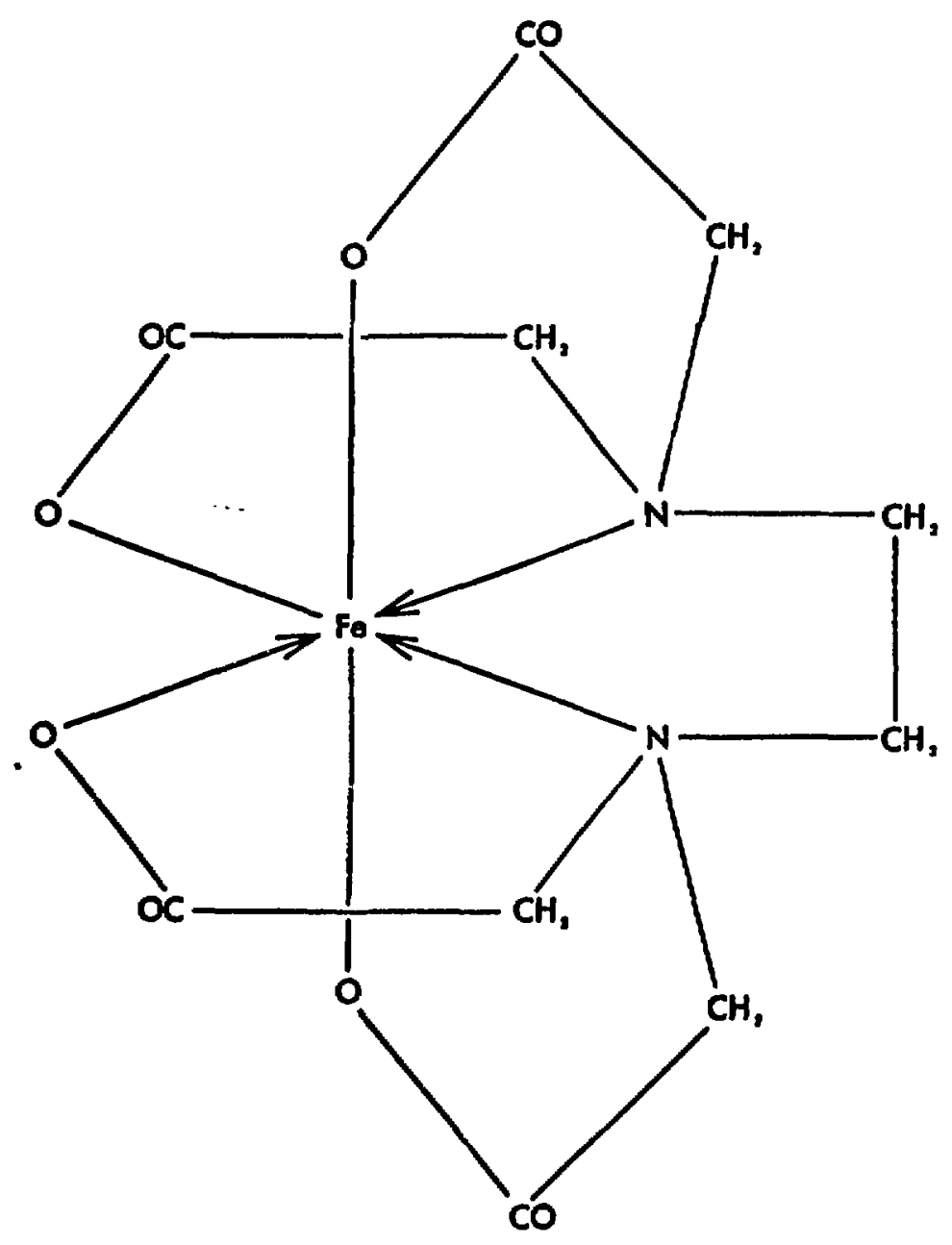

Fig. 6. Structural Diagram Illustrating how Fe is Sequestered and Chelated by Ethylenediaminetetraacetic Acid (EDTA). Copyright 1953

W. H. Freewan and Co. Reprinted by permission [WALTON]. 
Table 11. Sowe Comon Types of Unidentate Ligands. Copyright 1979 Cambridge Univeratty

Preas. Reprinted by permission [HOUGHTON].

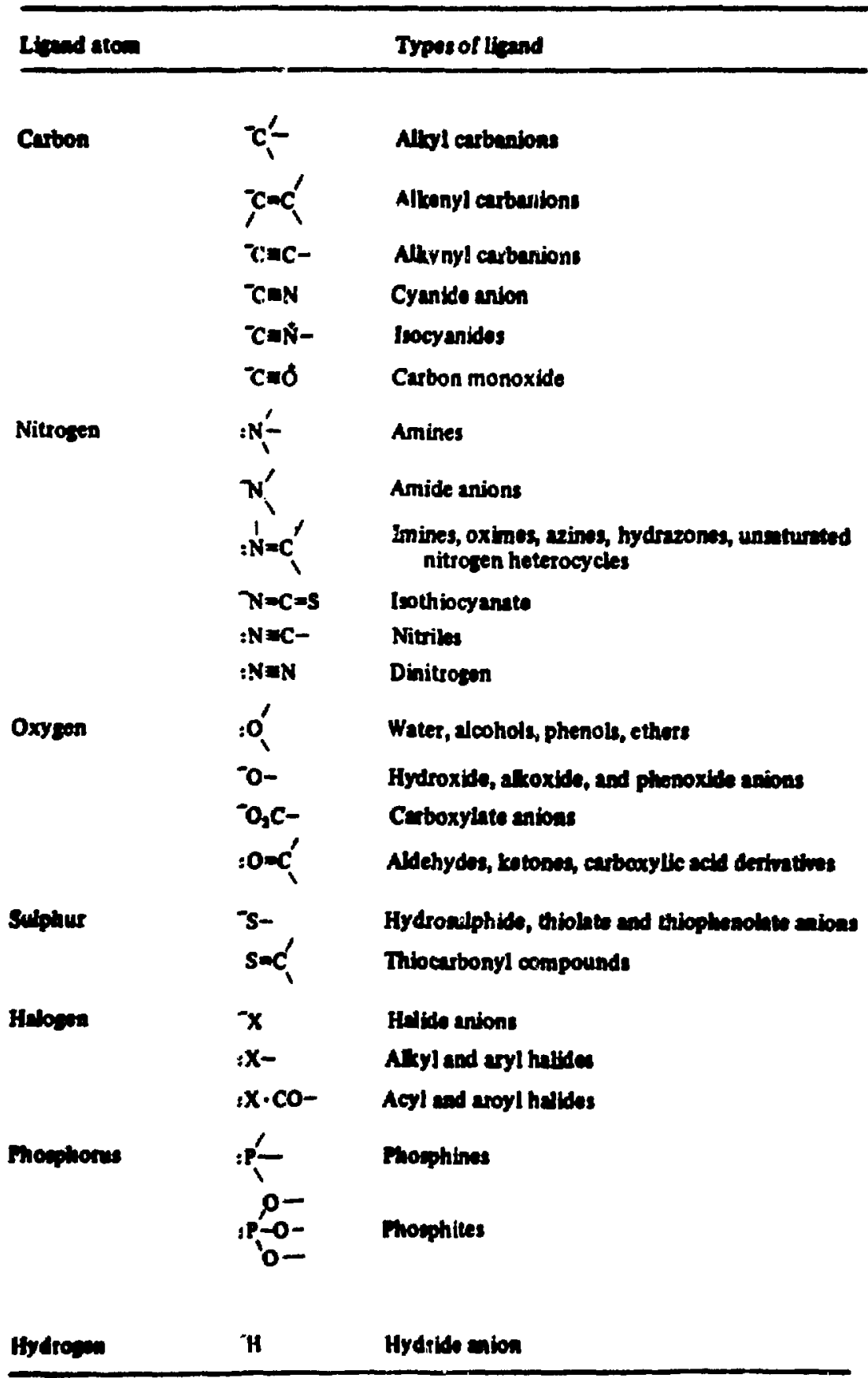


The solution atability of a metal complexed with an organic ligand any be expressed by the equilibrium relationship

$$
M+L \neq \mathbf{M}
$$

where $M$ refers to the metal ions and $L$ to the organic ligand. The concentration equilibrium constant for this reaction may be defined as

$$
K^{\prime}=\frac{[M]}{[M][L]}
$$

where $K^{\prime}$ is the experimentally determined stoichiometric stability constant and the brackets indicate that concentrations have replaced activities of the species.

In the formation of aeries of metal chelates, the reaction shown in Eq. 1 takes place stepwise:

$$
\begin{aligned}
& M+I \neq M L \\
& M L+L \neq M_{2} \\
& M M_{n-1}+L \neq M_{n}
\end{aligned}
$$

The step constants are given by

$$
\begin{aligned}
& \mathrm{K}_{1}=\frac{[\mathrm{ML}]}{[\mathrm{M}][\mathrm{L}]} \\
& K_{2}=\frac{\left[\mathrm{KL}_{2}\right]}{[\mathrm{ML}][\mathrm{L}]} \\
& k_{n}=\frac{\left[M L_{n}\right]}{\left[M L_{n-1}\right][L]} \\
& K^{\prime}=K_{1} \cdot K_{2} \cdot K_{3} \ldots K_{n}
\end{aligned}
$$

$K^{\prime}$ is the concentration or conditional stability constant, and its value varies with the ionic strength of the solution. It is not the same as the true thermodynamic stability constant $\left(\mathrm{K}^{t}\right)$, which is independent of the ionic strength and is given by the relationship

$$
K^{t}=\frac{[M L] \cdot Y(M L)}{[M][L] Y(M) \cdot Y(L)}
$$

where $\gamma(\mathrm{KL}), \gamma(\mathrm{H})$, and $\gamma(L)$ are activity coefficients. With increasing dilution, the activity quotient $\gamma(M L) / \gamma(M) \cdot \gamma(L)$ approaches unity and $K^{\prime}$ approaches $\mathrm{Kt}$. 
The thermodynamic constant $\left(K^{t}\right)$ is related to the standard free energy change $\left(G^{\circ}\right)$ of the reaction by

$$
\Delta G^{\bullet}=-\mathrm{RT} \ln \mathrm{K}^{\mathrm{t}}
$$

where $R$ is the molar gas constant (equal to $8.31 \mathrm{~J} \cdot m o 1^{-1} \cdot \mathrm{K}^{-1}$ ), $\mathrm{T}$ is temperature in kelvin, and $\Delta G^{\circ}$ is made up of enthalpy $\left(\Delta H^{\circ}\right)$ and entropy ( $\left.\Delta S^{\circ}\right)$ terms

$$
\Delta G^{\bullet}=\Delta H^{\bullet}-T \Delta S^{\bullet}
$$

Conditional stability constants are used to describe quantitatively systems for which activity-coefficient data are inadequate or unknown. Measurement of true thermodynamic stability constants for chelating agents, particularly organic chelating agents, is extremely difficult. Some organic chelates may not be soluble in water at a given $\mathrm{pH}$ and the structure of many organic chelates is very complicated and poorly understood. They are commonly ionic, generally contain dipolar ions, and may have dipolar ions and imple ionic groups in the same molecule. Not enough is know about the behavior of such structures to allow evaluation of their activities even in very dilute solutions.

Stability constants can be determined by several different methods based upon a variety of analytical techniques that can be used to measure metal and ligand concentrations [ROSSOTTI]. A method in common use today for calculating conditional stability constants involves application of the Scatchard equation [SCATCHARD-1949 -1956]. A detailed discussion of the Scatchard method and some of its shortcomings is given in Section III.D.6.

\section{The Importance of Stability Constants}

A stability constant found to be significantly greater than zero is convincing evidence for the existence of a particular complex in solution [ROSSOTTI]. Also, the magnitude of the stability constant is a measure of the bond strength of a metal complex or chelate. Furthermore, once the stability constants for a given system have been determined, it is theoretically possible to calculate the equilibrium concentrations or activities of each of the species present under a given set of conditions. As shown in Eqs. 11 and 12 , the equilibrium constant $(K)$ for any reaction is related to corresponding free-energy change by the expression

$$
-R T \ln K=\Delta G^{*}=\Delta H^{\bullet}-T \Delta S^{*}
$$

were $\Delta G^{\bullet}, \Delta H^{\bullet}$, and $\Delta S^{\bullet}$ represent change in free energy, enthalpy, and entropy, respectively. In theory, it is possible to determine $\Delta \mathrm{H}^{\circ}$ by measuring the stability constant at a series of temperatures, although in practice it is better to determine $\Delta \mathrm{H}^{*}$ by direct calorimetric measurements.

\section{Factors Influencing the Stability of Metal Coaplexes}

The stability of wetal complexes and chelates is affected by several factors. Hellor [MELLOR] grouped these factors into five principal categories: 
(1) The eize of the chelate rings. Four-membered rings are the smallest rings that have been established with certainty. Five- and six-membered rings are the most common among metal chelates, though structures with higher numbers of members have been postulated. Examples of four-, five-, and six-membered rings are illustrated in Fig. 7. Little quantitative work has been done to establish the effects on stability of ring size, though preliminary work on some chelates suggests that fivemember rings may be most stable. Many factors other than the number of members in the ring affect stability, however, and it is difficult to evaluate the influence of ring size alone.

(a)<smiles>CN(C)C1=C(N(C)C)S2=[SH]N2S1</smiles>

Fig. 7.

Examples of Chelate Rings.

(a) A four-membered chelate ring

[bis (N,N-di-n-propyldithiocarboma to)

(b)<smiles></smiles>

ring [bis (dithiooxalate-s, s')-

nickelate(II)]. (c) A six-membered

ring [diaquobis (acetylacetonato)

cobalt(II)]. Copyright 1964

Academic Press. Reprinted by

permission [MELLOR].

(c)

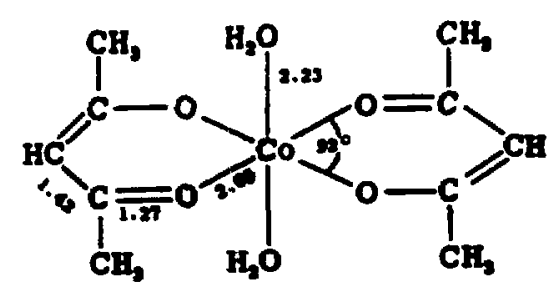

(2) Number of rings (fused rings in multidentate chelating molecules). Among similar chelating agents, those that form the greatest number of chelating rings with a given metal form the most stable complexes (and have the largest stability constants).

(3) The basic trength of the chelating molecules. Both metal ions and hydrogen ions are Lewis acids (e.g., electron acceptors) and there is a resemblance between the combination of a metal ion with a ligand and the neutralization of a base with hydrogen ions. Studies of the possible correlation between basic st rength of a series of ligands and the stability of the complexes they form with a particular netal show that for a series of closely related chelating agents, the greater the basic otrength, the greater the atability of the wetal chelate. 
(4) The effect of substitution in the chelating molecule. Several types of oubstitution reactions are possible in chelating molecules. These include ( 1 ) exchange reactions involving either exchange of ligand or exchange of central metal ion, (2) substitution reactions involving a net chemical change, and ( 3 ) isomerization reactions. Substitution may alter the basic strength of the chelating molecule, thereby changing the stability. Distorting the chelate ring from the normal structure necessary for bonding resonance may also prevent the ligand ion or molecule from acquiring the orientation about the central metal ion most favorable for chelation (steric effect). The effects of steric hindrance in substituted derivatives is il lustrated in Table 12: the 2-methyl-8-hyd roxyquinoline complexes have lower stabilities than either the 8-hydroxyquinoline or 4-methyl-8-hyd roxyquinoline complexes because the presence of methyl groups ad jacent to the nitrogen donor reduces the accessibility of the 2-methyl-substituted ligand to metal ions, thus leading to a decrease in stability of the complexes [BELL].

Table 12. The Effects of Steric Hindrance on Stability Constants, $18 \mathrm{~K}_{1} \mathrm{~K}_{2}$. Copyright 1977 Clarend on Press. Reprinted by permission [BELL].

\begin{tabular}{|c|c|c|c|c|c|}
\hline \multirow[b]{2}{*}{ Ligand } & \multicolumn{5}{|c|}{ Metal } \\
\hline & $\operatorname{Mn} 2+$ & $\cos 2+$ & $\mathrm{Ni} 2+$ & $\mathrm{Cu}^{2+}$ & $\mathrm{zn} 2+$ \\
\hline 8-Hyd roxyquinol ine & 15.5 & 19.7 & 21.4 & 26.2 & 18.9 \\
\hline 2-Me thyl-8-hyd roxyquinol ine & 14.0 & 18.5 & 17.8 & 25.8 & 18.7 \\
\hline 4-Me thyl-8-hyd roxyquinol ine & 15.5 & 20.0 & 22.3 & 26 & 20.2 \\
\hline
\end{tabular}

(5) The nature of the 1 igand (donor) atoms and the central metal (acceptor) atcm. The influence of the ligand atom on stability is tied closely to the central metal atom and it is difficult to separate the effects of the two or to make broad generalities about the stability arising from this relationship. Some central metal atoms are known to form their most stable complexes with ligand or donor atom of the first elenent of each group in the periodic table ( $N, 0, F$, etc.), whereas other. form their most stable complexes with atoms of the second or subsequent elements ( $P, \mathrm{~S}, \mathrm{Cl}$, etc.). For a part icular chelating agent, the stability of the ligand with a series of metals appears to be related to the atomic number of the metal. It has been shown, for example, that the stabilities (atability constants) of bivalent ions of the first transition series increase with increasing atomic nubers to axinum at copper. Thus, the series goes: $\mathrm{Zn}\langle\mathrm{Cu}\rangle \mathrm{Ni}\rangle \mathrm{Co}\rangle \mathrm{Fe}\rangle \mathrm{m}$. 
The type of bonding also has an influence on complex stability. In a very general way, complexes that are essentially covalentily bonded tend to be more table than those that are ionic. However, notable exceptions to this tendency are recognized; e.g., some of the'highly ionic complexes of alkaline-ear ths that form high-stability complexes.

\section{Types of Metal-0rganic Interactions}

Most investigations of metal-organic complexes have been concerned with their stability, and particularly the effects on stability of environmental variables such as $\mathrm{pH}$, Eh, metal ion and organic carbon concentration, and ionic strength. The complexing behavior of numerous metals has been studied, including $\mathrm{Al}^{3+}, \mathrm{Ba}^{2+}, \mathrm{Ca}^{2+}, \mathrm{Cd}^{2+}, \mathrm{Co}^{2+}, \mathrm{Cr}^{3+}, \mathrm{Cs}^{+}, \mathrm{Cu}^{2+}, \mathrm{Eu}^{3+}, \mathrm{Fe}^{2+}, \mathrm{Fe}^{3+}$, $\mathrm{Hg}^{2+}, \mathrm{Mg}^{2+}, \mathrm{Mn}^{2+}, \mathrm{Ni}^{2+}, \mathrm{Pb} 2+, \mathrm{R}, \mathrm{Sr}^{+}$, and $\mathrm{Zn}^{2+}$. The complexing of radionuclides by organic substances has also been investigated, and is discussed in Section IV. The organic substances of principal interest in complexing studies are humic and fulvic acids, which occur in soils, sediments, fresh and marine surface waters, and groundwaters (Sec. II). Most investigators extract humic substances from soils for use in experimental complexing studies because soil humics are the simplest humic substances to extract in large quantities and they are commonly assumed (perhaps incorrectly in some cases) to be similar in character to those found in natural waters. The characterization of humic substances from soils is extensive but by no means complete [SCHNITZER-1978]. Only a few studies have attempted to characterize humic substances from grounu..aters [MEANS-1982A, THURMAN-1979].

The types of interactions that occur between metal ions and the organic acids found in natural waters range from complexing reactions to the formation of colloids [MORTENSON]. Many complexes between humic substances and metals have been reported to be chelates. To identify metal-humate chelates, investigators examine the ratio of metal cations complexed per mole of organic material and then compare the types of functional groups found in humic and fulvic acids to those present in other organic acids that have simpler structures and are known to form chelates. The formation of simple complexes and chelates can occur by ion-exchange and surface absorption reactions [MORTENSON]; however, the various processes involved in the formation of metal-humic complexes and the characteristics of the complexes are still poorly understood.

Most investigators who have analyzed and studied the functional groups of humic and fulvic acids conclude that phenolic oH and carboxyl groups [of both phenolic (C-ring) and aliphatic (C-chain) character] are two of the most important functional groups involved in complexation and chelation of metal ions [SCHNITZER-1972]. Knowledge of these functional groups has been applied in modeling studies to investigate metal-organic complexing under natural conditions using organic acids of known composition. Salicylic and phthalic acids (Fig. 8) have been used in such studies as structurally simple analogs for humic substances. Both salicylic and phthalic acids are bidentate ligands (a ligand that has two active functional groups per molecule) where the former contains one carboxyl and one hydroxyl group and the latter contains two carboxyl groups. These organic acids of known composition can be used to sinulate the chelation tendency of humic and fulvic acids, which are not easily characterized chemically. 
Phthalic Acid<smiles>O=C(O)c1ccccc1C(=O)O</smiles>

Salicylic Acid<smiles>O=C(O)c1ccccc1O</smiles>

F18 - 8.

Structure of Phthalic and Salicylic Acids

Several wrkers have discussed the types and stab1lities of chelates that are thought to form between metal lons and natural organic acids. As an example, Van DIJK [VAN DIJK] reports the results of metal titrations of a humic acid and discusses possible sources of the $\mathrm{H}^{+}$lons that are released upon addition of $\mathrm{Cu}^{2+}$ at both $10 \mathrm{wH}$ and high initial pH. If chelation is assumed, one possibility for the formation of a Cu-chelate is

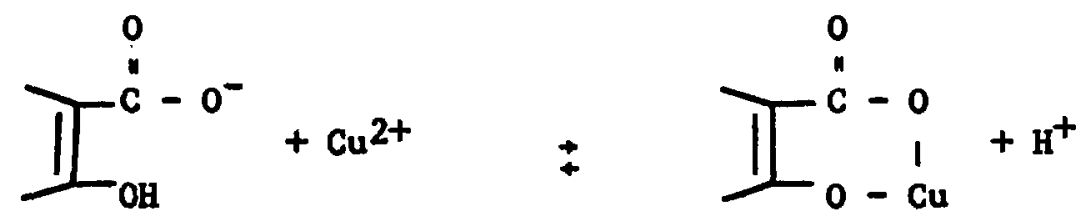

The number of $\mathrm{H}^{+}$ions released, measured by the decrease in $\mathrm{pH}$, will depend upon whether one or both of the functional groups was already protonated. At higher pH values between 6 and 7 , the $\mathrm{H}^{+}$release upon addition of $\mathrm{Cu} s a l t$ is not expected. Van Dijk proposes that the $\mathrm{Cu}$-ion remains hydrated when it forms the complex with the humic acid and that, at higher $\mathrm{pH}$ values, one of the $\mathrm{H}^{+}$ions is released from a water molecule to form a Cu-hydroxy-humate chelate, such so show in the following reaction:<smiles>[Y]OC[C@@H]1OC(C)=C(C)[C@@H](O)O1</smiles><smiles>CC1=C(C)[C@@H](O)[C@@](O)(CO)OC1=O</smiles>

This procese of $\mathrm{H}^{+}$release should increase the atability of the chelate at higher pH oring to the newly formed hydroxyl, a concluaion supported by the wrk of Stevenson [STEVENSON-1976]. Van D1jk suggest that, if these hydroxy conplexes form in a colution, the chelate atability could be expected to refiect the Increasing tendency of a given metal to form hydroxy conplexes wth increasing pH. He determined experinentally that this relationship holds for $\mathrm{Mn}, \mathrm{Co}, \mathrm{N1}, \mathrm{Pb}$, and $\mathrm{Cu}$, wich increase in metal-hydroxy otability and huilc chelate atability at higher $\mathrm{pH}$, in the order given. 
Martel1 [MARTELL-1971] discusses the chelation of metals by organic acids in the light of thermodynamic properties. The increased stability of a metal chelate is directly related to the entropy of the chelate, where increase in entropy of a solution with an increase in metal ion concentration is reflected by an increase in the stability of the chelate. Martell demonstrates that a metal complex with four specific ligands is much less stable than its chel ate counterpart with identical functional groups. One reason for this difference is the increase in entropy that results from the bridging of negaicive and positive ions in a chelate, which increases the concentration of the remaining free ions in the solution. The coordination number is the number of sites at which a coordinated ligand can combine with a metal ion. The coordination number of a metal ion in solution is variable, but is a function of ionic radius and the charge on the metal, in addition to the characteristics of the ligand being coordinated. The chelate will become less stable if the coordination number is exceeded by the number of coordinated ligands. The size of a chelate ring also affects the chelate stability. The smaller the ring, the more stable the particular chelate. The enthalpy and entropy effects that influence solution stability of complexes are given in Table 13.

Table 13. Factors Influencing Solution Stabilities of Complexes. Copyright 1971 Marcel Dekker, Inc. Reprinted by permission from [MARTELL-1971].

\begin{tabular}{ll}
\hline \multicolumn{1}{c}{ Enthalpy Effects } & \multicolumn{1}{c}{ Entropy Effects } \\
\hline $\begin{array}{l}\text { Variation of bond strength with } \\
\text { electronegativities of metal } \\
\text { ions and ligand donor atoms. }\end{array}$ & Number of chelate rings. \\
$\begin{array}{l}\text { Ligand field effects. } \\
\begin{array}{l}\text { Steric and electrostatic repulsions } \\
\text { between ligand donor groups in } \\
\text { the complex. }\end{array}\end{array}$ & $\begin{array}{c}\text { Changes of solvation on complex } \\
\text { formation. }\end{array}$ \\
$\begin{array}{l}\text { Enthalpy effects related to the } \\
\text { conformation of the uncoor- } \\
\text { dinated ligand. }\end{array}$ & $\begin{array}{l}\text { Arrangement of chelate rings. } \\
\text { dinated ligands. }\end{array}$ \\
$\begin{array}{l}\text { Other coulombic forces involved in } \\
\text { chelate ring formation. }\end{array}$ & $\begin{array}{l}\text { Effects resulting from differences } \\
\text { in configurational entropies of } \\
\text { the ligand in complex compounds. }\end{array}$ \\
\hline
\end{tabular}

Most recent investigations of metal-organic interactions focus on complexing or chelation as the primary uptake reaction of metals by organic ligands. The extent to which a molecule of humic or fulvic acid may behave as a colloidal particle in solution is often ignored. Schnitzer and Khan [SCHNITZER-1972] give a brief discussion of the behavior of organic colloids in metal binding; however, the formation of metal-organic colloids is frequently overlooked by workers inveatigating metal-humic complexing. 
Colloids are particles less than $10 \mu \mathrm{m}$ in size that commonly remain suepended in water because their gravitational settling rate is less than $10^{-2} \mathrm{~cm} / \mathrm{s}$. "Dissolved" humic substances may be considered as true solutions of macro-ions or negatively charged hydrophilic colloids. Because of their negative charge, one of their properties is coagulation by electrolytes [SCHNITZER-1972]. They can be readily coagulated by $\mathrm{Ca}^{2+}$ and $\mathrm{Mg}^{2+}$; therefore, surface waters with high $\mathrm{Ca}^{2+}$ and $\mathrm{Mg}^{2+}\left(\mathrm{e} . \mathrm{g} .,>10^{-3} \mathrm{M}\right)$ contain almost no humic substances $(<1 \mathrm{mg} / \mathrm{L}$ ) [STUMM]. Some investigators have reported that trivalent ions are more effect ive in coagulating humic substances than divalent ions, and divalent ions are more effective than monovalent ions. Also, it has been determined that the order of increasing effectiveness of metal ions for coagulating humic acids is $\mathrm{Mn}^{2+}<\mathrm{Co}^{2+}<\mathrm{Ni}^{2+}<\mathrm{Zn}^{2+}<\mathrm{Cu}^{2+}$ $<\mathrm{Fe}^{3+}<\mathrm{Al}^{3+}$ [SCHNITZER-1972]. The formation of metal-humic colloids may play an important role under some conditions in the formation of waterinsoluble metal humates.

As discussed in Section III.B.3, the stability of metal-organic complexes or chelates is commonly expressed by some type of stability constant. Binding constants, conditional stability constants, successive stability constants, complexing capacities, and distribution coefficients are all experimentally determined values that investigators use in an attempt to describe the tendency of a cation to form a complex with an organic ligand under specified environmental conditions. Ultimately, the purpose of all these experimentally determined constants is to find the the rmodynamic equilibrium constants ( $k^{t}$ of Eq. 10) for complexes formed between humic and fulvic acios and metal cations. Realistically, however, it may be impossible to determine true thermodynamic equilibrium constants owing to the chemical complexity of humic substances and the lack of uniformity between humic materials of different origins [PERDUE -1983B]. Chemical characteristics of humic substances vary with the environment (soil, surface water, groundwater, sediment) and origin, i.e., the type of organic material from which the humic substances were derived. For these reasons, humic and fulvic acids cannot be asoigned specific elemental compositions or functional groups, but are instead commonly characterized by a range in these properties. Therefore, it is desirable in any study that attempts to evaluate the environmental effects of metal-organic complexes to characterize the natural organic acids from the study area and, if possible, to use these natural materials in experimental modeling studies.

The thermodynamic equilibrium constant is defined for any dissolution reaction between a metal ion as shown in Eq. 10 . Conditional stability conotants or binding constants (Eq. 2) are simplified forms of the thermodynamic equilibrium constants in that they hold only under given experimental conditions. In effect, all stability constants found between metals and humic and fulvic acids are conditional owing to the fact that these organic acids do not have fixed chemical compositions. Successive stability constants refer to "interwediate" stability constants that, when multiplied together, will give the overall conditional stability constant (Eq. 6-9).

The complexing capacity of a ligand is the maximum number of metal ione that can be complexed by the ligand. The complexing capacity apparently depends upon the coordination number of the ion and the stability of the wetal ion complex or chelete. The distribution coefficient is used to describe the 
equilibrium concentration of a metal, usually between a liquid and a solid phase. For example, the distribution coefficient between metal ions, expressed in $\mathrm{mL} / \mathrm{g}$, in a solution in contact with rock materials such as basalt can be defined as

$$
K_{d}=\frac{\text { metal activity / gram of rock }}{\text { metal activity / mililifiter of solution }}
$$

\section{Techniques for Studying Metal-0rganic Interactions}

Many of the common methods used to study metal-organic complexing are reviewed by Schnitzer and Khan [SCHNITZER-1972]. The advantages and disadvantages of the more popular analytical techniques are discussed by Saar and Weber [SAAR-1980]. A few of the more commonly used analytical methods are reviewed in this section to provide a background for understanding how metal-organic interactions are investigated. The methods reviewed include: (1) potentiometric titration, (2) ion-exchange equilibrium techriques, (3) equilibrium dialysis, (4) gel filtration chromatography, and (5) the use of ion-selective electrodes.

\section{Potentionetric Titration}

This procedure is probably the simplest method for studying metalorganic complexing. It involves titrating a solution containing a known concentration of a specific metal until it reaches its endpoint owing to precipitation of a metal hydroxide. A second titration is then carried out on a duplicate solution to which a measured sample of an organic acid is added. The $\mathrm{pH}$ of the duplicate solution will decrease upon addition of the organic acid owing to the displacement of protons in the organic acid by the metal in solution. The shift in endpoint observed in the second titration is taken to be the result of the metal forming complexes with the organic acid. The drop in $\mathrm{pH}$ caused by release of $\mathrm{H}^{+}$ions is a qualitative ind icator of complex formation, and can also be used for quantitative measurements of the stability of the metal complex.

\section{Ion-Exchange Equilibrium}

The ion-exchange method involves use of an ion-exchange resin as a sorbent for metal ions. Two solutions are used, one with and one without an organic ligand. The solutions are al lowed to equilibrate separately with the ion-exchange resin for a specific period of time. The amount of metal ions sorbed from each solution onto the exchange resin is then measured. Distribution coefficients are calculated for each equilibrated solution to establish the ratio of metal ion sorbed onto the exchange resin to metal ion remaining in solution. Distribution coefficients for the solution without the organic ligand are calculated from the relationship

$$
\lambda_{0}=\frac{\mathrm{MR}}{\text { [M] }}
$$

and those for the solution with the organic ligand by 


$$
\lambda=\frac{M R}{[M]+[M L]}
$$

where MR is the concentration of metal sorbed to resin, $M$ is the free metal concentration, and $\mathrm{ML}_{x}$ is the concentration of metal complexed with the organic ligand. The symbol $\lambda_{0}$ is the distribution coefficient for the solution containing no organics and $\lambda$ is the distribution coefficient for the solution containing an organic complexant. The stability constant for the given conditions will be

$$
x=\frac{\left[M L_{x}\right]}{[M][L]^{x}}
$$

which upon substitution of Eqs, 15 and 16 becomes

$$
K=\frac{\lambda_{0} / \lambda-1}{[I]^{x}}
$$

or

$$
\log x=\log \left(\lambda_{0} / \lambda-1\right)-x \log L
$$

A plot of $\log \left(\lambda_{0} / \lambda-1\right)$ versus $\log \mathrm{L}$ gives $\log \mathrm{K}$ as the $\mathrm{y}$-intercept and has a slope of $x$, the number of moles of 1 igand bound per mole of metal ion.

\section{Equilibrium Dialysis}

A dialysis membrane bag having a specified molecular weight cutoff is used to separate two solutions, one containing metal ions and an organic ligand and another containing neither metal ions nor organic $1 i$ sand. The solution containing the metal and organic ligand is placed outside the bag; the blank solution is put inside the bag. The solutions are allowed to equilibrate through the dialysis membrane. The uncomplexed metal is able to pass freely through the membrane, whereas the complexed metal is retained by the membrane. After the solutions have equilibrated, direct measurements of the free metal that has passed through to the inside of the bag and the complexed wetal that remains outside the bag can then be made. The equilibrium concentrations of free and complexed metals allow the strength of the complexes to be calculated.

\section{Gel Filtration Chromatography}

The principle of gel filtration chromatography is similar to that of equilibriu dialyais except that the "membrane" used in gel filtration takes the for of amall beads of dextran gel. A chromatographic colunn is packed with a suitable gel and a colution containing metal ions and an organic complexant is al lowed to pass through the column. As the solution passes down the column, the larger complexed ions are excluded from the anall pores of the gel and pass freely and quickly through the column. The maller free metal ions enter the gel pores and wove more slowly through the colunn. A 
the solution is eluzed from the column, it can be monitored for ligand concentration by UV-visible spectrophotometry and for metal concentration by suitable analytical techniques. The initial elution volume contains the metal-organic complexes, whereas the volume eluted later contains the free metal ions that were delayed because they passed into the pores of the dextran beads during equilibration. Comparis on of the metal-1igand content of the eluted volumes permits the extent of complexing to be evaluated. Additional details of the gel filtration process are given in Section II.G.8.

\section{Ion-Selective Electrodes}

The ion-selective electrode measures the free metal concentration of a solution through changes in electrical potential between an ion-specific electrode and a reference electrode, just as $\mathrm{pH}$ is measured with an $\mathrm{H}^{+-8 p e c i f i c}$ electrode. The ion-selective electrode method can be used in conjunction with any of the methods discussed above to measure the free metal concentration. The principal drawback to the method is that it can be applied to the study of only a very 1 imited number of metals, such as $\mathrm{Ag}, \mathrm{Ca}, \mathrm{Cd}, \mathrm{Cu}, \mathrm{K}, \mathrm{Na}$, and $\mathrm{Pb}$, but not to most trace metals or any of the radionuclides.

\section{Calculation of Stability Constants from Experimental Data}

The results obtained by the various analytical methods described above are generally used to calculate conditional stability constants. The simplest of these stability constants is calculated by assuming that $1: 1 \mathrm{com}-$ plexes of metal ions to the binding sites of organic ligands are the only complexes that occur (i.e., no chelation takes place) and that the binding site concentrations on the ligand are known. Proceeding from these assumptions, an expression can be written to indicate the reaction between the metal ion and the organic ligand:

$$
\mathrm{Mz}^{+}+\mathrm{HL}^{\mathrm{l}-\mathrm{z}}+\mathrm{ML}+\mathrm{H}^{+}
$$

The conditional stability constant is then expressed as

$$
K=\frac{[\mathrm{ML}]\left[\mathrm{H}^{+}\right]}{\left[\mathrm{M}^{2+}\right]\left[\mathrm{HL}^{1-2}\right]}
$$

On the assumption that $\mathrm{pH}$ and $\left[\mathrm{Mz}^{2+}\right],\left[\mathrm{HL}^{1-\mathrm{z}}\right]$, or [ML] can be measured, then the conditional stability constant can be calculated from the mass balance relationships for the metal and organic ligand:

$$
\begin{aligned}
& {[M]_{T}=\left[\mathrm{M}^{2+}\right]+[\mathrm{ML}]} \\
& {[\mathrm{L}]_{T}=\left[\mathrm{HL}^{1-2}\right]+[\mathrm{ML}]}
\end{aligned}
$$

If the metal-1igand binding ratios are not known, then the Scatchard method [SCATCHARD-1949] for calculating conditional stability constants is commonly used. For exanple, for the reaction 


$$
[\mathrm{M}]+[\mathrm{L}]=[\mathrm{ML}]
$$

a conditional stability constant can be written with a substituted mass balance relationship oimilar to that in Eq. 23:

$$
K=\frac{[\mathrm{ML}]}{[\mathrm{M}]\left[\mathrm{L}_{\mathrm{T}}-\mathrm{ML}\right]}
$$

In the case of the Scatchard method, several binding sites might exist where

$$
\left[\mathrm{L}_{\mathbf{T}}\right]=\Sigma_{\mathbf{i}} \mathbf{n}_{\mathbf{i}}
$$

where $n_{i}$ is the number of sites of type $i$ on each ligand. Saatchard [SCATCHARD-1949] used these relationships to yield the expression

$$
\frac{\bar{v}}{[M]}=k_{i}\left(n_{i}-\bar{v}\right)=-k_{i} \bar{v}+k_{i} n_{i}
$$

where $\bar{v}=[M L] /\left[L_{T}\right]$. If experiments are run at a range of concentrations of $M$, plotting $\bar{v} /[M]$ vs. $v$ will yield a straight line, the slope of which is equal to $-K_{i}$, the $v /[M]$ intercept is $K_{i} n_{i}$, and the intercept on the uxis is $n_{i}$ (Fig.9). Scatchard plots may display a second straight line segment with a more ôntle slope (Fig. 9) that yields a lower stability constant and is interpreted to indicate binding to "weaker" sites. Thus, two stability constants for a given metal-humic conplex are often reported; however, the exact seaning of the two constants is not completely clear. They have been suggested to indicate two different types of binding complexes (i.e., $1: 1$ and $1: 2$ ) [BERTHA]; however, published data appear inconsistent with regard to which of these constants implies complexes of type $1: 1$ and of type 1:2. Marinsky [MARINSKY] suggests that the different effects arise out of the tendency of humic and fulvic acids to aggregate and form separate phases, rather than indicating $1: 1$ and 1:2 complexes. Stifl another interpretation of their meaning is that the different values of the two constants simply represent binding to two different types of functional groups (e.g., phenolic OH vs. carboxylic).

Furthermore, Perdue and Lytle [PERDUE-1983A] have now cast doubt on the validity of conditional stability constants for metal-humic complexes based on application of the two-component Scatchard equation. They point out that, in a complex mixture of ligand, the conditional average stability conatant is not a constant at all, but varies with colution composition. This fact raises an important question. Can conditional average etability constants deternined at one set of solution concentration values be extrapolated to other experimental conditions? Perdue and Lytle suggest that "...the calculated 'con-cants' for 1:1 and 1:2 complexes cannot be regarded as anything more than curve-fitting parmeters with no cheaical significance. While it is indeed possible that $1: 1$ and $1: 2$ complexes are formed, it is not possible to deternine the relevant average equilibrium 'constant' because they are not constant in multiligand systems." Thus, the Scatchard equation "...while being rigorous for two-component eyeteas, becomes simply an enpirical curve-fitting equation with four ad justable parmeters wen applied to multiligand ayeteas that contain three or sore ligands.... The derived constante have little or no chenical significance." 


\section{Fig. 9.}

Scatchard Plot for the Binding of Copper(II) by Fulvic Acid at $\mathrm{pH}$ 8.0. The linear components of the curve are the resolved contributions from the "strong" sites (-.-) and the "weak" sites $(-.-$.$) . Copyright 1975$ slsevier Science Publishers. Reprinted by permission [MANTOURA-1975].

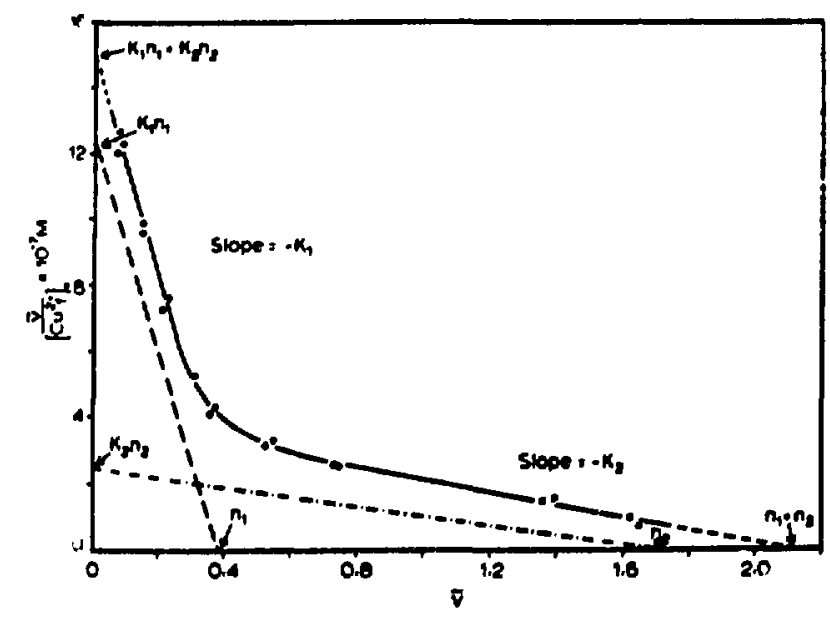

Perdue and Lytle [PERDUE-1983A] suggest that, for complex ligands such as humic substances, rigorous discrete complexation models can be approximated by continuous models. They propose a statistical-chemical approach using a Gaussian distribution model with only two curve-fitting parameters, which they believe shows promise for describing complex multiligand systems. Such a model could be used to predict the extent of metal complexing at environmentally significant metal concentrations from the results of laboratory experiments that must be carried out at much higher concentrations.

The limitatirns of the Scatchard plots for analyzing the stability of fulvic acid complexes are also noted by Dempsey and $0^{\prime}$ Melia [DEMPSEY]. Commenting on the shape of Scatchard curves, they state that "...there is continuous change in the slope over the entire length of the curve. If the curve is enlarged to examine the smaller sections, the same continuous slope is seen. This indicates that there are many different sites or there is an interaction between sites - or both are true.... Scatchard plots are useful for determination of modeling parameters only if the nature and number of sites or the interactive parameter is known.... Scatchard plots are of little use for analysis of H-FA reactions, other than to illustrate that the behavior of FA is complex."

E. Influences of Metal-Ligand Concentrations and Environmental Variables on the Stability of Metal-Organic Complexes

Several recent studies have investigated the relative stability of setal-humic acid (HA) and metal-fulvic acid (FA) complexes (chelates) as a function of metal-ligand concentrations and environmental variables such as solution $\mathrm{pH}$ and ionic strength. All the analytical methods for studying netal-organic interactions described above, in addition to other methods not discussed here, have been used to determine stability constants for metal-HA and metal-FA complexes. Owing to the variability of HA and FA types, various 
uncertainties introduced by the different analytical methods used, and the variety of laboratory conditions present during experiments, the stability data on metal-HA and metal-FA interactions are complex. Nonetheless, despite some uncertainties in the absolute values of metal-organic stability constanto, some general trends in complexing behavior as a function of environmental and concentration variables have been established. For example, many studies have shown that complexing capacity of $\mathrm{HA}$ and FA differs with different metal ions at a given $\mathrm{pH}$, and that $\mathrm{pH}$ has a strong influence on complexation-which increases for many metals as $\mathrm{pH}$ increases. Complexing capacity also generally increases with an increase in IiA and FA concentration, but may decrease with an increase in metal ion concentration. These trends are discussed in greater detail below.

\section{Influence of Metal Type}

In one of the earlier studies of metal-HA binding, Van Dijk

[VAN DIJK] used a titration method to determine the relative stabilities of 11 metal cations with HA at a constant pH of 5 . Van Dijk's results revealed two distinct types of cations, those that are weakly bound and those that are more firmly bound to $\mathrm{HA}$. The weakly bound cations are $\mathrm{Ba}^{2+}, \mathrm{Ca}^{2+}, \mathrm{Mg}^{2+}, \mathrm{Mn}^{2+}$, $\mathrm{Co}^{2+}, \mathrm{Ni}^{2+}, \mathrm{Fe}^{2+}$, and $\mathrm{Zn}^{2+}$; bond strength between the metal cations and HA increases slightly with each metal of the series in the order shown. The more strongly bound cations, in order of increasing bond strength, are $\mathrm{Pb}^{2+}, \mathrm{Cu}^{2+}$, and $\mathrm{Fe}^{3+}$.

Experimental work by several investigators has shown that, under a given set of environmental conditions, $\mathrm{Cu}^{2+}$ is complexed more strongly by HA than $\mathrm{Cd}^{2+}$ [MANTOURA-1978, SOHN, STEVENSON-1976 -1977, TAKAMATSU]. The cation $\mathrm{Cu}^{2+}$ is also complexed by FA more strongly than Cd2+ [MANTOURA-1978, RAINVILLE, SAAR-1980, TRUITT-1981A -1981B]. Other st udies indicate that $\mathrm{Zn}^{2+}$ and $\mathrm{Mn}^{2+}$ have binding abilities similar to $\mathrm{Cd}^{2+}$ when complexed with HA [HIRATA, MANTOURA-1978, ROSELL, SOHN, STEVENSON-1977, ZUNINO] and FA [HIRATA, MANTOURA-1978, RAINVILLE, SCHNITZER-1970]. The cation $\mathrm{Pb}^{2+}$ has been shown to behave more like Cu2t in complexes with HA [STEVENSON-1976 -1977, TARAMATSU] and FA [SAR-1980, SCHNITZER-1970]. Zunino and Martin [ZUNINO] found the binding strength of $\mathrm{Ca}^{2+}$ and $\mathrm{Mg}^{2+}$ with humic substances to be intermediate between that of $\mathrm{Cu}^{2+}$, wich is strongly bound, and $\mathrm{Zn}^{2+}$, which is weakly bound. On the other hand, Mantoura and Riley [MANTOURA-1975] found both $\mathrm{Ca}^{2+}$ and $\mathrm{Mg}^{2+}$ to be only weakly complexed with HA or FA, with otability constants 1 ess than that for $2 \mathrm{n}^{2+-h u m i c}$ complexes and mucl: 1 eso than that for $\mathrm{Cu}^{2+}$ complexes.

Some studies have focused on the relationship between wetal-HA or -FA binding and the Irving-Willims (I-W) series [IRVING]. The I-W series predicts relative bond etrength for divalent wetals of the first transition ceries irrespective of the ligand type or number of 1 igand wolecules. The bond strength varies inveraely with the ionic radius and the second ionization potential of the wetal concerned. The resulting $I-W$ series is: in $<\mathrm{Fe}<\mathrm{Co}_{\mathrm{O}}<\mathrm{Ni}<\mathrm{Cu}>\mathrm{2n}$.

Van Dijk [VAN DIJK] studied a series of netals that included those of the I-H series, but found little correlation between the stabilities predicted by the I-W series and the binding of these metale by hunic acid. On the other hand, Mantoura et al. [MANTOURA-1978] used sel filtration techniques 
to determine that the relative binding strength of complexes between these wetale and HA or FA did follow the I-W series. Schnitzer and Hansen [SCHNITZER-1970] and Remdorff and Schnitzer [KERNDORFF] also found a good correlation between the I-W series (excluding $\mathrm{Fe}^{2+}$, which was not studied) and binding strength of metals with FA and HA.

Kerndorff and Schnitzer [KERNDORFF] allowed solutions of HA containing three trivalent metals ( $\mathrm{Fe}, \mathrm{Al}$, and $\mathrm{Cr}$ ) and eight divalent metals $(\mathrm{Hg}, \mathrm{Pb}, \mathrm{Cu}, \mathrm{Ni}, \mathrm{Cd}, \mathrm{Zn}, \mathrm{Co}, \mathrm{Mn}$ ) to equilibrate at varying $\mathrm{pH}$ values, and then determined the atability constants for each metal-HA complex. They found t.lat the metals with higher stability constants were able to compete more successfully for the binding sites on the HA molecules. The metals were broken down into three groups according to the relative strengths of their bonds with HA:

$$
\begin{aligned}
\text { Strong: } & \mathrm{Fe}^{3+}, \mathrm{Hg}^{2+} \\
\text { Intermediate: } & \mathrm{Cu}^{2+}, \mathrm{Pb}^{2+}, \mathrm{Al}^{3+} \\
\text { Weak: } & \mathrm{Ni}^{2+}, \mathrm{Cr}^{3+}, \mathrm{Zn}^{2+}, \mathrm{Mn}^{2+}, \mathrm{Co}^{2+}, \mathrm{Cd}^{2+}
\end{aligned}
$$

These results agree very well with those of most previous studies, some of wich also considered the relative binding strengths of divalent $\mathrm{Mg}$ and $\mathrm{Ca}$. If $\mathrm{Mg}$ and $\mathrm{Ca}$ are added to this series in their proper positions, the expanded relative stability series for the binding of the common metals with humic substances becomes:

$$
\begin{aligned}
\text { Strong: } & \mathrm{Fe}^{3+}, \mathrm{Hg}^{2+} \\
\text { Intermediate: } & \mathrm{Cu}^{2+}, \mathrm{Pb}^{2+}, \mathrm{Al}^{3+} \\
\text { Weak: } & \mathrm{Ni}^{2+}, \mathrm{Cr}^{3+}, \mathrm{Zn}^{2+}, \mathrm{Mn}^{2+}, \mathrm{Co}^{2+}, \mathrm{Cd}^{2+}, \mathrm{Mg}^{2+}, \mathrm{Ca}^{2+}
\end{aligned}
$$

\section{Type of Organic Matter}

Metals are bound relatively weakly by HA and FA compared to binding by some organic pollutanta found in the envi ronment, e.8., EDTA [MEANS-1978]; however, humic materials are the most important natural organic substances found in surface waters and groundwaters (Sec. II.B) and, thus, are of great interest in studies of metal-organic complexing. Some studies have exmined the relative binding strength of complexes formed with HA versus those formed with $R A$, and have reported that the binding of metals by $F A$ is stronger than that by HA; however, this assertion is an oversimplified generalization because HA and FA from different environments are known to have different complexing capacities. For example, Mantoura et al. [MANTOURA-1978] compared the binding of copper with HA and FA obtained from several different environments. Their results show that binding capacities vary among humic materials from different sources, but in all cases where the binding capacities of HA and FA from the same general environment were compared, HA was a stronger binder of Cu2t than FA. The stability constants for $\mathrm{Cu}^{2+}$ binding with everal types of humic aterials increased in the order: 
soil FA $<$ soil HA $<$ peat FA $<$ peat HA $<$ seawater HM $<$

lake HM < river HM $<$ marine sediment FA $<$ marine sediment HA

where HM refers to undifferentiated humic matter.

\section{Metal and Organic Acid Concentrations}

The effects of changes in metal or organic concentration are sometimes expressed as the ratio of the metal concentration to the concentration of humic organic matter, i.e., [M]/[FA] or [M]/[HA]. Ong et al. [ONG] studied the stability of five metals ( $\left.\mathrm{Cu}^{2+}, \mathrm{Al}^{3+}, \mathrm{Fe}^{3+}, \mathrm{Zn}^{2+}, \mathrm{Pb} 2+\right)$ with several types of organic acids, including $\mathrm{HA}$ and $\mathrm{FA}$, and found in all cases that decreases in [M] or increases in [FA] or [HA] (i.e., decrease in [M]/[HM]) tended to increase the stability of the metal-organic complex (colloid). Saar and Weber [SAAR-1979] found that a decrease in [M]/[FA], produced by an increase in [FA], increased the stability of $\mathrm{Cu}^{2+}$ and $\mathrm{Pb}^{2+}$ complexes, while decreasing Cd2+-FA complex stability. Saar and Weber surmise that the decrease in stability of the Cd-FA complex with a decrease in [M]/[FA] is due to conformational changes of the FA molecule; that $i s$, a decrease in the apparent size of the molecule, which results in the blocking of sites on the FA molecule to which $\mathrm{Cd}^{2+}$ is weakly bound at lower [FA]. Both $\mathrm{Cu}^{2+}$ and $\mathrm{Pb} 2+$ ions, which are bound more strongly than $\mathrm{Cd}^{2+}$ at low [FA], apparently overcome the additional intramolecular forces that occur at higher [FA] and are consequently more strongly bound with a decrease in [M]/[FA]. Saar and Weber [SAAR-1980] found that at low $[\mathrm{M}] /[\mathrm{FA}], \mathrm{Cu}$ and $\mathrm{Pb}$ are bound to FA with similar strengths, but as [M]/[FA] increases owing to increase in the cation concentration, the $\mathrm{Pb}-\mathrm{FA}$ complex is precipitated from the solution even before the FA complexing capacity is reached.

Truitt and Weber [TRUITT-1981A -1981B] examined $\mathrm{Cu}^{2+}$ and $\mathrm{Cd}^{2+}$ binding in seven natural water samples with DOC concentrations ranging from 6.8 to $12.5 \mathrm{mg} / \mathrm{L}$. They found little or no correlation between changes in [M]/[DOC] and the relative strength of binding of $\mathrm{Cu}$ or $\mathrm{Cd}$. They did not maasure the [HA] or [FA] as percentages of the total [DOC], and concluded that the low correlations must be the result of unknown fluctuations in the relative proportions of [HA] and [FA] in the total [DOC].

Kerndorff and Schnitzer [KERNDORFF] used a method of simultaneous equilibration of several metals with HA to study binding of $\mathrm{Fe}, \mathrm{Hg}, \mathrm{Cu}$, and $\mathrm{Pb}$. They report that the difference in bond etrength between the typically strongly bound $\mathrm{Fe}$ and $\mathrm{Hg}$ and the less strongly bound $\mathrm{Cu}$ and $\mathrm{Fb}$ becme relatively amal1 as metal concentrations were reduced to low levels (10w [M]/[HA]).

\section{Effecto of $\mathrm{pH}$}

The influence of $\mathrm{pH}$ on binding of metal ions with humic substances has been examined in numerous studies. With minor exceptions, these sudies show a general increase in stability of metal-hunic anter coplexes with increasing pH. Kerndorff and Schnitzer [KERIDORFF] tudied HA complexing (sorption) by 11 metals $\left(\mathrm{Hg}^{2+}, \mathrm{Fe}^{3+}, \mathrm{Pb}^{2+}, \mathrm{Cu}^{2+}, \mathrm{Al}^{3+}, \mathrm{Ni}^{2+}, \mathrm{Cr}^{3+}, \mathrm{Cd}^{2+}\right.$, $\mathrm{Zn}^{2+}, \mathrm{Co}^{2+}, \mathrm{In}^{2+}$ ) at $\mathrm{pH}$ values ranging from 2.4 to 5.8 . Their resulto indicate that the atrength of al1 the wetal-HA complexes increased with 
increasing pH. Ong et al. [ONG] found in studies with both HA and FA that the atability of nost, but not all, metals investigated increased with increasing pH. Complexes of $\mathrm{HA} / \mathrm{FA}$ with $\mathrm{Cu}^{2+}$ increased in stability from $\mathrm{pH} 6$ to 9 , Al ${ }^{3+-L A} / \mathrm{FA}$ complex stability increased from $\mathrm{pH} 4$ to 9 , and $\mathrm{Fe}^{3+-H A} / \mathrm{FA}$ complexes increased in stability from $\mathrm{pH} 5$ to 9 . $\mathrm{Pb}^{2+}$ complexes increased in otability from $\mathrm{pH} 5$ to 7 , but decreased in stability from $\mathrm{pH} 7$ to 9 , and $\mathrm{Zn}^{2+}$ complexes decreased in stability from $\mathrm{pH} 7$ to 9.

Takamatsu and Yoshida [TAKAMATSU] studied $\mathrm{Cu}^{2+}, \mathrm{Pb}^{2+}$, and $\mathrm{Cd}^{2+}$ binding by HA and found that stabllity constants for all metals increased as pH increased from 4 to 7 . Bresnahan et al. [BRESNAHAN] found that $\mathrm{Cu}^{2+} \mathrm{com}-$ plexes with FA in 8011 and water increased in stability with increase in pH from 4 to 6. Saar and Weber [SAAR-1979] examined the formation of Cd2t complexes with FA derived from soll and water and found that complex stability increased from $\mathrm{pH} 4$ to 8 . Truitt and Weber [TRUITT-1981A -1981B] determined that stability of both $\mathrm{Cu}^{2+}$ and $\mathrm{Cd}^{2+}$ complexes with soil FA Increased with increasing $\mathrm{pH}$. Rainville and Weber [RAINVILLE] otudied the complexing of 8011 FA with $\mathrm{Cu}^{2+}, \mathrm{Cd}^{2+}, \mathrm{Mn}^{2+}, \mathrm{N}^{2+}$, and $\mathrm{Zn}^{2+}$ and observed that the stability of all metal-FA complexes increased with increase in $\mathrm{pH}$ from 5 to 7; however, in a study of $\mathrm{Cu}^{2+}$ complexing with another soll $\mathrm{FA}$, Ryau and Weber [RYAN] found no significant increase in complex strength with increase in $\mathrm{pH}$ from 5 to 7 .

\section{Effects of Ionic Strength}

The fonic strength of a solution is a function of the concentrations of lons in the solution and the charges on the ions. ${ }^{*}$ Schnitzer and Hansen [SCHNITZER-1970] studied the effect of lonic strength on the stability constants determined for $\mathrm{FA}$ complexes with ten metals $\left(\mathrm{Cu}^{2+}, \mathrm{Fe}^{3+}, \mathrm{Ni}^{2+}, \mathrm{Pb}^{2+}\right.$, $\left.\mathrm{Co}^{2+}, \mathrm{Mn}^{2+}, \mathrm{Zn}^{2+}, \mathrm{Ca}^{2+}, \mathrm{Al}^{3+}, \mathrm{Mg}^{2+}\right)$. In each case, an increase in ionic strength caused a decrease in the stability of the metal-FA complex. Regression plots of ionic strength vs. stability constant show that as lonic strength Increased from 0 to 0.15 , the stability constants of all the metal-FA complexes decreased linearly; however, the metals could be divided into two groups according to the slopes of the regression 1ines. The metals forming relatively strong complexes ( $\mathrm{Fe}^{3+}, \mathrm{Al}^{3+}, \mathrm{Cu}^{2+}, \mathrm{Ni}^{2+}, \mathrm{Co}^{2+}$ ) yielded regression Iines with steep slopes, 1 .e., their stability constants decreased relatively rapidly wth increasing lonic strength, whereas the metals that form weaker complexes $\left(\mathrm{Pb}^{2+}, \mathrm{Ca}^{2+}, \mathrm{Zn}^{2+}, \mathrm{Mn}^{2+}, \mathrm{M}^{2+}\right)$ yielded regression Iines with relatively gentle slopes--indicating a slower rate of decrease in binding atrength wth increase in ionic strength.

Stevenson (STEVENSON-1976) studled the effect of lonic atrength on binding of $\mathrm{Pb}^{2+}, \mathrm{Cu}^{2+}$, and $\mathrm{Cd}^{2+}$ by soll and peat $\mathrm{HA}$. He observed that the atability constants of these metal-hA complexes also decreased with increasing lonic strength. Lang ford et al. [LANGFORD] demonstrated a very strong inverse relationship between bound (complexed) $\mathrm{Cu}^{2+}$ and ionic strength at fixed $\mathrm{pH}$ and $[F A](B 1 g, 10)$.

II $=\sum c_{1} z_{1}{ }^{2}$, where $I$ is lonic strength, $C$ is concentration, and $z$ is Ionic charge. 


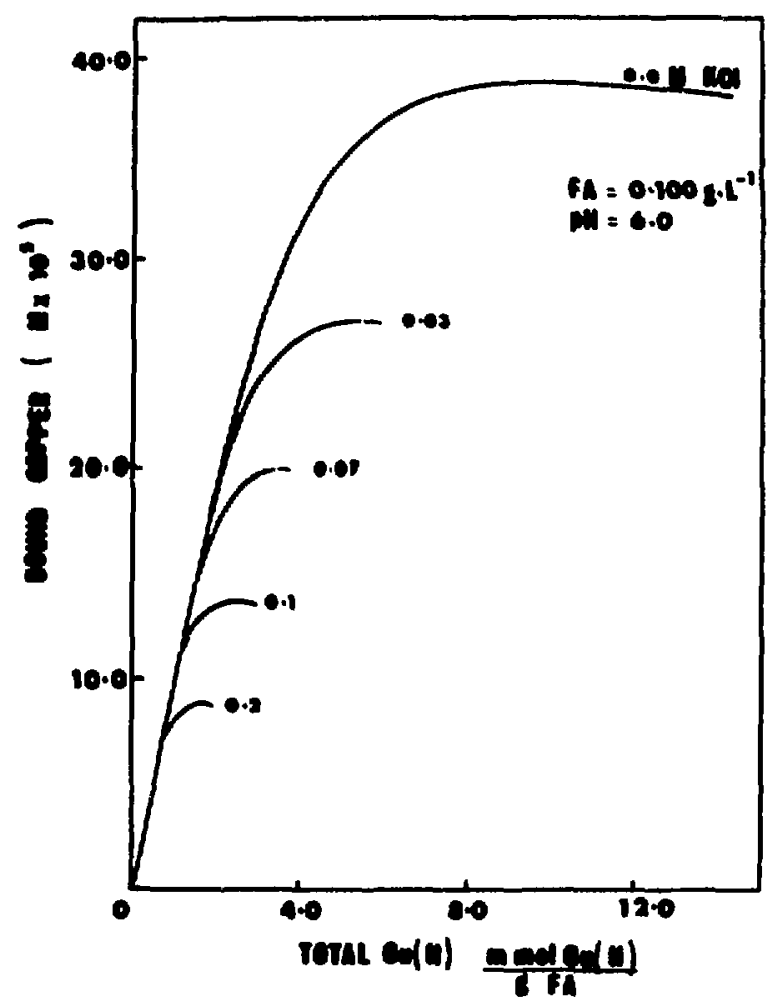

Fig. 10.

Plot of Bound $\mathrm{Cu}^{2+}$ va. Total $\mathrm{Cu}^{2+}$ at Various Ionic Strengths as Derived from Ion-Selective Electrode Titration of the Fulvic Acid with $\mathrm{Cu}^{2+}$. [LANGFORD].

The observed decrease in complex stability with increasing ionic strength apparently reflects the effects of increased competition for binding sites on the humic materials by other cations in solution. High concentrations of "foreign" cations in solution have the effect of reducing the available sites for complexation by a particular metal. Owing to the inhibiting effects on trace metal-organic complexing caused by high concentrations of $\mathrm{Ca}^{2+}$ and $\mathrm{Mg}^{2+}$, Stumm and Morgan [STUMM] questioned the importance of organometallic complexes in natural waters enriched in $\mathrm{Ca}$ and $\mathrm{Mg}$. They used thermodynmic data to model the effect of $\mathrm{Ca}^{2+}$ on $\mathrm{Fe}^{3+}$ complexes with EDTA and citrate and found that high ratios of $\left[\mathrm{Ca}^{2+}\right] /\left[\mathrm{Fe}^{3+}\right]$ in water significantly reduce the amount of Fe3+-EDTA complexes, which are normally very stable at lower $\left[\mathrm{Ca}^{2+}\right]$. A similar effect was observed with $\mathrm{Fe}^{3+-c i t r a t e}$ complexes, al though a high $\left[\mathrm{Ca}^{2+}\right] /\left[\mathrm{Fe}^{3+}\right]$ ratio has less effect on the wount of $\mathrm{Fe}^{3+}$ that complexes with citrate than on the mount that complexes with BDTA. The difference in complexing behavior of $\mathrm{Fe}^{3+}$ with citrate and with EDTA suggeats that the effect on organometallic complexing of a high $\left[\mathrm{Ca}^{2+}\right] /$ [trace metal] ratio is less pronounced with the less strongly binding organic substance (in this case, citrate). This possibility implies that trace aetal-HW/FA complexes way be less affected by ionic strength than complexes with strong complex formers such as EDTA. 


\section{COMPLEXING OF RADIONUCLIDES BY ORGANIC SUBSTANCES}

\section{A. Introduction}

In Section III we reviewed the interactions that take place between organic compound: and metals. We examined the factors that influence complexing of various metals by humic substances and developed a base of information on metal-organic complexing to provide a background for understanding the more secific problem dealing with the complexing of radionuclides by humic materials--the main focus of this report. The potential for increased mobility of radionuclides in groundwater systems owing to complexing by humic substances creates concern for the safe disposal of high-level radioactive wate in geologic repositories.

Preliminary evidence suggests that dissolved organic carbon (DOC) in natural waters may influence the sorption behavior of radionuclides (which might leach from high-level waste into groundwater systems) by forming soluble complexes with the radionuclides. These soluble complexes may resist sorption onto rock materials, thereby causing increased mobility of the radionuclides as they migrate through subsurface formations. It is apparent from the discussion in Section III that metal-organic complexing is an extremely complex phenomenon. The complexing capacity of humic substances for varicus metals is affected by a variety of factors including $\mathrm{pH}$ and $\mathrm{Eh}$, the type of metal, concentration of humic substances, concentration of the complexing metal, concentration of competing metal ions and overall ionic strength of the solutions, and the molecular weight range and other chemical characteristics of the organic substances that participate in complexing. In this section, we are concerned with the specific problem of radionuclide-organic interactions, particularly the complexing of actinide metals by organic substances.

We must deal here with two aspects of the complexing problem because there are two categories of mobile organic ligands that may act as complexing agents for radionuclides: synthetic organic ligands and natural organic ligands. Organic ligands in the first category are derived from decomposing organic matter introduced as waste along with radioactive materials into low-level radioactive waste disposal sites. Organic wastes can include a wide variety of products ranging from animal carcasses to paper, rubber and plastic products, and various types of synthetic organic solvents used in nuclear cleanup and decontamination operations. These synthet ic organic chemicals include polyphosphates, mono, di-, and tributyl phos phate, aninepolycarboxylic acids such as ethylenediaminetetraacetic acid (EDTA), diethylenetriaminepentaacetic acid (DTPA), nitrilotriacetic acid (NTA), N-hyd roxye thyl ethyl ened iaminetriacetic acid (HEDTA), cyclohexanediami netetraacetis acid (CDTA), and carboxylic acids such as citric, hydroxyacetic, oxalic, and tartaric acids [HIGGINS]. Thus, the first aspect of the radionuclide-organic complexing problem deals with the potential dangers of mobilizing radionuclides in low-level waste disposal sites owing to complexing with synthetic organic substances such as EDTA and NTA. Considerable attention has been focused on this problem since the discovery about 1978 that oynthetic organic compounds in some low-level waste sites have al ready ceused significantly enhanced mobility of certain radionuclides. 
The second type of organic 11 gand consists of water-moblle, humic organic constituents, primarily humic and fulvic acids, that occur in natural concentrations in so1ls, surface waters, and groundwaters. The nature of these oryanic substances is discussed in detall in Section II. We are particularly concerned with humic substances because their concentraticns in natural waters cannot be controlled; thus, they pose a potential problem to disposal of highlevel radloactive waste in deep repositories. They may form soluble complexes witi actinide elements, such as Am and $\mathrm{Pu}$, that could leach from repositories and thereby promote migration of these actinides through the groundwater system back to the surface and the biosphere. Because of the significance we perceive in radionuclide-humic organic complexing, the remainder of this report focuses on that relationship. He first examine briefly the complexing of radionuclides by synthetic organic compounds. We turn then to the potentially more important problem of radionuclide complexing by natural humic organic substances in ourface waters and groundwaters.

\section{B. Complexing of Radionuclides with Synthetic Organic Compounds}

The problem of increased mobility of radionuclides in the environment owing to chemical interaction with organic compounds was first Identified in low-level radioactive waste disposal sites. Some of these sites are located In areas of moderately high ralnfall where transport paths to the groundwater table are short. Such conditions provide an environment in which enhanced mobility of radionuclides owing to organic complexing can significantly affect nuclide transport. Means et al. [MEANS-1978] discovered that the presence of the synthetic organic compounds EDTA, NTA, DTPA, and CDTA increased the mobility of certain radionuclides. Even trace levels ( $1 \mathrm{ppm}$ ) of these chelating agents significantly increased the mobility of ${ }^{60} \mathrm{Co}$, and also affected the migration of the rare earths, radium, and actinide metals such as Am, Cm, and Th. Means et al. concluded that "...wherever EDTA and similar compounds have been introduced Into terrestrial disposal sites the aqueous transport of transition metals, rare earths, and transuranics, which characteristically form the most stable chelates, may be augmented."

Since this initial report of radionuclide-organic complexing with synthetic organic compounds, several studies have examined the potential seriousness of such complexing to the safe disposal of low-level radioactive waste. These studies have encompassed both oite-specific field investigations and experimental approaches. Examples of site-specific investigations include the work of Cleveland and Rees [CLEVELAND-1981], who studied plutonium conplexing in Maxey Flats radioactive trench leachates. These authors found that most of the plutonium was in true solution as a result of forming strong couplexes with synthetic organic compounds such as EDTA and DTPA. Weiss et al. [WEISS] also studled Maxey Flats water-8011 chemistry and reported that in, $\mathrm{Co}$, and $\mathrm{Pu}$ were made more soluble by the presence of EDTA, whereas Sr and $\mathrm{Cs}_{8}$ were unaffected under the same conditions. Cryecinski and Kinaley [CZ YSCINSKI] used simulated experimental methods to examine the atability of radionuclideorganic complexes in the Maxey Flat system. The1r work revealed that Co-DTPA complexes and Co-EDTA complexes persisted in solution under both low redox conditions $\left(-200 \mathrm{vV}, \mathrm{NHE}^{*}\right)$ and more oxidizing conditions (O $\left.\mathrm{NV}, \mathrm{NHE}\right)$. They

\footnotetext{
*Nornalized to the hydrogen electrode.
} 
conclude that the temporal stabilities of chelated radionuclides in low redox geochemical environments are not easily predicted from comparisons of appropriate association constants and solubility products, and that empirical information is required to reliably predict the behavior of chelated radionuclides under field conditions.

Means [MEANS-1982B] experimentally investigated the complexing effect of both EDTA and oxalic acid (another complexant used in the nuclear industry) with $\mathrm{Cs}, \mathrm{Sr}, \mathrm{Co}_{\mathrm{O}}$, and $\mathrm{U}$, and found that the effect of these organic substances on the sorption and migration behavior of radionuclides varied with different radionuclides. Neither EDTA nor oxalic acid affected the sorption of $C s$ and Sr onto clay minerals, but EDTA had a strong solubilizing effect on Co, as Means et al. [MEANS-1978] had previously reported. Oxalic acid had little effect on $C_{0}$, but increased the solubilization of $U$ within the temperature range of 50 to $100^{\circ} \mathrm{C}$. Swanson [SWANSON] examined the effects of EDTA, DTPA, oxalate, and citrate (an organic complexant also used in the nuclear industry) on solubilization of $\mathrm{Cs}, \mathrm{Sr}, \mathrm{Ni}, \mathrm{Co}$, and $\mathrm{Eu}$. He found, as Means [MEANS-1982B] had reported, that the ef fects of the complexants varied widely. No effect of the organic complexants was obsezved with $\mathrm{Cs}$ and $\mathrm{Sr}$; however, pronounced complexant effects were found with Ni/EDTA, Ni/DTPA, Co/EDTA, Co/DTPA, Eu/EDTA, $\mathrm{Ni} / \mathrm{citrate}$, and $\mathrm{Ni} / \mathrm{oxalate.}$

Clayton et al. [CLAYTON-1981 -1982] conducted batch partitioning experiments to study the effects of EDTA, humic acid, acetic acid, salicyclic acid, and the organic compounds 1-nitroso-2-naphtol and 1,10-phenathroline on sorption of $\mathrm{Co}, \mathrm{Ru}, \mathrm{Cs}$, and $\mathrm{Am}$ onto lake and river sediments. In the 1981 study, EDTA and humic acid were found to solubilize both Am and Co, thereby reducing sorption onto the solids, whereas 1-nitroso-2-naphtol and 1,10-phenanthroline actually increased sorption of $\mathrm{Am}$ and $\mathrm{Co}$ onto the sediments. The Cs and Ku adsorption behavior was not changed by any of the organic compoundr tested. The 1982 study showed that, among all the organic ligands used in the experiment, only EDTA caused solubilization of any of the radionuclides--and then only at ligand concentrations $>10^{-6} \mathrm{M}$. The radionuclides $57 \mathrm{Co}$ and $241_{\mathrm{Am}}$ were significantly mobilized by EDTA at these greater concentrations; however, $137 \mathrm{Cs}$ was not markedly affected by EDTA or any of the other organic ligands. Also, ${ }^{106} \mathrm{Ru}$ was not affected by any of the organic complexants in the experiments with river water, but showed slightly decreased solubilization (increased sorption onto sediment) with all the organic compounds in experiments with lake water. The fact that some of the organic ligands caused increases in adsorption (decreased solubilization) of radionuclides such as $57 \mathrm{Co}, 106 \mathrm{Ru}$, and $241_{\mathrm{Am}}$, implies that these ligands are involved in at least two concurrent reactions: (1) complexing the radionuclides, and (2) actively sorbing to the sediment particles. Clayton et al. [CLAYTON-1982] suggest that the relative importance of these two effects may depend upon the ligand concentration. At concentrations less than about $10^{-5} \mathrm{M}$, the ligands tend to conplex or solubilize the radionuclides, whereas at higher concentrations they would have an affinity for the sediment. Thus, depending upon the relative affinity of an organic ligand molecule for radionuclides and sediment particles and the actual concentration of such a ligand molecule, some organic compounds can apparently either increase or decrease the mobility of radionuclides.

These field investigations and laboratory studies show that some synthetic organic compounds are strong complexants for some radionuclides, causing increased mobility of these radionuclides in natural water systems. On the 
other hand, these same compounds have little effect on other radionuclides, or actually cause their mobilities to decrease. The synthetic organic compounds that appear to be the strongest complexants are EDTA and DTPA, and the radionuclides that seem to be most affected (1.e., undergo increased mobility) by organic complexing among those tested are Co and Am; those least affected are $\mathrm{Cs}, \mathrm{Sr}$, and $\mathrm{Ru}$. The general conclusions that can be drawn from these studies of radionuclide complexing by synthetic organic compounds are that (1) use of alternative decontaminants for nuclear cleanup operations that do not have the complexing properties of EDTA, DTPA, etc. could reduce the risk of radionuclide mobility in low-level radioactive waste disposal sites and (2) prediction of radionuclide-organic complexing on the basis of theoretical considerations 18 likely to be risky; experimental studles and emplrical, site-specific field investigations will be necessary to determine the effects of each type of organic complexant on each radionuclide.

\section{Complexing of Radionuclides with Humic Organic Substances}

Although the complexing of varlous substances with trace metals has been under active investigation since Werner proposed the concept of chemical complexes in 1893 [MELLOR], the nature of the complexes that form between natural humic substances and radionuclides has come under scrutiny only very recently. A review of avallable published literature on this subject reveals that the total number of papers dealing specifically with radionuclide-humic organic complexing is relatively small and that most of these papers were published after the $1960 s$. Most interest has focused on this field of study since Means et al. [MEANS-1978] reported the effects of synthetic organic compounds on complexing and mobillzing radionuclides in shallow landfills, as discussed in Section IV.B. Their study and other subsequent site-specific studies of radionuclide complexing with EDTA and various synthetic organic compounds have inevitably ralsed concerns about the possible effects of natural humic organic substances on the mobility of actinide elements and other rad 10nuclides. Published studies of radionuclide-humic organic complexing are of two general types: those dealing with the effects of soll humic substances on radionuclide behavior and those dealing with the complexing effects of humic substances dissolved in surface waters and groundwaters.

\section{Complexing of Soil Humic Substances with Radionuclides}

Several published studies have examined the effects of soll humic natter on rad fonuclide complexing and mobllity. These studies reveal two opposing tendencies in radionuclide behavior in the 8011 environment. Under some conditions, certain radionuclides appear to form soluble complexes with the so11 humlc substances that promote radionuclide mobility in the soll-water system. Other radionuclides, or the same radionuclides under different enviromental conditions, can apparently form elther insoluble complexes that become bound to soll particles or radlocollolds that precipitate and reduce solubilization, thereby inhibiting removal of the radionuclides from the soll. A few specific otudies illustrating the effects are discussed below.

Bond 1ett1 et al . [BONDIETTI-1975] Investigated the Interactione of Pu in various oxidation states with organlc substances in so1ls wich were contaninated wth trace levels of Pu in the aiddle 1940s. The nuclide Pu 
existo in four oxidation states in solution (III, IV, V, and VI); however, reduction of the higher valence states occurs in the presence of soil humic substances; $\mathrm{Pu}$ (IV) appears to be the predominant state that stabilizes in natural environments at pH values above 6 .

Soil resin transfer studies by Bondietti et al. showed that a substantial fraction of the $\mathrm{Pu}$ in the contaminated soil did not readily desorb under conditions favoring exhaustive removal (Fig. 11). They conclude from these results that $\mathrm{Pu}$ forms strong insoluble complexes with soil humic matter and is not readily solubilized by organic resins; that is, the humic materials appear to stabilize $\mathrm{Pu}$ in the soil and prevent its mobilization and removal.

Fig. 11.

Resin Extraction of Pu-Contaminated Soil. (Error bars $=96 \%$ confidence leve1.) [BONDIETTI-1975].

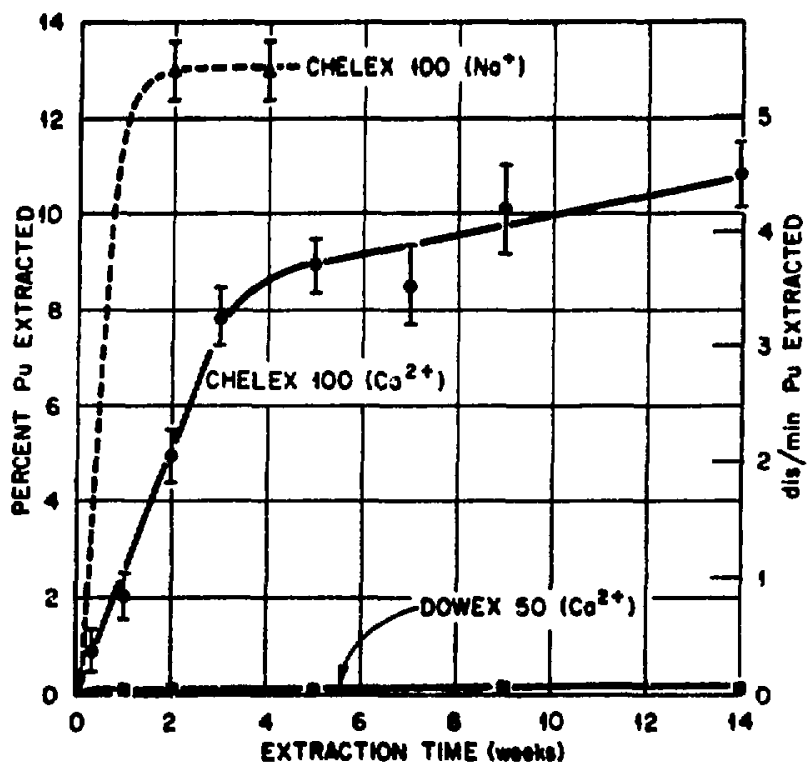

Cleveland and Rees [CLEVELAND-1976] investigated solubilization of Am and $\mathrm{Pu}$ in radionuclide-contaminated soils that were allowed to react with fulvic acid solutions. They reported little solubilization in suspensions ranging in $\mathrm{pH}$ from 6.5 to 7.5 , although a slight solubilization was observed in suspensions adjusted to a pH of 9 by addition of $\mathrm{Na}_{2} \mathrm{CO}_{3}$. However, at high $\mathrm{pH}$ they found it was difficult to discriminate between fulvic acid and $\mathrm{HCO}_{3}-/ \mathrm{CO}_{3}{ }^{2-}$ as solubilizing agents. Their results suggest that Pu forms strong, insoluble complexes with humic substances and that soil humic compounds are not a major factor in the solubilization of $\mathrm{Pu}$ and $\mathrm{Am}$ in the soils studied. This conclusion may not be totally justified, however, because their experimental procedures did not take into account the possible effects of indigenous fulvic acid in the soil samples, which dissolved during the experiments and yielded as much as $125 \mathrm{ppm}$ of additional fulvic acid to the blank test solutions (assumed to contain no fulvic acid) that were used for comparison in the experiments. Therefore, the effects of fulvic acid on solubilizing Pu and Am could be greater than their results indicate.

Cleveland and Rees suggest that what little solubilization did occur during their experiments was probably due to complex formation and/or colloid 
peptization. They observed that the resulting solutions were unstable, and over a period of a few days most of the Pu and Am precipitated, either as the result of colloid coagulation or hydrolysis.

Nash et a1. [NASH-1981] studied the complexing of U, Np, and Pu by humic acid and clays. They found that humic acid strongly adsorbs U(VI), $\mathrm{Np}(\mathrm{VI})$, and $\mathrm{Pu}(\mathrm{VI})$ from aqueous bicarbonate-carbonate media and complexes the IV and VI valence states strongly enough to prevent carbonate complexes. Complexing of $\mathrm{NpO}_{2}$ with humic acid occurs at both neutral and alkaline pH values. These authors suggest that because humic acids are strongly bound to clays, these results imply probable low mobility of actinide ions in waters contacting humic sediments.

Wiggins and Franz [WIGGINS] summarize and discuss available information on the mobility of organic complexes of radioactive $\mathrm{Zr}$, Nb, Ni, and $\mathrm{Tc}$. They report that relatively little work has been done to characterize the behavior of $\mathrm{Zr}$ with soil humic substances, but predict that $\mathrm{Zr-organic}$ compiexes would be absorbed less by soil than uncomplexed $\mathrm{Zr}$. They suggest that, despite its high stability constants, complexed $\mathrm{Nb}$ will be absorbed by 80 il because of its hydrolysis to insoluble hydrous $\mathrm{Nb}_{2} \mathrm{O}_{5}$. A few studies of $\mathrm{Ni}$ and Co (which is chemically similar to $\mathrm{Ni}$ ) organic complexes suggest that $\mathrm{Ni}$ is solubilized by soil humic substances. Chebotina [CHEBOTINA] reports that plant extracts increase the movement of Co through soil and can also desorb Co from soils. Schnitzer [SCHNITZER-1969] claims that fulvic acid interacts in two distinct fashions with $\mathrm{Ni}$. One interaction appears to involve the formation of a complex incorporating both a carboxyl function and phenolic oH; a second category of complex formation involves only a weakly acidic carboxylic function. The complex involving both carboxylate and phenolic of in fulvic acid material is more effective in preventing the absorption of $\mathrm{Ni}$ by fixed soil constitutents. Very little is yet known about the mobility of Tc in soils, but initial data suggest that it is absorbed only very slightly by soils.

In a series of papers [SHEPPARD-1979 -1980 -1983], Sheppard and his coworkers examined the influence of soil organic matter on the mobility of actinide elements in the soil environment. The organic contents of representative soils from various areas of the United States were determined by the dichromate oxidation method. The soils were then shaken at room temperature $\left(25^{\circ} \mathrm{C}\right)$ with distilled water cont aining $241 \mathrm{Am}, 244 \mathrm{~cm}$, and $237_{\mathrm{Np}}$ and allored to equilibrate for periods of time ranging up to six months. Samples were removed periodically for analysis. The supernatant was centrifuged at speeds ranging from 1750 to $7000 \mathrm{rpm}$ before the solutions were analyzed by alpha or gamma counting to determine the activity remaining in solution. The counting data were then used to calculate effective distribution ratios, $R^{*}$, defined as

$$
R^{*}=\frac{\text { cpm of actinide per unit volume of supernatant }}{\text { cpm of actinide per unit mass of } 80 \text { il before equilibration }}
$$

This equation differs from that usually used to calculate distribution ratios or distribution coefficients, as shown in $\mathrm{Eq} .14$. 
On the basis of these atudieo, Sheppard and K1ttrick [SHEPPARD-1983] suggest that two reactions of radionuclides with soil humic materials may be important. On the one hand, formation of complexes of actinides such as $\mathrm{Am}^{3+}$, $\mathrm{Cm}^{3+}$, and $\mathrm{Np}(\mathrm{V})$ (designated by " $\mathrm{M}$ ) ) th fulvic (or humic?) acid (H.Fulv) can be represented by

$$
M \cdot \text { Soll }+\mathrm{H} \cdot \text { Fulv }-\longrightarrow \mathrm{M} \cdot \mathrm{Fulv}+\mathrm{Soll}+\mathrm{H}^{+}
$$

This process forms soluble aqueous complexes that have the potential to increase mobility of actinide elements in the soil-groundwater environment. On the other hand, adsorption and cation exchange of actinides on humic acid in the soll can work in the oppooite direction to that of complex formation. Thus,

$$
\mathrm{Meq}_{\mathrm{eq}}+(\mathrm{H} \cdot \mathrm{Hum})_{8011} \rightarrow(\mathrm{M} \cdot \mathrm{Hum})_{8011}+\mathrm{H}^{+}
$$

Sheppard and Kittrick [SHEPPARD-1983] caution that these equations should not be taken too literally, because fulvic and humic acids are compounds with rather indefinite compositions.

Perhaps the most interesting result emerging from the research by Sheppard's group was the demonstration that effective distribution ratios are a function of both an ionic component and an actinide-bearing particle component (colloids or ratiocolloids). The ionic component is small compared to the particle component and can be subdivided into two principal fractions. (1) Actinide-bearing particles with radi1 less than $1 \mathrm{~nm}$ (equivalent molecular weight 5000). This fraction may include actinide cations and their hydrolysis products (e.g., $\mathrm{AmCl}_{2}, \mathrm{Am}(\mathrm{OH})_{2}$ ), and presumably small humic and fulvic acid complexes with radii less than $1 \mathrm{~nm}$. (2) Actinide-bearing particles with peak molecular weights between 8000 and 50,000. These are humic acid complexes and polymers with radil mainly between 2 and $3 \mathrm{~mm}$. The particle component includes actinide-bearing soll particles (colloidal clay particles?) greater than $3 \mathrm{~m}$ (particularly greater than $10 \mathrm{~mm}$ ) and humlc acld complexes with molecular weights greater than 50,000 . The contribution of this component to the calculated distribution ratios depends upon the centrifuging conditions of the experiment. As centrifuging speed is increased from 1750 to $7000 \mathrm{rpm}$, a progressively increasing fraction of radionuclide-bearing particles is removed from the solution (supernatant); thus, distribution ratios decrease as a function of increasing speed of centrifugation. Distribution ratios were also found to decrease with time, apparently as a result of growth of small particles, flocculation of perticles, or redistribution of actinides from small to larger particles.

Sheppard and Kittrick [SHEPPARD-1983] suggest that their data indicate the ionic contribution to the distribution ratio is anall and not significant. Also, the contribution from larger actinide particles (radil $>10 \mathrm{~nm}$ ) 18 even lese important. Thus, intermediate-size soil particles, which are nost likely himic acid polymers, are the chlef complexing agents of upper horizon so11s. Sheppard and Kittrick assumed that humic acid polymers have the approximate composition $\left[\mathrm{C}_{20^{\mathrm{H}}}{ }_{12}(\mathrm{COOH})_{6}(\mathrm{OH})_{5}(\mathrm{CO})_{2}\right]_{n}$, where a ts the number of humic aid monomer units per polymer (polyelectrolyte), and that humic acids have the poteritial to complex many actinide cations, such as Am(III). Many of the carboxyl and phenol groups mut be involved 
in the hydrogen bonding that stabilizes the humic acid polywer. They suggest that if the following assumptions are made, (1) half the carboxyl and phenol groups are hydrogen bonded, (2) the molecular weight ranges from 8000 to 50,000 , and (3) only carboxyl groups complex metal cations, euch humic acid polymer can complex 12 to $75 \mathrm{Am}$ (III) cations; however, many complexing sites under natural conditions in the soil environment are occupied by $\mathrm{Ca}^{2+}, \mathrm{Fe}^{3+}$, and other cations, resulting in the complexing of fewer Am(III) cations. Thus, humic acid polymers have variable capacities to complex Am(III) and other actinides depending upon the degree to which complexing sites are occupied by other cations.

Sheppard and Kittrick [SHEPPARD-1983] also considered the transport of actinides in aquifers in the presence of humic compounds. Based on theoretical considerations, they suggest that when the humic acid (or fulvic acid?) concentration is zero, the actinide flow velocity is determined by the actinide distribution coefficient or ratio $\left(K_{d}\right)$; however, in the presence of increasing humic acid concentration, (1) actinide flow velocity is proportional to the humic acid concentration, (2) actinide transport rates are inversely proportional to their respective $K_{d}$ values, and (3) the magnitude of the actinide flow velocity depends upon the size of the formation complexing constant. These factors are incorporated into the following equation:

$$
V(\text { act }) / V\left(\mathrm{H}_{2} \mathrm{O}\right)=B[\mathrm{HA}] /(\mathrm{p} / \mathrm{O}) \mathrm{K}_{\mathrm{d}}(\mathrm{O})
$$

where $V($ act $)=$ actinide flow velocity,

$\mathrm{V}\left(\mathrm{H}_{2} \mathrm{O}\right)=$ aquifer flow velocity,

B = humic acid formation constant,

[HA] = humic acid concentration,

$\mathrm{p}=$ soil density, $\mathrm{g} / \mathrm{cm}^{3}$,

0 soil porosity, and

$K_{d}(0)=$ distribution ratio in the presence of humic acid.

Using a calculated value of $10.4 \times 10^{6}$ for the apparent formation constant of humic acid, Sheppard and Kittrick [SHEPPARD-1983] used the modified FORTRAN computer code GARD to simulate transport of actinides through soil or 8 and in the presence of various concentrations of humic acid, assuming groundwater flow rates ranging from 0.3 to $3 \mathrm{~m} / \mathrm{y}$. The results, shown in Fig. 12, indicate that humic acid has a dramatic influence on rates of actinide transport in groundwater. Humic acid concentrations as low as $10^{-6} \mathrm{~mol} / \mathrm{L}$ cause a oignificant increase in the groundwater transport rates of Am(III), and presumably other actinide cations, and confirm the prediction from Eq. 25 (sec. III.D.6) that the time required for an actinide ion to reach a discharge point from an aquifer is inversely proportional to the humic acid concentration.

The movement of $99 \mathrm{Tc}$ through soils was monitored by Balogh and Grigal [BALOGH] using soil column layer chromatography (CLC). Under aerobic conditions, ${ }^{99} \mathrm{Tc}$ occurs as the pertechnetate anion, $\mathrm{TCO}_{4}{ }^{-}$. In the 80 il. studied uncier the short-term $(n 24-h)$ aerobic conditions of the experiment, Tc was found to be quite wobile. These results are in contrast to stronger adeorption reported by Landa et al. [LANDA] in experiments lasting from two to five weeks, which they actributed in part to microbial fixation. Balogh 


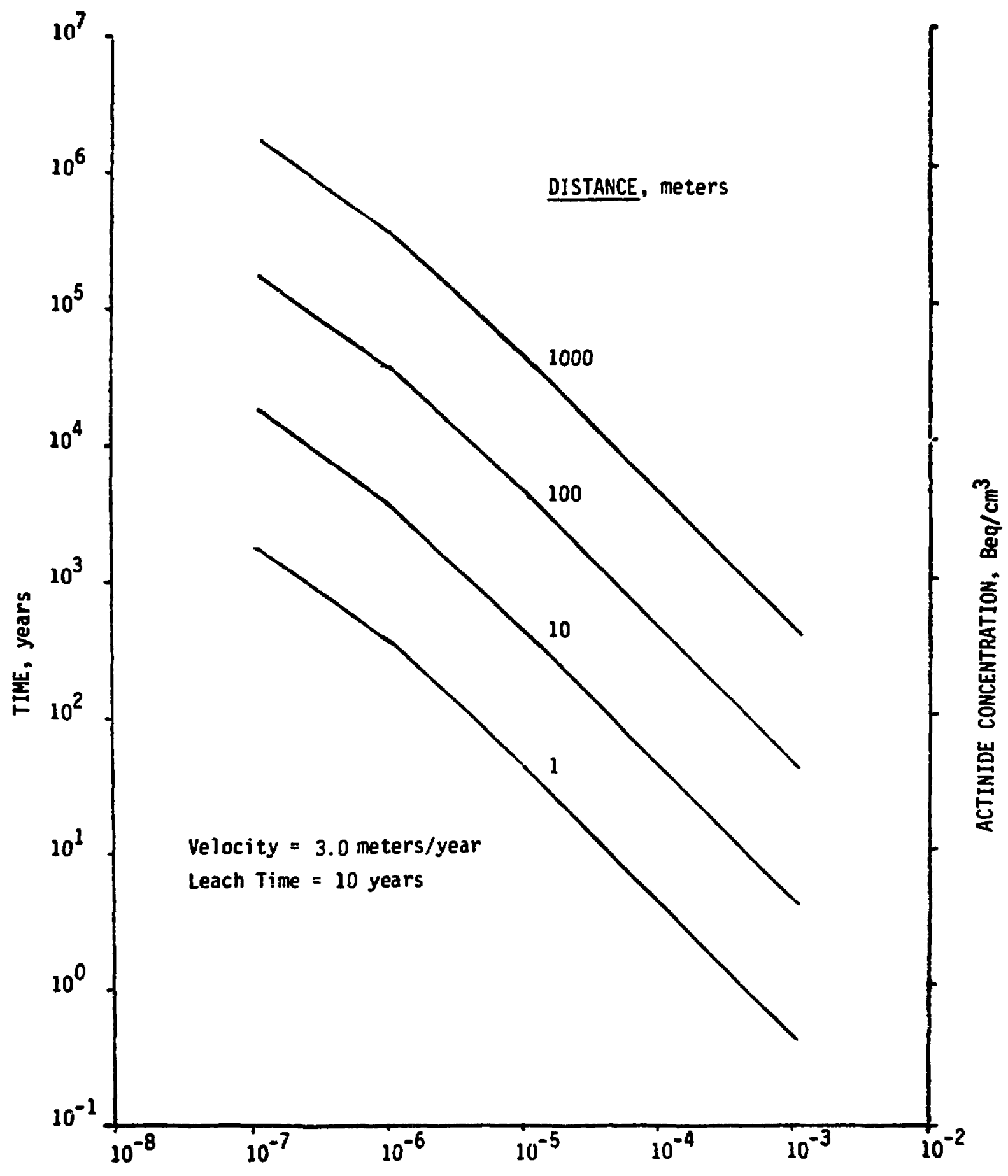

HUMIC ACIO CONCENTRATION, moles/liter

Fig. 12. Influence of Humic Acid on the Rate of Am(III) Traneport in Groundwater. [SHEPPARD-1983]. 
and Grigal interpret the results of their experiment to indicate that, under field conditions, some ${ }^{99} \mathrm{TC}$ would move with or near the infiltrating waterfront, and that continued rewetting of soil would cause the mobile $\mathrm{T}_{\mathrm{c}} \mathrm{O}_{4}{ }^{-}$ anion to move deeper with in the soil profile. However, Bondietti and Francis [BONDIETTI-1979] suggest that, under stronger anaerobic conditions, $99 \mathrm{Tc}$ would be reduced, leading to fixation and diminished mobility. They propose that under the oxidarion-reduction conditions expected for groundwaters not in contact with the atmosphere, $\mathrm{TCO}_{4}{ }^{-}$is not the stable state and would be reduced to more insoluble forms such as $\mathrm{TCO}_{2}$.

Nishita and Haug [NISHITA] used an equilibrium batch technique to study the effects of fulvic and humic acids a-t inorganic phases in soil on the sorption and extractability of $239 \mathrm{Pu}$ (IV). Comparisons of extractability of Pu were made uaing (1) untreated soil; (2) soil from which organic matter was removed (fraction $I$ ); and (3) soii from which organic matter, free iron oxides, and free silica and aluminum we re removed (fraction II). Extractability of $\mathrm{Pu}$ was determined by centriiuging both (1) $\mathrm{Pu}\left(\mathrm{NO}_{3}\right)_{4}$ solutions to which fulvic and humic acids were subsequently added and (2) Pu-dosed suspensions that had been equilibrated with the three types of soil solids for 72 hours. Centrifugation was carried out at $34,858 \mathrm{~g}$ for 15 minutes to separate the sorbed and the extractable phases.

The results of Nishita and Haug's experiments indicate that both $\mathrm{pH}$ and the presence of humic and fulvic acids have a marked influence on Pu extractability, Pu activity remaining in solution after centrifugation (Fig. 13). Figure $13(\mathrm{a})$ shows that $\mathrm{Pu}$ extractability from $\mathrm{Pu}\left(\mathrm{NO}_{3}\right)_{4}$ solutions was at a maximum at a $\mathrm{pH}$ of about 1.2 , where $\mathrm{Pu}$ is presumably in ionic form. Extractability dropped to about $40 \%$ at $\mathrm{pH} 3.3$ owing to hydrolysis, polymerization, colloid formation, and coagulation, and remained about constant between $\mathrm{pH}$ 3.3 and 7.2. Extractability increased abruptly between $\mathrm{pH} 7$ and 8.5 , apparently because previously formed coagulates were dispersed (deflocculated) into finer particles that were not carried down by centrifugation. The sharp decrease in extractability again at $\mathrm{pH}$ values above 10.7 is apparently the result of the formation of larger particles of some polymerized form of $\mathrm{Pu}(\mathrm{OH})_{4}$.

Figure $13(\mathrm{a})$ shows that extractability of $\mathrm{Pu}$ from $\mathrm{Pu}\left(\mathrm{NO}_{3}\right)_{4}$ solutions is dramatically changed by the addition of dissolved fulvic acid. Its addition caused Pu extractability to remain at about 907 throughout the pH range of 2.3 to 11.7, indicating that fulvic acids form soluble complexes or chelates with ${ }^{239} \mathrm{Pu}$ that are stable under both acid and alkaline conditions. The addition of humic acid had aboul the same effect as fulvic acid pH values above 5 , but caused sharply decreased extractability below pH 5 . This decrease suggest. that Pu was complexed with humic acid, wich precipitated out with decreasing $\mathrm{pH}$ (humic acid is insoluble at low pH), indicating that Pu-hunic acid complexes also are stable under both acidic and alkaline conditions.

The results of the equilibriu batch experiments with the untreated coil are hown in Fig, 13(b) and those for fraction I soil (organic anter removed) are show in Fig. 13(c). These figures indicate that (1) the presence of the inorganic fraction of the soil dignificantly decreases extractability (increases sorption) of $\mathrm{Pu}$, particularly at pH values above 3 ; (2) the 
(a)

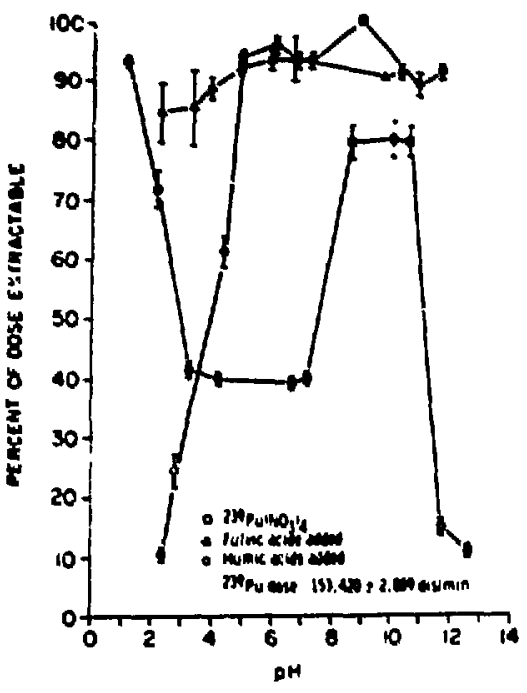

(b)

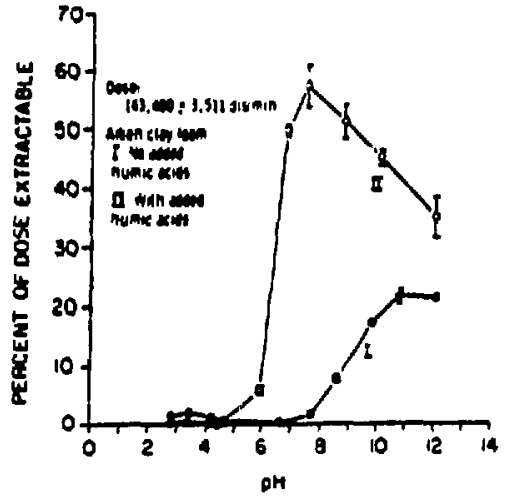

(c)

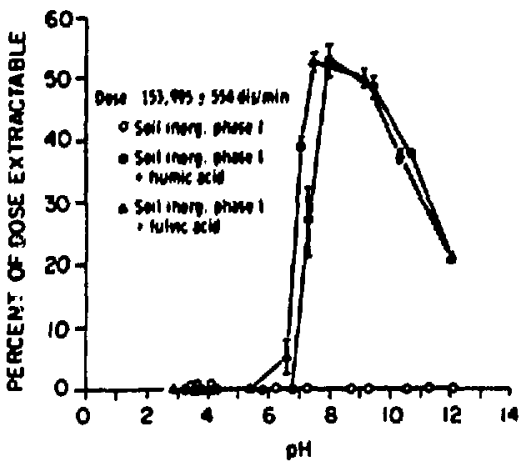

Fig. 13. Effect of pH on Extractability of 239pu. (a) From $\mathrm{Pu}\left(\mathrm{NO}_{3}\right)_{4}$ solution and solutions of fulvic and humic acids. (b) From Aiken clay loam (untreated soil) with and without humic acid amendment. (c) Interaction of fulvic and humic acids with inorganic fraction I of Aiken clay loam. (Standard deviations of triplicate samples are shown by vertical lines; when $<0.5 \%$ of dose, they are not shown.) Copyright 1979 Williams and Wilkins Co. Reprinced by permission [NISHITA].

Iddition of fulvic acic and humic arid to the test solutions causes a prolounced increase in Pu extractability (decrease in Pu sorption); and ( 3 ) ihe magnitude of this increase depends upon the ph and the nature and amount if organic matter preexisting in the soil. Increase in extractability owing o addition of humic or fulvic acid was greatest in the pH range from about - to 7 or 8; extractability decreased at higher $\mathrm{pH}$ values, apparently owing o increasing breakdown of the alkali-soluble Pu-organic complex and the oncurrent precipitation of Pu as the hydroxide.

The presence of indigenous organic matter in the untreated soils organic matter not removed) had the effect of sharply increasing Pu extractbility above pH 7 owing to the extraction of alkali-soluble organic matter fulvic acid?) with wich the Pu was associated [curve I, Fig. 13(b)]; howver, compared with the Pu extractability fron untreated soils to which no unic acid was added [curve I, Fig. 13(b)], that from the humic acid-fraction I lixture (soil organic mater rewoved, but humic acid added) was markedly reater above pH 6.82 [Fig. 13(c)]. This effect indicates that the indigenous reanic enter was sorbed wore strongly to the inorganic fraction in the atreated soil than the introduced humic acid in the fraction I mixture. his difference my be due to the horter tine available for the introduced uic acid to react with the inorganic phase. On the other hand, the $\mathrm{Pu}$ 
extractabllity from fraction I 8011 amended by humic acid addition was generally lower conpared with the extractability from the untreated soll to which hunic acid added, and its threshold for sharp increase was shifted to a higher pH level [curve II, Fig - 13(b)]. Itis difference between fraction I and the untreated 8011 amended wth humic acid Indicates primarily the influence of preexisting organic matter on the extractibility of Pu, owing to the fact that the preexisting organic matter w11l have already occupled many of the sorption sites and will limit the number avallable to the added organic natter.

Nishita and Haug's experiments [NISHITA] show that plutonium forns complexes or chelates with fulvic and humic acids that are quite stable under normal environmental pH conditions. These complexes have the effect of Increasing Pu extractability, and their influence $18 \mathrm{greate}$ (t) at higher $\mathrm{pH}$ ranges, generally above $\mathrm{pH}$ 6. Nsshita and Haug suggest that the mobility of Pu in soils under the leaching action of water will depend upon the kinds of organic matter present. "If both ooluble and Insoluble forms of organic matter are present in the soll under either alkaline or acidic conditions, the contaminating $\mathrm{Pu} 1 \mathrm{~s}$ likely to show relatively high mobility. In this case, the Pu movement will be due mainly to that of the soluble complexed or chelated forms. If the soluble forms of organic matter in the soll are very low In amount, the contaminating $\mathrm{Pu} 1 \mathrm{~s} 11 \mathrm{kely}$ to show only small movement. In this case, the movement is 1 ikely to be due mainly to the movement of inorganic and/or organic colloidal particles on which $\mathrm{Pu}$ is adsorbed and to the movement of insoluble $\mathrm{Pu}$ compounds such as $\mathrm{PuO}_{2}$. In $8011 \mathrm{~s}$ devold of or extremely low In organic matter, the main mechanism of Pu movement obviously must be in the form of inorganic colloidal particles."

\section{Complexing of Radionuclides by D1s80lved Humic Substances In Surface Waters and Groundwaters}

The complexing of radionuclides with humic substances in surface waters and deep groundwaters has been investigated using a broad spectrum of analytical approaches, including both empirical studies and purely experimental techniques. We examine the results of several of these investigations before attenpting to draw some broad generalizations and conclusions about the overall algnificance of radionuclide-organic complexing to the problea of radionuclide migration in the 8011 and groundwater enviroment.

Whigren and Orlandin1 [WAHLGREN-1982] otudied the partitioning of fallout $\mathrm{Pu}$, natural $\mathrm{Th}$, and $\mathrm{U}$ between suspended particulate material and lake mter in eelected North American lakes. The fallout Pu 18 present in both the (IV) and (V) oxidation states. The concentration of all these elenents was measured in both filtered lake water and suspended solids and the data were wed to calculate diatribution coefficlents for each radionuclide species. The diatribution coefficients were then regresed againat various Ifmbolosical parameters wch as mean water depth, $\mathrm{pH}$, wapended solid concentration, total alkalinity, and DOC. The diatribution coefficients for Pu(IV) and Th were found to show a nearly linear reiationship of decreasing distribution coefficiente (decreasing sorption of the radionuclide onto the solid phace) with increasing concentration of DOC within the concentration range of about 1 to $100 \mathrm{go}(\mathrm{C}) / \mathrm{L}(F 1 \mathrm{~g}$. 14). No olgnificant correlation was eatabliahed with the other lake parametera. The distribution coefficiente for $v$ ahow a 
(a)

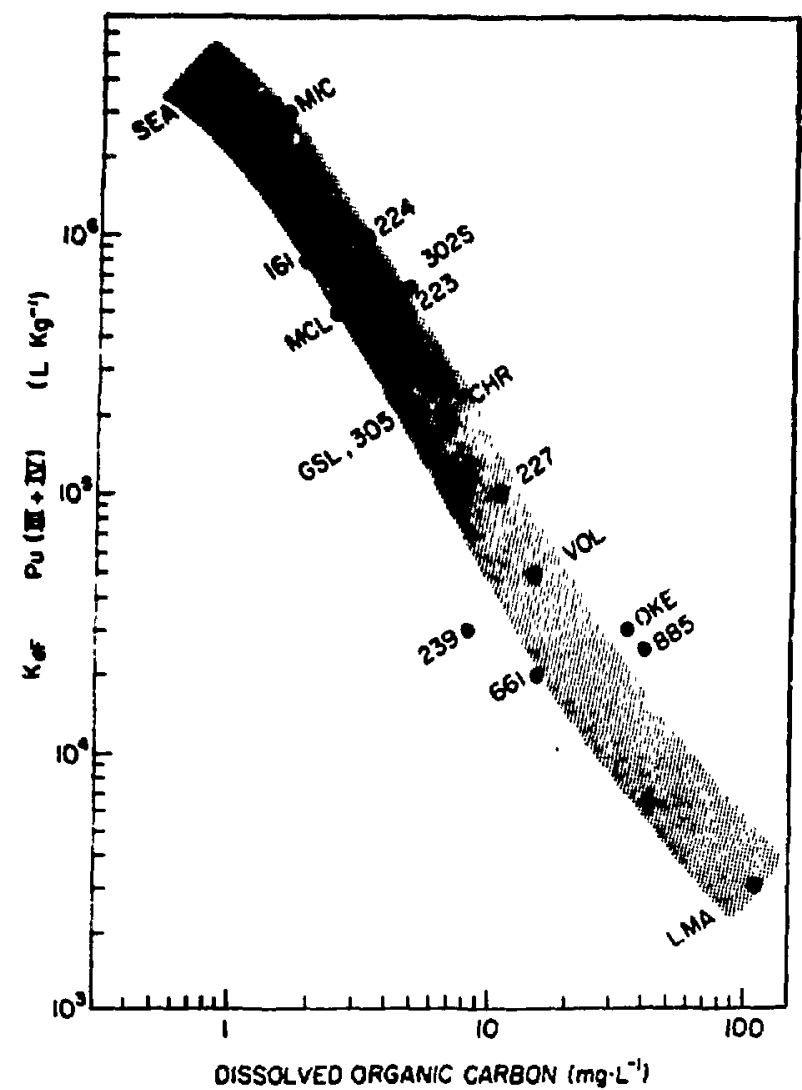

(b)

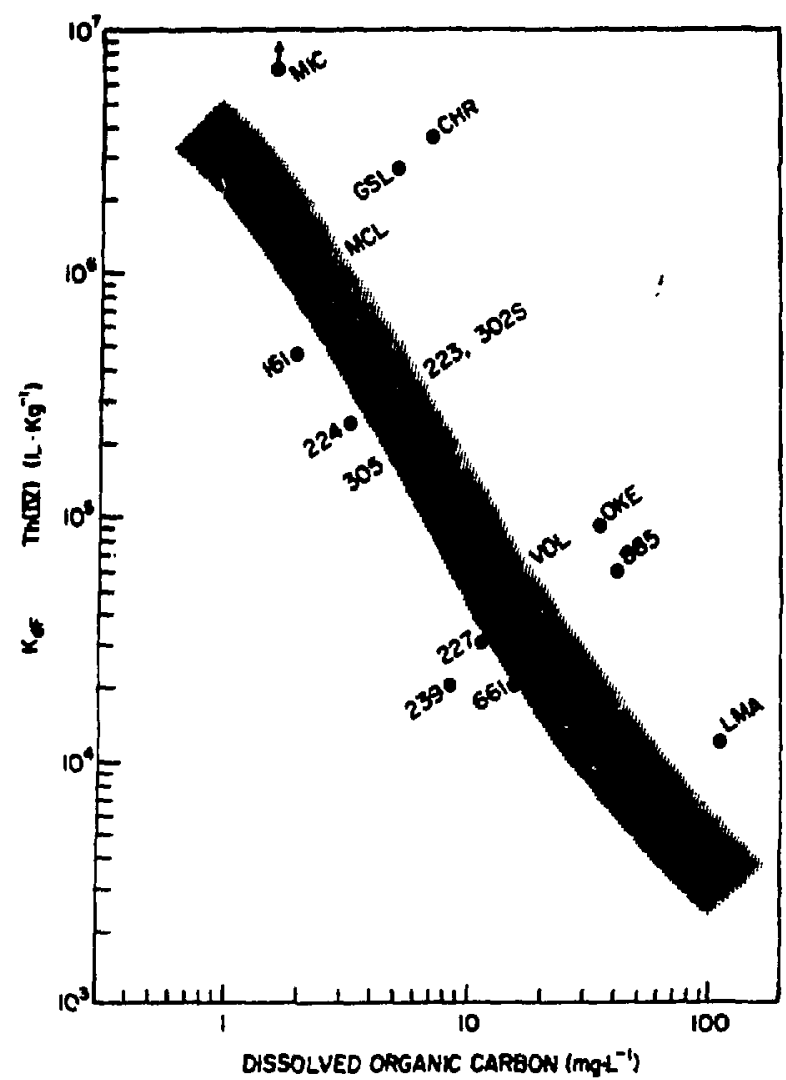

Fig. 14. The Relationship of Distribution Coefficient and Concentration of Dissolved Organic Carbon. (a) Pu(IV). (b) Th(IV). [WAHLGREN-1982].

similar trend of decreasing distribution coefficients with increasing concentration of DOC in natural waters with low total alkalinity; however, Wahlgren and Orlandini suggest that when alkalinity is high and $\mathrm{pH}$ exceeds 7.5, alkslinity rather than DOC appears to control the adsorption behavior of $U$.

Orlandini [ORLANDINI] reported the results of a similar study of Am behavior in lake waters. Orlandini calculated a distribution coefficient based on the ratio of the Am concentration on the $\langle 35-$ to $\rangle 0.45-\mu \mathrm{m}$ suspended particulate (dried) to the Am concentration in water. Values of the coefficient were plotted against the various linnological parameters, including DOC concentration, $\mathrm{pH}$, and alkalinity. A strong inverse relationship was demonstrated between DOC concentration and the distribution coefficients--indicating increased solubilization of $\mathrm{Am}$ with increasing DOC concentration. Except for - possible correlation with high alkalinity values $\left(>300 \mathrm{mg} / \mathrm{L} \mathrm{CaCO}_{3}\right)$, no significant correlation was found with any other limnological partaeter.

Melson et a1. [MELSON-1980] examined the effect of DOC on Pu mobility in certain oligotrophic lakes (1akes with oxygen-rich lowernost water layers). The divoolved $\mathrm{Pu}$ in these lakes is primarily in the oxidized forn [preaumably as Pu(v)], which is more weakly sorbed onto solide then the 
reduced form [Pu(IV)]. Some Pu(IV) is present in all lakes studied, however, and the apparent solubility of this reduced form varies markedly from lake to 1ake.

The partitioning of $\mathrm{Pu}$ (IV) between lake water and suspended solids was examined by determining a distribution ratio $\left(K_{f}\right)$, which was calculated by dividing the measured concentration of ambient $239,240 \mathrm{Pu}$ (IV) sorbed to suspended solids ( $\mathrm{fCi} / \mathrm{kg}$ ) by the measured concentration of $239,240 \mathrm{Pu}$ (IV) in solution ( $\mathrm{fCi} / \mathrm{L})$. Nelson et al. [NELSON-1980] found that the apparent solubility of Pu(IV), as measured by $K_{d}$, varied among different lakes as a function of the concentration of DOC in the lakes, but did not appear to be related to the concentration of inorganic constituents in the water. The relationship of DOC to $K_{d}$ values is illustrated in Fig. 15, which also includes $K_{d}$ values derived from the results of laboratory experiments in which various natural waters were opiked with $237 \mathrm{Pu}$ and equilibrated with aliquots of a single sed iment type.

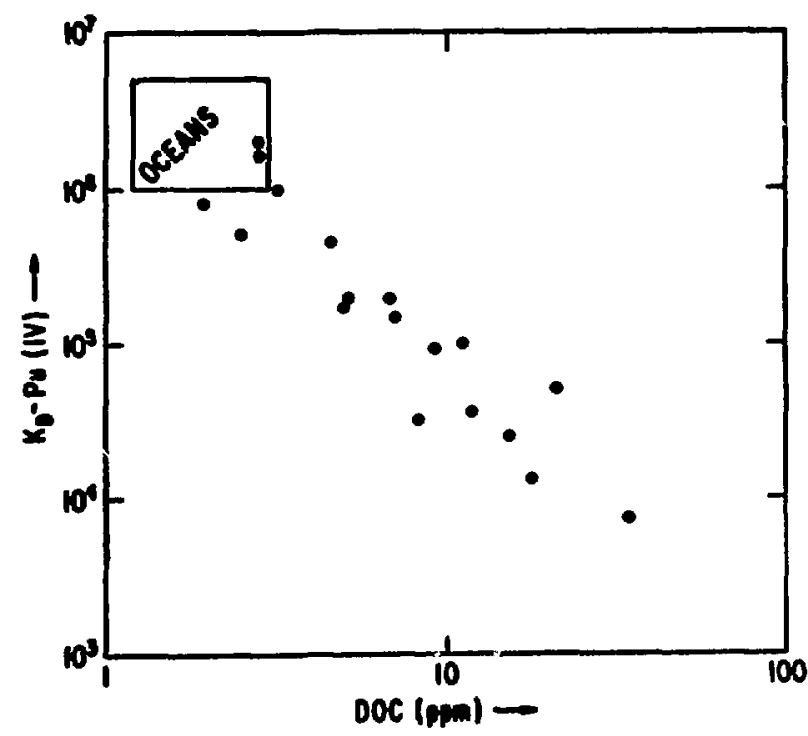

Fig. 15.

Variation of Distribution Ratio as a Function of Ambient Dissolved Organic Carbon Concentration for Several Natural Waters (o represents field measurement 8 , - represents laboratory equilibrations). [NELSON-1 980].

Nelson et al. [NELSON-1980] also conducted several experiments in which $K_{d}$ values were measured as a function of $D O C$ concentrations that had been adjusted to specific levels. The organic substances used in these experiments were collected from natural water. by ultrafiltration through $1000 \mathrm{~mol}$ wt cutoff membranes. Portions of these organic concentrates were then combined with the corresponding ultrafiltered water to produce a series of waters assuned to differ fron the original water only in their DOC concentrations. These waters were spiked with $237 \mathrm{Pu}$ tracer, an al iquot of sediment $(\sim 40 \mathrm{mg} / \mathrm{L})$ was added, the systems were equilibrated for a week, and the $K_{d}$ for the reduced Pu was deternined. An example of the results of these experiments is shown in Fig. 16. In this exemple, the DOC content of the water has a pronounced inverse effect on sorption of Pu(IV) even at concentrations less than $1 \mathrm{mg}(\mathrm{C}) / \mathrm{L}$. Nelson et $a$. found, however, that the effects of DOC concentration varied ang lakes. In experiments with sowe lake waters, the 
Fig. 16.

Variations of Distribution Ratio as a Function of Dissolved Organic Carbon Concentration. (a) Okefenokee Swamp. (b) Lake Michigan. [NELSON-1980].
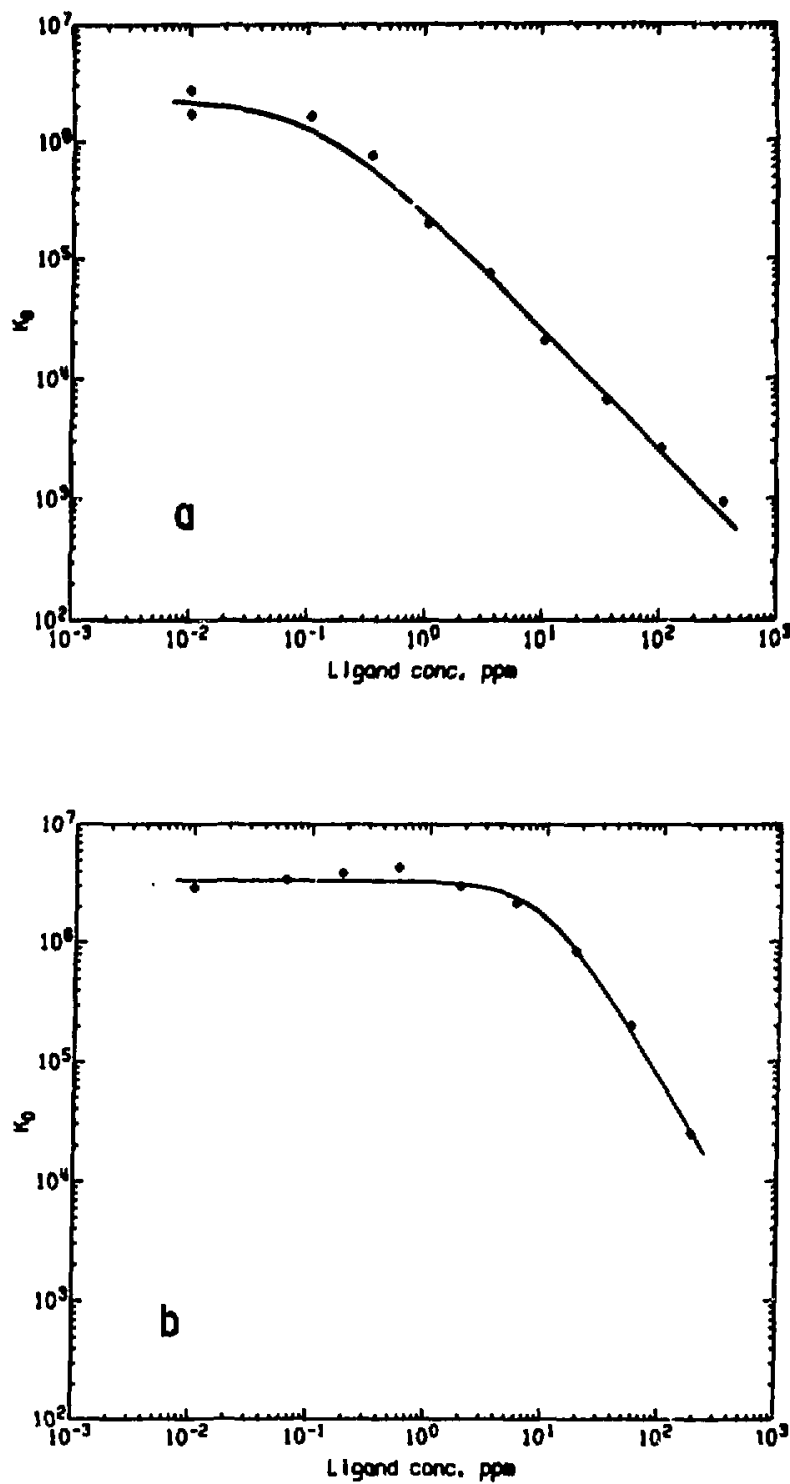

DOC caused a decrease in $K_{d}$ values only at concentrations well above $1 \mathrm{mg}(C) / L$. They link these variations in the effects of DOC concentration to differences in the atability constants of the Pu(IV)-organic complexes, although it is not clear what causes the variations in atability of the complexes.

In evaluating Fig. 16, it should be noted that ultrafiltration techniques are now known to fractionate major inorganic constituents of water such as $\mathrm{Ca}, \mathrm{Mg}, \mathrm{F}$, and $\mathrm{S}$, as well as the total organic carbon [BOGGS-1984B, RIM]. These results auggeat that the organic molecules any exist as a complex with large fractions $(230 \%)$ of major constituents of groundwaters. In any case, the concentrate prepared by Nelson et al. way include concentrates of inorganic elesente 20 well as the total organic carbon. The inorganic elewents, whether complexed or not with the organic molecules, way contribute to the results depicted in Fig. 16. 
In a subsequent paper, Nelson et al. [NELSON-1982] determined that two types of Pu-organic complexes were formed, one with one ligand per Pu atom, and the other with two ligands. They developed an equation assuming competitive equilibrium between $\mathrm{Pu}(\mathrm{IV})$ and soluble complexing ligands and between Pu(IV) and a solid adsorber:

$$
\frac{1}{K_{d}}=\frac{1}{K_{d}^{0}}+\frac{K_{1}}{K_{3}}[D O C]+\frac{K_{2}}{K_{3}}[D O C]^{2}
$$

where

$K_{1}$ and $K_{2}$ are conditional stability constants for the $1: 1$ and $2: 1$ complexes of $\mathrm{Pu}$ with organic ligands, respectively;

$K_{d}$ is the observed distribution ratio when organic matter is added;

$K_{d}$ is the distribution ratio of uncomplexed ions and all low molecular weight inorganic and organic complexes ( $<1000$ mol wt; i.e., very low DOC concentrations); and

$K_{3}$ is the conditional stability constant for the association of Pu with the solid adsorber.

The absolute values of $K_{1}, K_{2}$, and $K_{3}$ cannot be obtained from these experiments; however, because the value of $\mathrm{K}_{3}$ is presumably the same for all experiments, the ratios of $K_{1} / K_{3}$ and $K_{2} / K_{3}$ can be determined. Thus, the relative complexing power of colloidal DOC from two bodies of water can be compared by comparing the values of $\mathrm{K}_{1} / \mathrm{K}_{3}$ and $\mathrm{K}_{2} / \mathrm{K}_{3}$ for the two waters. High values of $\mathrm{K}_{1} / \mathrm{K}_{3}$ indicate strong $1: 1$ complexes of $\mathrm{Pu}$ with $\mathrm{DOC}(1 \mathrm{~mol} \mathrm{DOC} / \mathrm{Pu}$ atom) and lower values indicate relatively weaker complexes. This relationship means that dissolved organic substances would cause a much greater decrease in $K_{d}$ in waters with high $\mathrm{K}_{1} / \mathrm{K}_{3}$ ratios than in waters with low ratios. Similarly, the value of the $K_{2} / K_{3}$ ratio indicates the relative importance of $2: 1 \mathrm{com}-$ plexes of Pu with DOC (2 mol DOC/Pu atom).

Nelson et al. [NELSON-1982] found that an increase in pH causes a decrease in $K_{1} / K_{3}$ values but an increase in $K_{2} / K_{3}$ values, and vice versa. That is, an increase in $\mathrm{pH}$ causes a decrease in the stability constants for $\mathrm{Pu}$ (IV)-organic complexes but an increase in the stability constants that measure the strength of the association of uncomplexed Pu(IV) with the solid absorber. Because these changes are offsetting at moderate DOC concentrations, the principal effect of pH change is to alter the type of complex ion formed, and causes only minor changes in $K_{d}$.

Li et al. [LI] used dialysis techniques to investigate the effects of $\mathrm{pH}$ and $U$ concentration on the interaction of $U(V I)$ and $U(I V)$ with fulvic, huic, and tannic acids. The effect of pH on $v$-organic complexing was studied by preparing solutions containing $20 \mathrm{mg} / \mathrm{L}$ of humic, fulvic, or tannic acid spiked with either $50 \mathrm{ng} / \mathrm{mL}$ U(VI) in $0.01 \mathrm{M} \mathrm{KNO}_{3}$ olution or $50 \mathrm{ng} / \mathrm{mL} \mathrm{U}$ (IV) in $0.01 \mathrm{M} \mathrm{NaCl}$ solution. The pH of the solutions was varied from 2 to 9 by adding $\mathrm{FHO}_{3}$ or $\mathrm{NaOH}$, a appropriate. The solutions were placed inaide 
dialyais bage (having a cutoff of 3500 mol wt) for 24 hour to separate by size the U(VI) or U(IV) species complexed with humic, fulvic, or tannic acid (larger ize) from the inorganic complexes of $U(V I)$ and $U$ (IV) (omaller aize).

The reenlts of these experiments are shown in Fig. 17; a high value for $Z U$ dialyzed indicates a low degree of complexing with organic ligands. Note that $\mathrm{pH}$ has a very pronounced effect on complexing and that complexing increases with increasing $\mathrm{pH}$, with a particularly sharp increase taking $\mathrm{place}$ within the $\mathrm{pH}$ range of about 3 to 6 . Note also that humic acid (HA) can bind uranium at lower pH values than fulvic acid (FA) or tannic acid (TA). This difference is related to the difference in $\mathrm{pK}_{\mathrm{a}}$ values of the humic, fulvic, and tannic acids, which are reported by Guy and Chakrabarti [GUY] to be about 4 for $H A, 5$ for $F A$, and 6 for TA. [ $p R_{a}$ is the dissociation constant for the degree of dissociation represented by $a_{\text {.] }}$ If the stability constants of the $U$ (VI) complexes of $\mathrm{HA}, \mathrm{FA}$, and TA are similar, then the magnitude of and difference in the $\mathrm{pk}_{\mathrm{a}}$ values $(4,5,6)$ would indicate that at low $\mathrm{pH}(24)$, the amount of free $U(V I)$ ion would follow the order of the $\mathrm{pK}_{\mathrm{a}}$; i.e., $\mathrm{pK}_{\mathrm{a}}$ : TA $>$ FA $>\mathrm{HA}$, which was experimentally observed as shown in Fig. 17(a). That is, the percentage of $U(V I)$ dialyzed (the amount of free, uncomplexed ion) is greatest for FA and least for HA. Above $\mathrm{pH} \mathrm{5,} \mathrm{the} \mathrm{concentration} \mathrm{of} \mathrm{free} \mathrm{ions}$ is small (most of the $U$ (VI) is complexed) for the three acids and increases in the order FA > HA > TA, which may reflect the order of inherent stabilities of the complexes with U(VI). Fig. 17(b) shows that very similar results were obtained for U(IV). A comparison of the curves in Fig. 17(a) with those in Fig. 17(b) indicates that U(IV) forms stronger complexes with HA, FA, and TA than U(VI), especially at low $\mathrm{pH}$ ( 4 or less).

(a)

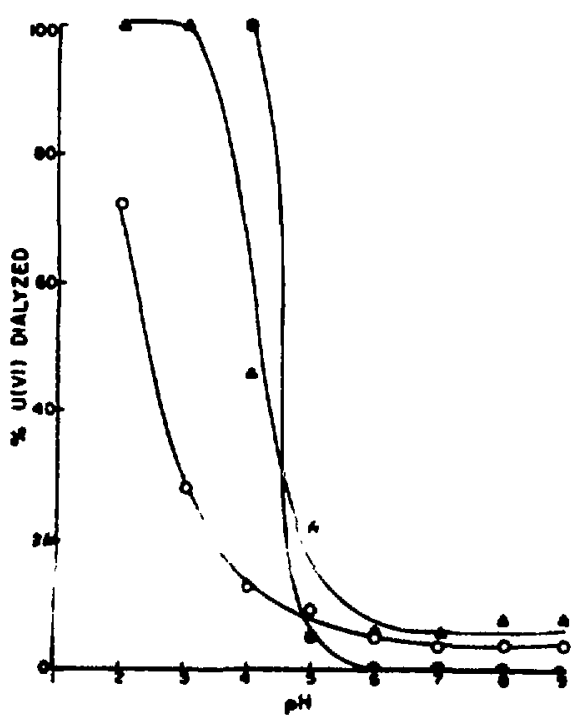

(b)

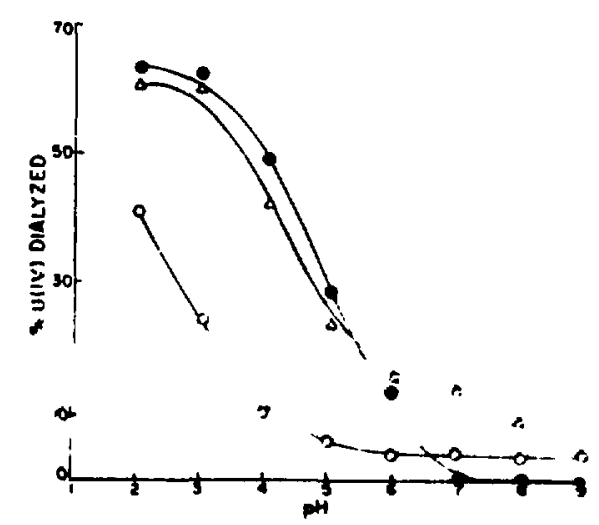

Fig. 17. Dialysis of an Aqueous Solution of Uranium as a Function of $\mathrm{pH}$ in: $O$ humic acid, $\Delta$ fulvic acid, - tannic acid. (a) U(VI) in $0.01 \mathrm{M} \mathrm{KNO}_{3}$. (b) $\mathrm{U}(\mathrm{IV})$ in $0.01 \mathrm{M}$ NaC1. Copyright $1 \overline{9} 80$ Ame rican Chemical Society. Reprinted by permission [II]. 
Li et al. [LI] studied the effect of $U(V I)$ and $U(I V)$ concentration on the interaction of $U$ (VI) and $U$ (IV) with humic, fulvic, and tannic acide by preparing oolutions of $20 \mathrm{mg} / \mathrm{L}$ humic, fulvic, or tannic ac id to which were added various amounts of a standard solution of $U(V I)$ and $U(I V)$. The $p H$ of the systems was adjusted to 6.0 . The systems were equilibrated for 48 hours using dialysis bags containing $10 \mathrm{~mL}$ of ultrapure water. The results of these experiments are summarized in Fig. 18. Figure 18(a) shows that, in experiments with each of the three organic acids, the amount of free U(VI) ions increases only slightly with increasing total $U(V I)$ concentration at very low ranges of concentration, but increases essentially linearly at concentrations exceeding 5 to $10 \mu \mathrm{g} / \mathrm{mL}$ (i.e., organic complexing becomes less important with increasing $U(V I)$ concentration.) Figure $18(b)$ indicates a similar trend for U(IV), although the linear increase in free U(IV) ions with increasing concentration begins at concentrations of only 1 to $2 \mu \mathrm{g} / \mathrm{mL}$ of $\mathrm{U}$ (IV).

(a)

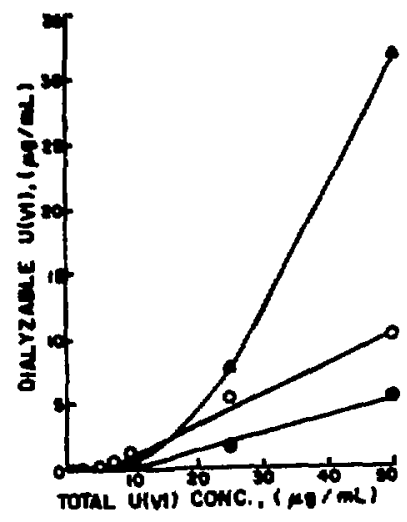

(b)

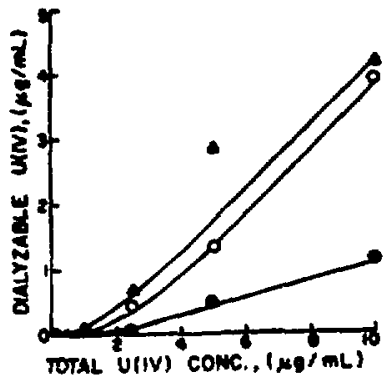

Fig. 18. Dialyzable Uranium Concentration as a Function of Total Uranium Concentration at $\mathrm{pH} 6.0$ in an Aqueous Solution Containing $20 \mathrm{mg} / \mathrm{L}$ of: a humic acid, $\Delta$ fulvic acid, tannic acid. (a) $U(V I)$. (b) U(IV). Copyright 1980 American Chemical Society. Reprinted by permission [LI].

Li et al. [LI] used the results of these experiments to determine the stability constants and the number of binding sites per unit weight of organic ligand. Their data indicate that there are two binding ites on all three 1 igands, one "strong" and one "weak," as ahom by the stability conotants in Table 14. The two different binding sites make a difference of about two orders of magnitude in the stability constants. The order of stability constante for U(VI) is: FA > HA > TA and for U(IV) is HA > TA > FA. The order of the number of binding sites is TA $>\mathrm{HA}>\mathrm{BA}$. The tability conotante for HA and TA complexed with U(IV) are larger than for U(VI), whereas the otability constants for FA complexed with U(IV) are analler than for U(VI). The number of binding aites on these organic ligande for $U(I V)$ is about half the nuber 
Table 14. Stability Conatants for Uranium-Organic Complexes. Copyright 1980 American Chemical Society. Reprinted by permisaion [LI].

\begin{tabular}{|c|c|c|c|}
\hline Uranium Ion & Ligand & $\mathbf{k}_{\mathbf{i}}$ & $\mathrm{n}_{\mathrm{i}}, \mathrm{mmol} / \mathrm{g}$ \\
\hline uranium(VI) & $\mathbf{H A}$ & $\begin{array}{l}5.4 \times 10^{6} \\
5.3 \times 10^{4}\end{array}$ & $\begin{array}{l}1.0 \\
9.5\end{array}$ \\
\hline uranium(VI) & FA & $\begin{array}{l}2.7 \times 10^{7} \\
3.6 \times 10^{5}\end{array}$ & $\begin{array}{l}0.2 \\
3.8\end{array}$ \\
\hline uranium(VI) & TA & $\begin{array}{l}2.3 \times 10^{6} \\
9.2 \times 10^{4}\end{array}$ & $\begin{array}{r}0.6 \\
11.4\end{array}$ \\
\hline uranium( IV ) & HA & $\begin{array}{l}9.5 \times 10^{6} \\
3.2 \times 10^{4}\end{array}$ & $\begin{array}{l}0.5 \\
4.5\end{array}$ \\
\hline uranium(IV) & FA & $\begin{array}{l}4.4 \times 10^{6} \\
8.8 \times 10^{4}\end{array}$ & $\begin{array}{l}0.3 \\
1.8\end{array}$ \\
\hline uranium(IV) & TA & $\begin{array}{l}8.5 \times 10^{6} \\
1.1 \times 10^{5}\end{array}$ & $\begin{array}{l}0.9 \\
4.5\end{array}$ \\
\hline
\end{tabular}

for $U(V I)$. Li et al. interpret this fact to mean that U(VI) exists in solution as $\mathrm{UO}_{2}{ }^{2+}$ (divalent) and $U$ (IV) as $U^{4+}$ (tetravalent); hence, $1: 1$ complexes of organic ligands are formed with $\mathrm{UO}_{2}{ }^{2+}$, whereas $1: 2$ complexes are formed with $\mathrm{u}^{4+}$.

The formation of soluble chemical complexes is considered to be the most common metal-organic interaction; however, some studies have suggested that metal-organic interactions possess both the qualities of chelation and colloid formation. At low metal concentrations natural organic substances presumably remain in true solution, but at higher concentrations of metal ions the organic substances and metals may associate to form larger particles of colloidal dimensions that can precipitate or be removed by filtering through a $0.45-\mu m$ filter. Means [MEANS-1982B] performed a series of flocculation experiments with different metal ions ( $\mathrm{Na}, \mathrm{Ca}, \mathrm{Al}, \mathrm{Fe}$ (II), $\mathrm{Fe}$ (III), U, Th, $\mathrm{Np}, \mathrm{Am}, \mathrm{Pu}$ ) to examine the colloid-forming behavior of these ions with $\mathrm{HA}$ and FA. The concentrations of the metal ions used in the experiments were (in $\mathrm{ppm}): \mathrm{Na}(900-1000), \mathrm{Ca}(50-500), \mathrm{Al}(10), \mathrm{Fe}$ (II) (40-50), $\mathrm{Fe}$ (III) (10-50), U(IV) $(40-50), \operatorname{Th}(\mathrm{IV})(10-50), 237_{\mathrm{Np}}(4.7), 241_{\mathrm{Am}}(1.02)$, and $239 \mathrm{Pu}$, presumably present $\varepsilon_{8} \mathrm{PuO}_{2}{ }^{2+},(0.54-5.4)$. Two different HA and FA concentrations were used: $36-51 \mathrm{ppm}$ and $5.1-7.8 \mathrm{ppm}$. The results of the experiments are oumarized below:

(1) The yalue of pH had little effect on blank HA and FA solutions (i.e., no metal ions added). About $97 \mathrm{FA}$ and 157 HA were

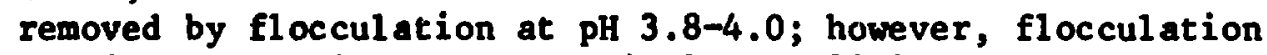
at higher $\mathrm{pH}$ values was practically negligible for both FA and HA.

(2) A11 the metals tested caused some flocculation of HA and FA and, in general, HA was flocculated to a greater extent than FA by all metals teated. The metals Na and $\mathrm{Ca}$ had the least influence on flocculation and Al and Fe had generally strong effects. 
(3) The solubility of the actinides (ability to remain in solution rather than to prec1pitate along with HA and FA collo1ds) varied with the actinide and the pH. Concentrations of Nip in solutions contalning 40-50 ppm HA or FA varied only olightly from those of blanks that contained no organic matter, although Np was slightly more soluble in the HA and FA solutions at $\mathrm{pH}$ 3.7-3.8 and 8.2-8.5 than in the blanks--suggesting formation of some soluble complexes of Np-HA or Np-FA. The Np caused flocculation of HA and FA but apparently remained soluble and did not precipitate along with the $\mathrm{BA}$ and FA. The metals $\mathrm{Th}$ and $\mathrm{Am}$ displayed enhanced solubility relative to blanks in the neutral to slightly basic $\mathrm{pH}$ range; however, in the low $\mathrm{pH}$ range, Th and Am precipitated along with flocculating HA and FA. Thus, Th and Am concentrations at low $\mathrm{pH}$ in the solutions containing organic matter are actually less than those in corresponding blank solutions. Little or no precipitation of $U$ was shown at low $\mathrm{pH}$ relative to blanks, and enhanced solubllity was shown at neutral to slightly basic pH. Enhanced solubility of Pu relative to blank solutions in all the solutions containing HA or FA was shown. The precipitation of HA and FA Is promoted by $\mathrm{Pu}$ at $\mathrm{pH} \mathrm{4,} \mathrm{and} \mathrm{some} \mathrm{of} \mathrm{the} \mathrm{Pu} \mathrm{presumably} \mathrm{precipitates}$ along with the organic matter as insoluble complexes; however, the soluble HA and FA form soluble complexes with a proportion of the $\mathrm{Pu}$, to increase its solubility relative to blanks.

(4) The concentrations of HA and FA had little effect on the portion of $\mathrm{BA}$ or FA flocculated by a given metal; that is, low concentrations of these acids, more typical of ambient levels in natural waters, were flocculated to a similar extent as were high concentrations. Flocculation at higher HA and FA concentrations was more dependent upon $\mathrm{pH}$, with increasing flocculation occurring with decreasing $\mathrm{pH}$. The $\mathrm{pH}$ value was 1 ess important at lower HA and FA concentrations.

(5) For experiments run at two different metal concentrations, the removal of organic matter increased with increasing metal content.

We can conclude from Means' experiments that some insoluble actinideorganic complexes (colloids) formed under the conditions of high metal ton concentrations used in the experiments, but most of the actinides remained in solution. The presence of the actinides clearly caused flocculation of some of the HA and FA; however, in general, the actinide elements formed soluble complexes with remaining $\mathrm{HA}$ and $\mathrm{FA}$, particularly at alkaline $\mathrm{pH}$. These results are in contrast to the suggestion by other workers that insoluble complexes would nost $11 \mathrm{kely}$ form under conditions of high metal ton concentration.

In a serles of papers published between 1978 and 198!, Choppin and cowrkers at Florida State University investigated the interaction of FA and/or $\mathrm{HA}$ with $\mathrm{An}$ (III), Eu(III), Th(IV), $\mathrm{VO}_{2} 2+$ (urany1), and radioactive calciu $(45 \mathrm{Ca})$. To better underatand the rype and number of active complexing groups 1n HA, Choppin and Kullberg [CHOPPIN-1978] deterained the $\mathrm{pK}_{a}$ and 
enthalpy of protonation (addition of $\mathrm{H}^{+}$ions) of $\mathrm{HA}$ by $\mathrm{pH}$ and calorimetric titration. The value of $\mathrm{pK}_{\mathrm{a}}$ was determined from the relationship

$$
\mathrm{pK}_{\mathrm{a}}=\mathrm{pH}-\log \frac{\mathrm{a}}{1-\mathrm{a}}
$$

where is the degree of dissociation, as calculated from titration data. Plotting $\mathrm{PK}$ versus and extrapolating to $a=0$ gives the dissociation constant of the polymer at zero ionization ( $\left.\mathrm{pk}_{0}\right)$. Figure 19 shows the presence of two acidic groups with $\mathrm{pK}_{\mathrm{a}}$ values of about 4.0 and 9.0. The $\mathrm{pK}_{\mathrm{a}}$ of the stronger acid $(24.0)$ was considered by Choppin and Kul lberg to indicate a carboxylic functional group, possibly benzoate or salicylate. The weaker acid group was about $75 \%$ less abundant than the strongcr group and is probably phenolic.

Fig. 19.

Plot of Apparent $\mathrm{pK}_{\mathrm{a}}$ Values as a Function of Degree of Dissociation. Copyright 1978 Pergamon Press. Reprinted by permission [CHOPPIN-1978].

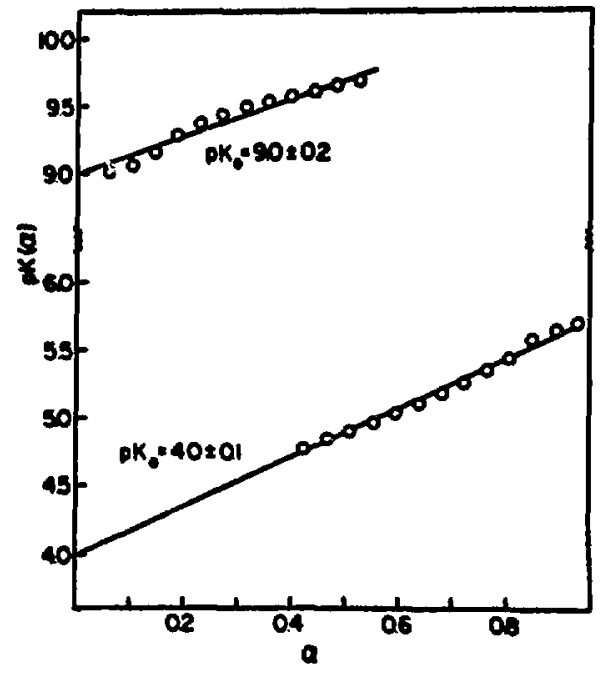

Choppin and Kul lberg also examined the heat change $(\Delta H)$ on protonation of the humates as a function of $\mathrm{pH}$ (Fig. 20). The $\Delta H$ values were calculated per mole of $\mathrm{H}^{+}$exchanged. Their experiments showed that protonation reactions are fast, particularly within the basic region, and the shapes of the heat curves support the assumption that two types of functional groups are present in HA.

Bertha and Choppin [BERTHA] measured the binding conotanta (otability conatants) of Eu(III) and Am(III) with HA and FA at a fixed $\mathrm{pH}(4.0)$ and ionic strength $(I=0.10)$ using a batch equilibrium technique. A tock solution of $0.09 \mathrm{M} \mathrm{KCl}+0.010 \mathrm{M} \mathrm{NaC}_{2} \mathrm{H}_{3} \mathrm{O}_{2}$, to which various concentrations of HA and FA were added, was spiked with $241 \mathrm{Am}$ (III) and $152 \mathrm{Eu}$ (III); $5 \mathrm{~mL}$ of this solution was added to a polyethylene vial containing 18 of Dowex $50 \times 8$ resin and allowed to equilibrate for 60 hours on a rotating wheel. Duplicate aliquots of the equilibrated solution were withdrawn, filtered, and counted for gaman ray activity on a well scintillation counter. 


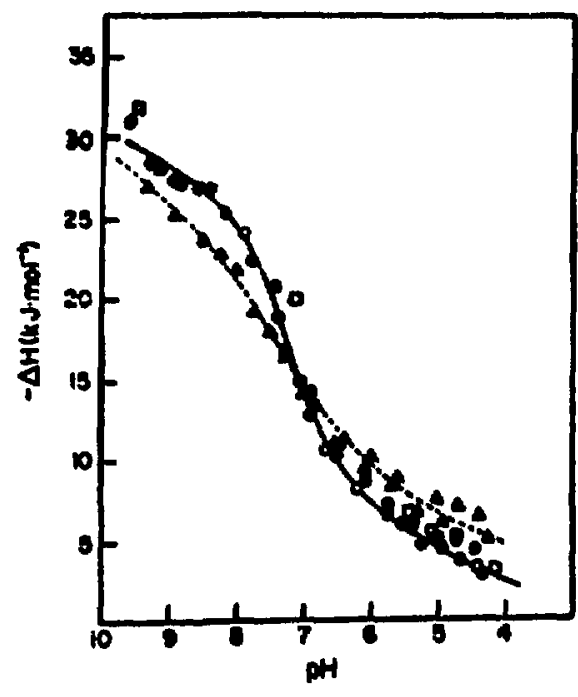

Fig. 20.

Variation of the Enthalpy of Protonation as a Function of the $\mathrm{pH}$ of the Measurement. The symbols indicate samples of huric acid from different sources. Copyright 1978 Pergamon Press. Reprinted by permi ssion [CHOPPIN-1978].

The generalized reaction of a metal ion with fulvate or humate ions can be written as:

$$
\begin{gathered}
M+m X=M X m \\
B=(M X m) /\left((M)(X)^{m}\right)
\end{gathered}
$$

where $M$ refers to metal ions, $X$ represents fulvate or humate anions, $m$ is an integer number, and $B$ is the binding constant or stability constant.

Distribution coefficients can be calculated from the relationship

$$
\lambda=\frac{(M) \text { resin }}{(M) \text { aq }+\left(M X_{m}\right)}
$$

Figure 21 shows a pronounced linear trend of decreasing distribution coefficients for Am(III) and Eu(III) with increasing ligand concentration, indicating that these elements are strongly complexed by HA and FA.

Observing that the ratio of bound to free metal increased wore rapidly than the concentrations of HA and FA, Bertha and Choppin [BERTHA] interpreted the results of their experiments to indicate the binding of An(III) and Eu(III) to two types of sites with $1: 1$ and $1: 2$ stoichiometry. Marinsky [MARINSKY] disagrees with this interpretation. He suggests that the effects observed by these authors arises out of the tendency of $\mathrm{HA}$ and FA to aggregate and for separate phases, and does not indicate that they are associated imultaneously in $1: 1$ and $1: 2$ complexes. Bertha and Choppin's calculated binding constante for An(III) and Eu(III) with FA and HA are ohown in Table 15. In this table, $B 1$ values appear to refer to the binding conotants of the $1: 1$ complexes and $B_{2}$ values to binding constants of the $1: 2$ complexes; the superscript (a) indicates values obtained after a correction factor was applied. Bertha and Choppin auggest that the enhanced bindins 
Fig. 21.

riation of the Distribution Coefcient $(\lambda)$ with Humic and Fulvic id Concentration. Each point the average of $2-4$ data. $\square$ is (III) and humic acid at $0.1^{\circ} \mathrm{C}$; is Eu(III) and fulvic acid at 'C. Copyright 1978 Pergamon ess. Reprinted by permission ERTHA].

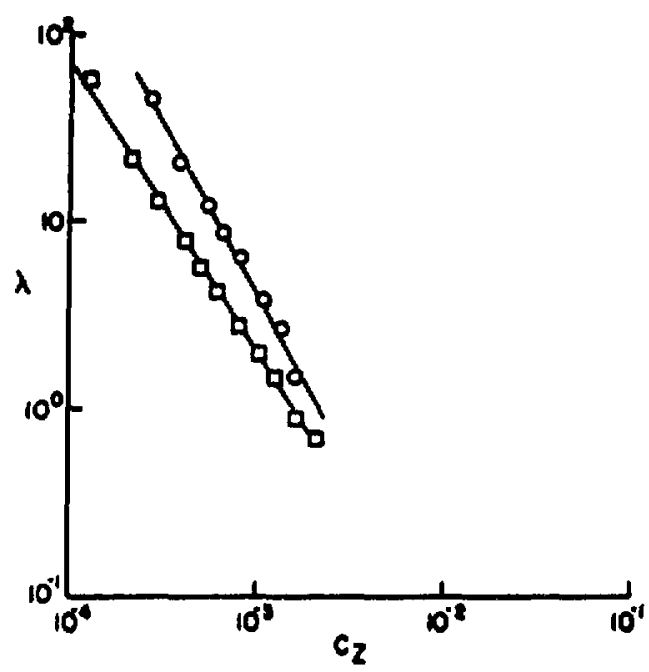

Table 15. Binding Constants for Eu(III) and Am(III) with Fulvic and Humic Acids at $\mathrm{pH}$ 4.5. Copyright 1978 Pergamon Press. Reprinted by permission [BEPTHA] .

\begin{tabular}{lrrrr}
\hline & $\beta_{1}\left(\times 10^{-6}\right)$ & $\beta_{1} a\left(\times 10^{-6}\right)$ & $B_{2}\left(\times 10^{-10}\right)$ & $\beta_{2} a\left(x 10^{-10}\right)$ \\
\hline Eub & $1.8 \pm 1.3$ & $3.1 \pm 2.2$ & $1.95 \pm 0.29$ & $3.28 \pm 0.49$ \\
& \multicolumn{5}{c}{ Ful vic Acid } \\
Eub & $14.2 \pm 1.7$ & $23.9 \pm 2.9$ & $1.07 \pm 0.13$ & $1.80 \pm 0.22$ \\
Amb & $4.1 \pm 1.2$ & $6.7 \pm 2.0$ & $2.29 \pm 0.10$ & $3.78 \pm 0.17$ \\
Amb & $8.7 \pm 1.2$ & $14.3 \pm 2.0$ & $1.31 \pm 0.15$ & $2.16 \pm 0.25$
\end{tabular}

avalues obtained after application of a correction factor.

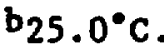

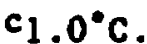

) of Eu(III) by HA relative to FA is consistent with the relative values of i of the two polyelectrolytes, which are 4.65 for HA and 3.88 for FA. The leral conclusion that Bertha and Choppin draw from this research is that the ivalent actinides would be atrongly held by humic materials. In a later ler, Choppin [CHOPPIN-1980] published an expanded list of binding constants ih in (Table 16), which also included values for $T h(I V)$ and $\mathrm{VO}_{2}{ }^{2+}$. The unn headed by $a$ in this table indicates the degree of ionization of HA.

Nash and Choppin [NASH-1980] studied the binding of Th(IV) to HA and Cation exchange capacity and degree of ionization as a function of $\mathrm{pH}$ were ;ermined by titration, and stability constants (Table 17) were measured by a vent extraction method; note that $\mathrm{HA}-\mathrm{Th}$ binding constants have higher values in do FA-Th binding constants. Nash and Choppin interpret their data to icate two types of thorium binding sites in the humic polymer containing 
Table 16. Binding Constants of Selected Radionuclides with Humic Acid. [CHOPPIN-1980].

Binding constants with humate $\mu=0.10 \mu ; T=25.0^{\circ} \mathrm{C}$

\begin{tabular}{|c|c|c|c|c|}
\hline \multicolumn{2}{|c|}{ Cation } & \multirow[b]{2}{*}{$\begin{array}{c}a \\
0.40^{a} \\
0.40^{a} \\
0.25^{a} \\
0.43^{a} \\
0.54^{a} \\
0.37^{b} \\
0.39^{c} \\
0.48^{c} \\
0.67^{c}\end{array}$} & \multirow[b]{2}{*}{$\begin{array}{c}\log \beta_{1} \\
7.78 \pm 0.04 \\
7.26 \pm 0.11 \\
11.14 \pm 0.01 \\
12.03 \pm 0.02 \\
13.18 \pm 0.04 \\
10.74 \pm 0.01 \\
10.94 \pm 0.02 \\
7.28 \pm 0.03 \\
8.20 \pm 0.03\end{array}$} & \multirow[b]{2}{*}{$\begin{array}{c}108 B_{2} \\
10.70 \pm 0.05 \\
11.04 \pm 0.02 \\
16.17 \pm 0.02 \\
17.29 \pm 0.04 \\
18.43 \pm 0.17 \\
15.79 \pm 0.04 \\
16.43 \pm 0.06 \\
10.69 \pm 0.04 \\
11.55 \pm 0.04\end{array}$} \\
\hline $\begin{array}{l}\mathrm{Eu} \text { (III) } \\
\text { Am (III) } \\
\text { Th (IV) } \\
\text { Th (IV) } \\
\text { Th (IV) } \\
\text { Th (IV) } \\
\text { Th (IV) } \\
\mathrm{JO}_{2}+2 \\
\mathrm{NO}_{2}+2\end{array}$ & $\begin{array}{l}(3) \\
(3) \\
(4) \\
(4) \\
(4) \\
(4) \\
(4) \\
(5) \\
(5)\end{array}$ & & & \\
\hline
\end{tabular}

a Humic acid from a lake.

bSoil humic acid.

chumic acid from Aldrich Chem. Co.

Table 17. Pinding Constants for Th(IV) to Humic and Fulvic Acids, Copyright 1980 Pergamon Press. Reprinted by permission [NASH-1980].

\begin{tabular}{cccccc}
\hline $108 B_{1}$ & log $B_{2}$ & $T\left({ }^{\circ} \mathrm{C}\right)$ & $\mathrm{pH}$ & $\alpha$ & Material \\
\hline $11.140( \pm 0.013)$ & $16.168( \pm 0.023)$ & $25.0( \pm 0.5)$ & 3.95 & 0.25 & HA \\
$12.027( \pm 0.023)$ & $17.289( \pm 0.043)$ & $25.0( \pm 0.5)$ & 4.60 & 0.431 & HA \\
$13.181( \pm 0.038)$ & $18.434( \pm 0.173)$ & $25.0( \pm 0.5)$ & 5.03 & 0.54 & HA \\
$11.534( \pm 0.024)$ & $16.746( \pm 0.054)$ & $50.0( \pm 0.1)$ & 4.04 & 0.30 & HA \\
$10.680( \pm 0.100)$ & $15.635( \pm 0.149)$ & $5.0( \pm 0.1)$ & 4.02 & 0.24 & HA \\
$10.738( \pm 0.010)$ & $15.789( \pm 0.040)$ & $25.0( \pm 0.5)$ & 3.99 & 0.37 & HA \\
$10.940( \pm 0.019)$ & $16.431( \pm 0.056)$ & $25.0( \pm 0.5)$ & 3.98 & 0.39 & HA \\
$9.798( \pm 0.029)$ & $13.495( \pm 0.056)$ & $25.0( \pm 0.5)$ & 4.01 & 0.70 & FA \\
$10.824( \pm 0.051)$ & $15.073( \pm 0.084)$ & $25.0( \pm 0.5)$ & 5.00 & 0.84 & FA \\
$9.528( \pm 0.044)$ & $12.838( \pm 0.078)$ & $4.3( \pm 0.1)$ & 3.98 & 0.68 & FA \\
$10.023( \pm 0.021)$ & $14.054( \pm 0.050)$ & $52.0( \pm 0.1)$ & 3.99 & 0.71 & FA \\
\hline
\end{tabular}

one or two carboxylate groups. (In a later paper, these authors studied the dissociation kinetics of Th and $\mathrm{HA}$ and concluded that Th(IV) is bound by at least four types of aites with different basicities and different local polymer structures [CHOPPIK-1981A].) They observed that complex stability is high and that Th-hunte binding contants increase with increasing ionization of the $B A$ and FA polyelectrolyte. Thernodymaic (entropy, enthalpy) data indicate that the great stability of these complexes is derived from a very favorable complexation encropy. Wah and Choppin conclude from their data that actirides 
would be complexed completely by the humic materials in waters in the absence of other competing ligand such as carbonate and hydroxide. In soils, the binding by humate material. would be highly retentive to actinide migration.

Shanbhag and Choppin [SHANBHAG] and Choppin and Shanbhag [CHOPPIN1981B] examined the binding of tracer leve $1 \mathrm{UO}_{2}{ }^{2+}$ ( uranyl) and radiotracer $45 \mathrm{Ca}$ to $\mathrm{HA}$ as measured by a solvent extraction technique. The binding of uranyl was interpreted as involving only the carboxyl groups of the humate, and both $1: 1$ and $1: 2$ ratios of $\mathrm{UO}_{2}{ }^{2+}: \mathrm{CO}_{2}$ - were observed. They suggest that uranyl binding by humic and/or fulvic materials is not significant in seawater because of competition from carbonate complexes, but may play a role in freshwater systems where lower pH values prevail. Retention of uranyl from groundwater by soil humic oubstances would be strong. The uranyl interaction with humic substances is particularly interesting because $\mathrm{UO}_{2}{ }^{2+}$ is a close chemical analog of $\mathrm{PuO}_{2}{ }^{2+}$ but is more resistant to reduction; therefore, the behavior of uranyl is a valid model for that of $\mathrm{PuO}_{2}{ }^{2+}$ in the absence of reduction of the $\mathrm{Pu}$ upon interaction with humate. Binding of $45 \mathrm{Ca}$ by $\mathrm{HA}$ was found to be pH dependent. For an ionic medium of $0.1 \mathrm{M} \mathrm{NaClO}$, the binding constant ranged from $2.25 \pm 0.04$ at $\mathrm{pH} 3.9$ to $3.32 \pm 0.04$ at $\mathrm{pH} 5.0$. Thermodynamic parameters of binding calculated from the temperature coefficient indicated that a large, positive entropy change accounts for the favorable free energy of complexation.

Complexing of Eu(III) by FA was studied in detail by Marinsky [MARINSKY], using potentiometric titration. He determined that FA at concentration levels as low as $10^{-4} \mathrm{M}(\sim 20 \mathrm{ppm})$, on a monomer basis, exists in aqueous media as small molecular aggregates that exhibit microgel properties. This conclus in was based upon two principal observations. (1) In studies of the distribution of 154Eu between $8 \%$ Dowex 50 resin in the Nat-ion form and FA at several different concentration levels, and over an extended pH range from 4 to 10, it was shown that only one FA-complexed species of Eu(III), $[\mathrm{Eu}(\mathrm{COOR})]_{\mathrm{n}}{ }^{++}$, was formed; its apparent constant of formation, $\beta_{\mathrm{Eu}}(\mathrm{COOR})^{++}$, is roughly proportional to the third power of the $\mathrm{NaCl}$ concentration used in the study. (2) An inverse relationship exists between apparent $\mathrm{pK}_{\mathrm{a}}$ and ionic strength. At low ionic strength the apparent $\mathrm{pk}_{\mathrm{a}}$ is higher than at high ionic strength. Marinsky also noted that $\mathrm{PK}_{\mathrm{a}}$ was lowered bar increasing the FA concentration. This decrease in $\mathrm{pk}_{\mathrm{a}}$ appears to indicate the formation of a more compact aggregate. The capacity of the samples studied by Marinsky varied from sample to ssaple and the capacity was also shown to decresise with time.

Marinsky [MARINSKY] examined the effects of FA concentration on binding with Eu(III) at an ionic strength of 0.1 and a wide range of $\mathrm{pH}$ values. He observed a 25-fold increase in the ratio of bound to free Eu(III) when the concentration of $\mathrm{FA}$ was increased by only a factor of five. At an ionic strength of 0.3 , the change of the ratio of bound to free Eu(III) for a similar fivefold increase in FA concentration was much smaller, about a twofold increase. This observed behavior is attributed to the existence of FA as a flexible wicrogel that forms as a result of the strong tendency for $F A$ nolecules to aggregate. At the lower ionic strength of 0.1 , the aggregate arrangewent apparently becomes more compact as the concentration of FA increases because cohesive forces originating in the polar sites of the FA wlecule are enhanced by the higher concentration of these sitea. At the higher ionic strength of 0.3 , an even more compact assenbly of FA wolecules becomes 
sonewhat less compact with increasing concentration of FA because repulsive forces originating in the positive charge on the partially dissociated molecule become slightly disruptive. Because of the closer approach of neighbor molecules owing to the more compact arrangement of the FA microgel, an increase in FA concentration apparently leads to a slight expansion of the microgel because of such repulsion.

Ionic atrength also affects the ratio of bound to free Eu(III), as shown in Fig. 22. Binding of Eu(III) with FA increases as ionic strength decreases. This behavior is apparently due to the fact that FA exists as a

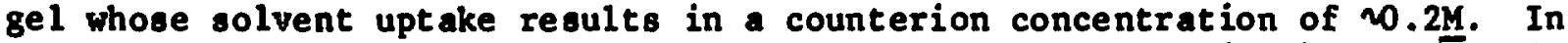
the most dilute salt systems, the ratio of bound to free Eu(III) measured is extremely large because of the fact that the concentration of free Eu(III) ions, to which the quantity of bound Eu should be related, is so much larger than that observed in the aqueous phase. Note in Fig. 22 that the ratio of bound to free Eu(III) increases sharply with increasing $\mathrm{pH}$ at $\mathrm{pH}$ values below *6, but reaches a plateau between $\mathrm{pH}$ values of about 6 and 8 . This plateau is thought to coincide with the pH range in which the availability of carboxylic acid groups of the FA has reached its maximum value. This behavior suggests that the complexed species of Eu(III) is exclusively associated with the carboxylic acid constitutents of the FA. The gentle increase in the binding ratios with increasing $\mathrm{pH}$ beyond the carboxylic acid equivalence point may signal the binding of another functional unit of FA, e.g., phenol, or may be just a reflection of gel phase contraction in this $\mathrm{pH}$ range. The somewhat anomalous binding behavior in the $0.30 \mathrm{M}$ solution, which shows an early plateau that persists over the $\mathrm{pH}$ range of $\sim 6$ to $\sim 10$ (Fig. 22), may be caused by the FA aggregate expanding over this pH range in this higher ionic strength sys tem.

Marinsky [MARINSKY] also examined the competitive complexing of Eu(III) by FA and $\mathrm{CO}_{3}{ }^{2-}$ ion. He concluded that, at a $\mathrm{pH}$ of 8 , Eu(III) can be expected to be complexed more strongly than $\mathrm{CO}_{3} 2-$ by as little as $2 \mathrm{ppm}$ of FA when the $\mathrm{HCO}_{3}^{-}$concentration does not exceed $250 \mathrm{ppm}$.

D. Discussion: Factors Affecting Radionuclide-Organic Complexing

The review in Sections IV.A, B, and $C$ serves to illustrate major trends of research in the field of radionuclide-organic complexing, as well as some of the problems that still face researchers in understanding organic complexing. Although it is quite clear from published research results that humic substances can form stable complexes with a variety of radionuclides under laboratory conditions, the effects of complexing on the mobility of radionuclides in the soil and groundwater environment arf less clear. If these sable complexes are soluble, radionuclide mobility can apparently be increased; however, insoluble complexe may also form that can either precipitate or bind chemically to soil particles, causing decreased mobility of the nuclides. One of the goale of future research must be to investigate nore thoroughly the relative importance of soluble and insoluble radionuclide-organic complexes in natural systens. It is particularly important that we develop a better underanding of the factors that control the formation of soluble and insoluble radionuclide-organic complexe in groundwater aquifer that my be oubject to contanination by high-level radioactive wate from deep repositories. 


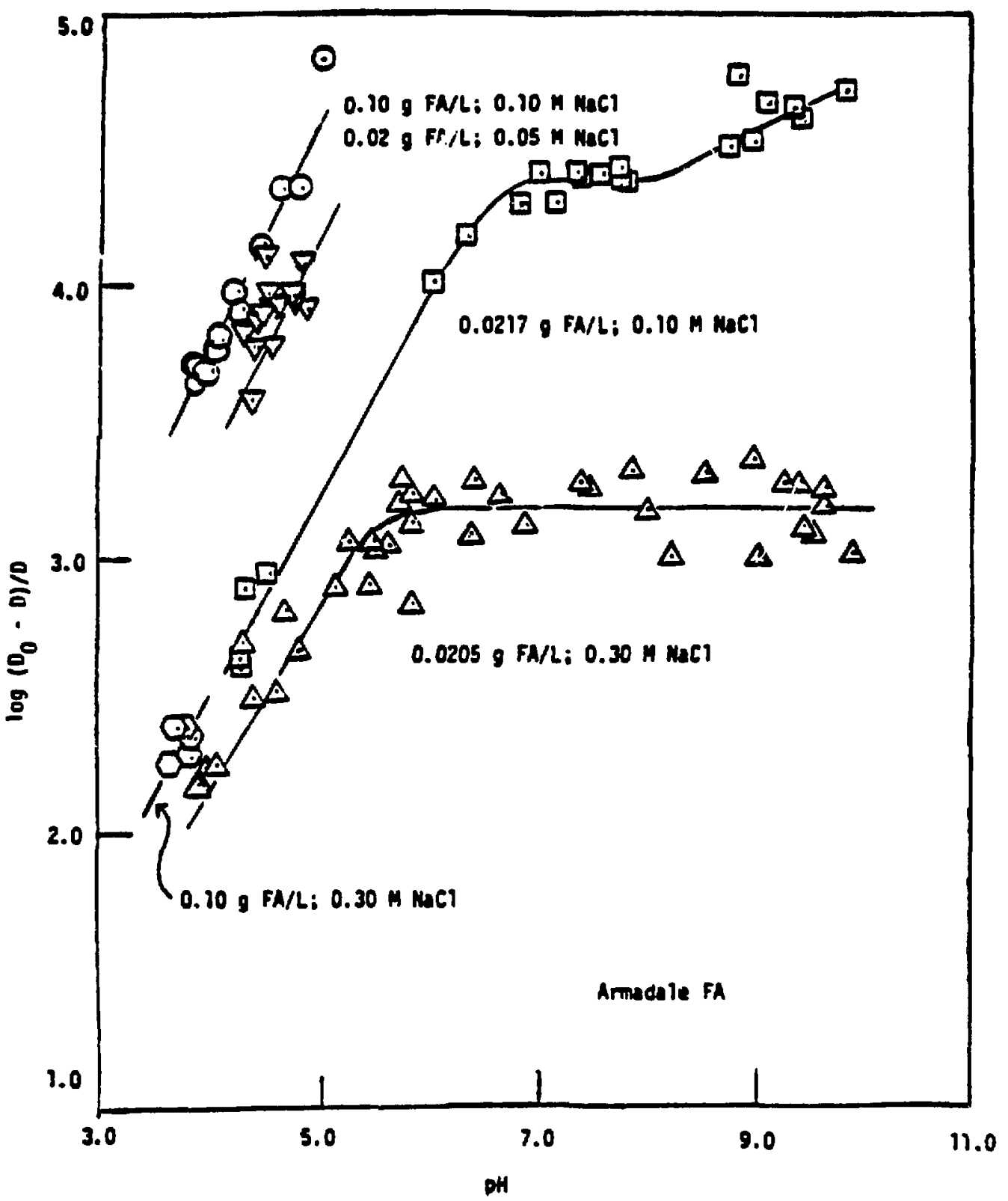

Fig. 22. Dependence of the Logarithmic Ratio of Bound to Free $154_{\mathrm{Eu}}$ (III) on $\mathrm{pH}$. Other variables: fulvic acid concentration, ionic strength. Copyright 1983 SKBF/KBS. Reprinted by permission [MARINSKY].

Several important factors are known to influence the solubility of radionuclides and trace metals. These factors include the oxidation state, $\mathrm{pH}$, temperature, ionic strength of the solutions, wetal or radionuclide concentration, and concentration of dissolved humic substances (HA and FA). The effects of these variables on complexing of trace metals by humic oubstances 
are diacussed In Section III. Considerable work has also been done to evaluate the effects of oxidation state, pH, temperature, Ionic strength, and radionuclide concentration on the solubility of lonic species and inorganic conplexes of radionuclides in solutions contalning little or no DOC. Much less research has been done to study the effects of these variables on the oolubility of radionuclide-organic complexes; however, enough work has now been done to provide some general insight into differences in behavior of radionuclides in aqueous systems that contain dissolved organic substances and in those that do not. The effects of environmental variables and radionuclide/DOC concentrations on radionuclide-organic complexing are examined in greater detall in this section.

\section{Oxidation State of Actinide Elements}

Oxidation state 18 generally considered to be one of the nost important controls on radionuclide mobllity. Many of the actinides exist in multiple oxidation states (Table 18); the most common oxidation states are represented by the $\mathrm{M}^{3+}, \mathrm{M}^{4+}, \mathrm{NO}_{2}{ }^{+}(\mathrm{V})$, and $\mathrm{MO}_{2}{ }^{2}(\mathrm{VI})$ specles. The oxidationreduction behavior of $\mathrm{U}, \mathrm{Np}$, and $\mathrm{Pu} 18$ particularly complicated, and multiple oxidation states can coexist in oolution [WATTERS-1980]. The oxidation states of importance for actinides under environmental conditions are $11 k e l y$ to be $\mathrm{Am}$ (III), U(IV), U(VI), Np(IV), Np(V), $\mathrm{Pu(IV),} \mathrm{and} \mathrm{Pu}(\mathrm{V})$ [BONDIETTI-1980 -1981]. The stable oxidation state in the environment will be governed by the presence of oxidizing and reducing agents and complexing ligands. Wahlgren et al. [WAHLGREN-1976] suggest that, because of similar electronic structure and ionic rad11, transuranic elements of a glven oxidation state should behave in a simllar manner chemically. Thus, the behaviors of $\mathrm{Pu}$ (III) and Am(III) are simllar, as are those of $\mathrm{Pu}(\mathrm{IV})$ and $\mathrm{Th}(\mathrm{IV})$, and $\mathrm{Pu}(\mathrm{VI})$ and $\mathrm{U}(\mathrm{VI})$. In general, the actinides appear to be more soluble in their higher oxidation states than in their reduced forms [SERNE-1982]. For example, both U(IV) and Th(IV) are extremely resistant to leaching; however, oxidation of $U(I V)$ to $U(V)$ results in much higher mobllization [BONDIETTI-1980].

Table 18. Comparison of Oxidation States for the Actinide Elements in Solution.a [WATTERS-1980].

\begin{tabular}{|c|c|c|c|c|c|c|c|c|c|}
\hline $\begin{array}{r}f=1 \\
\mathrm{Ac}\end{array}$ & $\begin{array}{l}2 \\
\text { Th }\end{array}$ & $\begin{array}{l}3 \\
\mathrm{~Pa}\end{array}$ & $\begin{array}{l}4 \\
0\end{array}$ & $\begin{array}{l}5 \\
\mathrm{~Np}\end{array}$ & $\begin{array}{l}6 \\
\mathrm{Pu}\end{array}$ & $\begin{array}{l}7 \\
\text { Am }\end{array}$ & $\begin{array}{l}8 \\
\mathrm{Cm}\end{array}$ & $\begin{array}{l}9 \\
\text { Bk }\end{array}$ & $\begin{array}{l}10 \\
\mathrm{Cf}\end{array}$ \\
\hline & & & & & & 2 & & & 2 \\
\hline 3 & & 3 & 3 & 3 & 3 & 3 & 3 & 3 & 3 \\
\hline & 4 & 4 & 4 & 4 & 4 & 4 & 4 & & \\
\hline & & 5 & 5 & 5 & 5 & 5 & & & \\
\hline & & & 6 & 6 & 6 & 6 & & & \\
\hline & & & & 7 & 7 & & & & \\
\hline
\end{tabular}

The colld lines bound the nost likely oxidation atates in aqueous colution. 
In the case of $\mathrm{Pu}, \mathrm{ll}$ oxidation states can exist in aqueous solutions under the Eh-pH conditions of environmental interest, and strong complexes are formed between $\mathrm{Pu}$ and oxygen-containing ligands $\mathrm{CO}^{2-}, \mathrm{OH}^{-}, \mathrm{CO}_{3}{ }^{2-}$, etc.) [ALLARD-1983]. The complex strength increases with the effective charge of the acceptor ion in the order: $\mathrm{Pu}^{4+}>\mathrm{PuO}_{2}{ }^{2+}>\mathrm{Pu}^{3+}>\mathrm{PuO}_{2}{ }^{+}$. As is the normal pattern for polyvalent ions, lower oxidation states of Pu are stabilized by more acidic conditions, whereas higher oxidation states become more stable as the basicity increases [CHOPPIN-1983].

The presence of dissolved humic substances in aqueous systems appears to have two opposing effects on the actinides. On the one hand, the presence of HA or FA can bring about reduction of actinides, such as $\mathrm{Pu}(\mathrm{V})$ to $\mathrm{Pu}$ (IV), causing a decrease in solubility and mobility; however, competitive chelation may act in the opposite direction to increase mobility [DAHLMAN]. The formation of complexes can affect oxidation-reduction potentials and stabilize different oxidation states in solution, depending upon relative values of stability constants. The general order of stability constants is $\mathrm{M}^{4+}>\mathrm{MO}_{2}{ }^{2+}>\mathrm{M}^{3+}>\mathrm{MO}_{2}{ }^{+}$[WATTERS-1980]. Dahlman et al. [DAHLMAN] sugge at that the tendency of the actinides to form complexes with organic ligands follows the order: $\mathrm{Pu}(\mathrm{IV})>\mathrm{Th}(\mathrm{IV})>\mathrm{Am}(\mathrm{III})=\mathrm{Cm}(\mathrm{III}) \cong \mathrm{U}(\mathrm{VI})>\mathrm{Pu}(\mathrm{VI})>$ Np (v).

Bondietti et al. [BONDIETTI-1975] experimentally investigated the redox behavior of $\mathrm{Pu}$ in the presence of $\mathrm{HA}$ and FA. Reduction of Pu(VI) and $\mathrm{Pu}(V)$ to $\mathrm{Pu}(\mathrm{IV})$ occurred readily. The most stable valence upon reaction with these humic substances was Pu(IV) and is therefore likely to be the predominant oxidation state in most environments where humic substances are moderately abundant. Further reduction of $\mathrm{Pu}(\mathrm{IV})$ to $\mathrm{Pu}(\mathrm{III})$ also occurred; however, reduction from the tetravalent to the trivalent state took place only at low values of $\mathrm{pH}(<3.1)$ under aerobic conditions. Reduction could also occur at higher $\mathrm{pH}$ values under anaerobic conditions, but probably not above $\mathrm{pH} 6$ owing to the stablizing effect of strong hydroxide complexes formed in the tetravalent state.

Because of the lower solubility of $\mathrm{Pu}(\mathrm{IV})$ compared to $\mathrm{Pu}(\mathrm{V})$ or Pu(VI), Pu should be relatively immobile in environmental systems; however, Bondietti et al. [BONDIETTI-1975] point out that, if Pu(IV) is the predominant valence that stabilizes in soils and other environmental matrices, the chemistry of $\mathrm{Pu}$ in the environment will be strongly affected by complex formation. Inorganic complexers such as hydroxides may be very significant, but organic complexers may be more important in maintaining $\mathrm{Pu}(\mathrm{IV})$ in forms that are mobile in the environment, i.e., complexed forms. On the other hand, Bondietti et al. demonstrated that much of the Pu in soils contaminated by fallout 30 years previously was complexed to insoluble humic substances that were bound to soil particles, resulting in very low mobility of the Pu.

Nash et al. [NASH-1981] studied the reducing effects of HA on hexavalent actinides. It strongly absorbs $\mathrm{U}(\mathrm{VI}), \mathrm{NP}(\mathrm{VI})$, and $\mathrm{Pu}(\mathrm{VI})$ from aqueous bicarbonate-carbonate media. The $\mathrm{HA}$ also reduced $\mathrm{Np}(\mathrm{VI})$ to $\mathrm{Np}(\mathrm{V})$ and $\mathrm{Pu}(\mathrm{VI})$ to $\mathrm{Pu}(V)$; however, it did not reduce U(VI). It complexed both the (IV) and (vI) valence states of $\mathrm{Pu}$ and Np strongly enough to prevent carbonate complexes. Complexee between $\mathrm{NpO}_{2}{ }^{+}$and $\mathrm{HA}$ occur at neutral to alkaline $\mathrm{pH}$. The mobility 
of the actinides in the (IV), (V), and (VI) oxidation states will thus be governed by the mobility of $\mathrm{HA}$. Nash et al. suggest that, because HA can be strongly bound to clays, their research results Imply probable low mobility of the actinides in waters contacting humic materials. This conclusion does not necessarily apply, however, If the HA forms soluble complexen with the actinides.

Nelson et al. [NELSON-1980] found that the Pu in many oligotrophic lakes is primarily in the oxidized form (presumably Pu(V)], which is weakly sorbed onto particulates in the water. Some reduced Pu, presumably Pu(IV), was also found in all the waters. The Pu(IV) formed strong, soluble complexes with the dissolved indigenous organic substances in the lake waters, inhibiting sorption of the Pu onto particulates. The solubility of the complexes varled directly (Increased) wth increasing concentration of Doc.

\section{Effects of $\mathrm{pH}$}

The complexing of actinides with $\mathrm{HA}$ and FA 18 strongly dependent upon pH because both the hydrolysis of the nuclides and the dissociation of the acids are $\mathrm{pH}$ dependent [OLOFFSON]. The $\mathrm{pH}$ also affects the oxidation state of polyvalent cations. In general, lower oxidation states are stabilized by more acidic conditions, whereas higher oxidation states become more stable as the basicity increases [CHOPPIN-1983]. Choppin points out, however, that this general trend can be negated by other factors, such as complexing, that can even reverse the trends and the relative stability of the different oxidation states.

Li et al. [LI] determined that complexation of $U(V I)$ and U(IV) with $\mathrm{HA}, \mathrm{FA}$, and TA was $\mathrm{pH}$ dependent. Complexation Increased with increasing $\mathrm{pH}$, with particularly strong enhancement taking place at $\mathrm{pH}$ values above about 5 , as shown in Fig. 17, which also shows that HA can complex with both U(IV) and U(VI) at lower $\mathrm{pH}$ values than FA. Shchebetkovskdi and Bochkov [SHCHEBETKOVSKII] studied the absorption of Pu by humic substances as a function of $\mathrm{pH}$. They observed that sorption onto the humic substances, measured by distribution coefficients $\left(K_{d}\right)$, increased linearly within the $\mathrm{pH}$ range of $\mathbf{0 . 5 - 1 . 5}$ with increasing $\mathrm{pH}$ according to the equation,

$$
\log \mathrm{K}_{\mathrm{d}}=(\mathrm{a}) \mathrm{pH}+\mathrm{b}
$$

where $a$ and $b$ are constants. These $\mathrm{pH}$ values are, of course, well below those that could be expected under most environmental conditions.

Flocculation studies by Means [MEANS-1982B] demonstrate that Am, $\mathrm{Np}, \mathrm{Th}$, and $\mathrm{Pu}$ solubilities are affected by the presence of $\mathrm{HA}$ and $\mathrm{FA}$ and by $\mathrm{pH}$. In $\mathrm{HA}$ and $\mathrm{PA}$ solutions at both low $\mathrm{pH}(3.7-3.8)$ and high $\mathrm{pH}(8.2-8.5)$, Np was found to be only slightly more soluble than in blank solutions containing no $\mathrm{HA}$ or $\mathrm{FA}$. Although $\mathrm{Th}$ and Am displayed enhanced solubility in neutral to basic $\mathrm{BA}$ and FA solutions, they flocculated or precipitated in the low $\mathrm{pH}$ range, indicating that their solubility at low $\mathrm{pH}$ is actually lower in HA and FA solutions than in blank solutions. Enhanced solubility was shown by $U$ at neutral to basic $\mathrm{pH}$ conpared with low $\mathrm{pH}$; $\mathrm{Pu}$ wo more coluble in all the colutions contalning $H A$ and $8 A$ than in blank solutiona. 
Cleveland and Rees [CLEVELAND-1976] found little solubilization of Pu and im in sol.1 suspensions at $\mathrm{pH}$ values ranging from 6.5 to 7.5 , but solubilization increased (though only slightly) at a pH of 9. Nishita and Haug [NISHITA] observed that pH has a marked Influence on extractability (solubility) of Pu in $\mathrm{HA}$ and FA solutions. Extractability 18 at a maximum at $\mathrm{pH}$ 1.2, drops to about $40 \%$ at $\mathrm{pH} 3.3$, remalns constant between $\mathrm{pH} 3.3$ and 7.2 , increases abruptly between $\mathrm{pH} 7$ and 10.7 , and decreases sharply above $\mathrm{pH}$ 10.7 .

All these reported studies Indicate a general trend of Increasing solubilization (decreasing sorption) of actinides with increasing pH in the presence of HA and FA, although the trend 18 by no means linear. Thus, in general, neutral to basic pH values favor solubilization over acidic pH values. (Note that HA becomes insoluble at acid $\mathrm{pH}$ values, particularly below $\mathrm{pH} 4$. ) This trend appears to be opposite to that apparently found in most studies in which the sorption of radionuclides to rock materlals has been examined in solutions free of humic or other organic substances. These adsorption studies typically show that nuclide adsorption onto solid phases increases (solubility decreases) as pH increases [SERNE], although this trend may not hold throughout the entire range of $\mathrm{pH}$ values. Allard and Beall [ALLARD-1979] have shown, for example, that sorption of Am increases with increasing $\mathrm{pH}$ in the range of 4 to about 6.5 , but decreases slightly at higher pH. On the other hand, sorption of Np increases only slightly below pH 4 to 6.6, or decreases slightly depending upon the adsorbing solid, but increases sharply at higher pH. Thus, increasing $\mathrm{pH}$ appears to favor formation of soluble complexes of radionuclides in the presence of humic substances and decreased sorption onto solid phases, in contrast to increased sorption onto solid phases in the absence of humic substances. Because the $\mathrm{pH}$ of most deep groundwaters is likely to be basic (about $8-9$ ), the presence of humic substances in these waters may be a critical factor in determining radionuclide mobility. Additional research on the effects of $\mathrm{pH}$ on the mobility of radionuclides in the presence of HA and FA is clearly needed.

\section{Effects of Temperature on Radionuclide Mobility in the Presence of Organic Complexants}

Relatively few studies have examined the effects of temperature on the mobjilty (solubilization) of radionuclides in the presence of organic complexants, although many studies have investigated the effects of temperature on sorption of radionuclides in organic-free solutions. Serne and Relyea [SERNE] summarize studies of radionuclide sorption performed under the Waste/ Rock Interactions Technology (WRIT) program and report that, in general, these studles show sorption of most radionuclides is not significantly affected by temperature variations within the range of 20 to $80^{\circ} \mathrm{C}$. Other published reports digagree with the se conclusions. For example, Salter et al. [SALTER] report that temperature has a strong effect on sorption of several radionuclides onto Columbia River basalts. Sorption of many radionuclides, as measured by distribution ratios $\left(K_{d}\right)$, increased with increasing temperature. Values of $K_{d}$ for $\mathrm{Ra}, \mathrm{Am}, \mathrm{Pu}$, and Se all increased between 25 and $60^{\circ} \mathrm{C}$. On the other hand, the distribution coefficient for $C s$ decreased with increasing temperature, and Sr corption was not affected between 25 and $60^{\circ} \mathrm{C}$. 
Means et al. [MEANS-1983] reported a Bignificant relationship between temperature and sorption of $U, C s, S r$, and $C_{0}$ onto kaolinite, illite, and montmorillonite in the presence (and absence) of the organic complexants, oxalic acid and EDTA. Figure 23 shows the results obtained in experiments with oxalic acid. A general trend of increasing sorption (decreasing concentration of radionuclides in solution) with increasing temperature with in the temperature range of 0 to $250^{\circ} \mathrm{C}$ is evident in runs both with and without organic complexants. Note, however, that considerable variation in sorption behavior of these radionuclides occurs. Some of the nuclides display reversals of this trend; that is, sorption decreases with increasing temperature with in certain temperature ranges. For example, $U$ adsorption on montmorillonite and illite generally increased to about $75^{\circ} \mathrm{C}$ in solutions without oxalic acid and then decreased; sorption of both $\mathrm{Cs}$ and $\mathrm{Sr}$ on kaolinite and montmorillonite first decreased and then increased. Nuclide sorption in the presence of oxalic acid showed the same general beharioral trends as in the absence of organic complexants; however, the presence of oxalic acid generally decreased sorption in all temperature ranges. Similar results were obtained in experiments with EDTA.

Boggs and Seitz [BOGGs-1984A] investigated the effects of temperature on sorption of Am and Np onto basalt in both humic-free solutions and solutions containing $\mathrm{HA}$ and FA ranging in concentration from 1 to $200 \mathrm{mg}(\mathrm{C}) / \mathrm{L}$. The results indicate a significant increase in sorption of Am and $\mathrm{Np}$ at $90^{\circ} \mathrm{C}$ in both HA and FA solutions compared with that at $22^{\circ} \mathrm{C}$. The greatest ef fect on sorption was evident in solutions containing no HA or FA; the effects of temperature on sorption decreased slightly with increasing concentration of HA and FA in solution. Temperature effects appear to be interrelated with phi effects in a complicated way; that is, the smallest increases in sorption with increasing temperature were observed in experiments in which $\mathrm{pH}$ was adjusted to 9.0 at all concentration levels of $\mathrm{HA}$ and FA, in contrast to experiments in which $\mathrm{pH}$ was allowed to range from 8.8 to 9.9 depending upon the concentration of HA and FA in solution.

Too few experimental data are yet available to allow definite conclusions about the effects of temperature on the mobility of radionuclides in the presence of humic substances and other organic complexants. Preliminary data suggest a general trend of decreasing solubilization of many radionuclides (increasing sorption onto solid phases) with increasing temperature; however, the effects vary with different ruclides and within different temperature ranges. Increase in concentration of HA and FA and other organic complexants generally works to increase solubilization, thereby reducing the tendency of increased temperature to cause reduced radionuclide solubility. The effects of temperature changes in the presence of organic chelates vary with different radionuclides and with in different temperature ranges. Means [MEANS-1983] reports that at temperatures of about 150 to $200^{\circ} \mathrm{C}$ organic complexants began to degrade and lose their metal-binding capabilities.

\section{Effects of Ionic Strength}

Serne and Relyea [SERNE] report that studies perforwed under the WRIT program generally show that nuclide adsorption for alkali and alkaline earth elewents exhibits a consistent decrease in distribution ratios (decreased sorption) as the groundwater $\left[\mathrm{Na}^{+}\right]$or $\left[\mathrm{Ca}^{2+}\right]$ increases. They indicate that 

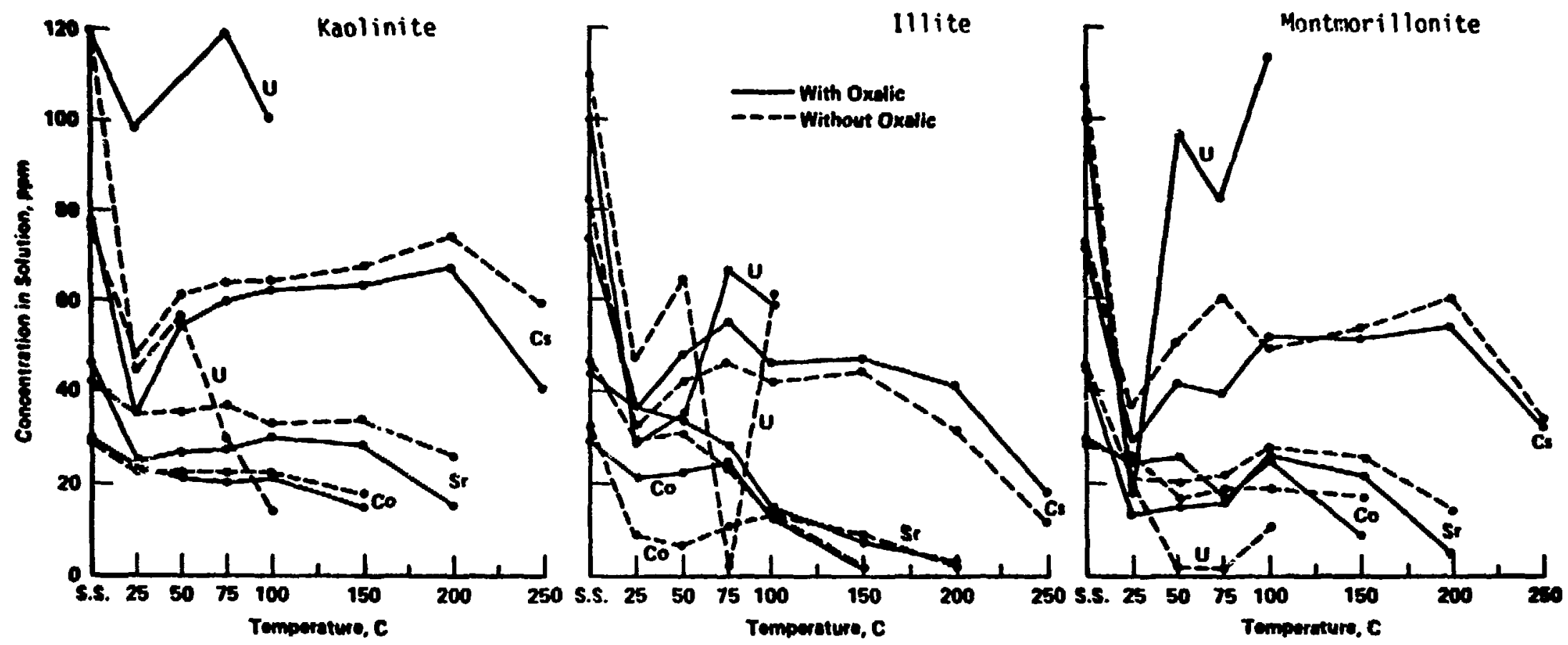

Fig - 23. Concentrations of $\mathrm{U}, \mathrm{Co}, \mathrm{Sr}$, and $\mathrm{Cs}$ in Aqueous Systems Containing Kaolinite, Illite, and Montmorillonite, Both with and without Oxalic Acid, as a Function of Temperature. Run durations: kaolinite $0-75^{\circ} \mathrm{C}, 8$ days; and $100-250^{\circ} \mathrm{C}, 8$ days; illite $0-75^{\circ} \mathrm{C}$, 9 days; and $100-250^{\circ} \mathrm{C}, 23$ days; montmorillonite $0-75^{\circ} \mathrm{C}, 16$ days; and $100-250^{\circ} \mathrm{C}, 12$ days. [MEANS-1 983 ]. 
distribution ratios at neutral pH values for lanthanide elements such as Eu and for the actinides are much less sensitive to lonic strength. Actually, $U$ and Np show Increased adsorption in brines. Serne and Relyea conclude on the basis of the WRIT studies that, except for $\mathrm{Sr}, \mathrm{Cs}$, Ra, and a few other long-lived nuclides, ideal ion exchange processes are of limited utility in explaining nuclide retardacion.

Most studies of metal-organic complexing discussed in Section III found that stability constants of the complexes decrease with increasing lonic strength, indicating that, in general, the stability of complexes formed between humic substances and divalent metals decreases with increasing lonic atrength. For exanple, thermodynamic modeling studies by Stumm and Morgan [STUM] suggest that metal-organic complexes in natural waters enriched in Ca and may be relatively unimportant owing to the inhibiting effect on trace metal-organic complexing caused by $\mathrm{high}^{\mathrm{h}}$ concentrations of $\mathrm{Ca}^{2+}$ and $\mathrm{Mg}^{2+}$. Unfortunately, only a few studies have examined the effects of lonic strength on the stability of radionuclide-organic complexes. In one such study, Marinsky [MARINSKY] reported the effects of lonic strength on binding of Eu by FA. Experiments with solutions ranging in concentration from 0.05 to $0.30 \mathrm{M} \mathrm{NaCl}$ demonstrated an increase in binding (complexing) of Eu with decreasing 1onic strength of the solutions, as shown in Fig. 22. As that figure shows, the magnitude of the decrease varies with pH. Preliminary studies thus suggest that the stability of radionuclide-organic complexes, like that of trace metal-organic complexes, decreases in the presence of Increasing concentrations of competing cations; however, additional studies of the effects of overall lonic strength on the stability of specific radionuclide-organic complexes are needed to refine this conclusion.

\section{Effects of Competing Ligands}

An additional problem related to ionic strength is the presence of Inorganic ligands such as $\mathrm{CO}_{3}{ }^{2-}, \mathrm{HCO}_{3}-, \mathrm{SO}_{4}{ }^{2-}, \mathrm{NO}_{3}{ }^{-}$, and $\mathrm{PO}_{4}$ in most natural waters. These inorganic liga:-1s can form complexes with avallable metals lons, including radionuclides; therefore, competition with inorganic ligands must be considered when evaluating the stability of radionuclide-organic complexes. In the alkaline groundwaters enviroment, within which most high-level radioactive waste repositories will probably be sited, carbonates are the most likely Inorganic ligands to interact with radionuclides.

Marinsky [MARINSKY] examined the possibility that carbonate lons could conplex with ${ }^{154} \mathrm{Eu}$ (III) more strongly than FA in the pH range of 8 to 9. Complexation of Eu(III) by both $\mathrm{CO}_{3}{ }^{2-}$ ion and FA was studied in a water eample containing $20 \mathrm{ppm}$ FA organic carbon ( $21.5 \times 10^{-4} \mathrm{M}$ ) with 200 ppa of $\mathrm{HCO}_{3}^{-}$ton $\left(3.3 \times 10^{-3} \mathrm{M}\right)$ and either 50 or $550 \mathrm{ppm}\left(10^{-3}\right.$ or $\left.10^{-2} \mathrm{M}\right) \mathrm{NaCl}$. Marinsky reporte that, at $\mathrm{pH} 8$, the Eu(III) is more strongly coaplexed by FA (fron three different sources) at both concentratious of $\mathrm{NaCl}$ exanined. At $\mathrm{pH} \mathrm{9,} \mathrm{the} \mathrm{preference} \mathrm{of} \mathrm{Eu}$ (III) for FA relative to the $\mathrm{CO}_{3}{ }^{2-}$ Ion 18 reduced, so that the least strongly binding FA source is only slightly more strongly complexed than the $\mathrm{CO}_{3}{ }^{2}$ - Ion in the more dilute Nacl syoten. At the higher concentration of $\mathrm{NaCl}$, Eu(III) is predicted to be four times more strongly bound to the carbonate lon than to the least strongly binding FA, but 3 to 20 tines more strongly bound to the other BA sources than to the carbonate Ion. Thus, it appears that the relative strengthe of $\mathrm{FA}-\mathrm{Eu}$ and $\mathrm{CO}_{3}{ }^{2-}-\mathrm{Eu}$ 
complexes are functions of the source (type) of FA as well as pH and ionic atrength. Marinsky concludes that, at a pH of 8 , Eu(III) can be expected to be complexed more strongly by FA than by the $\mathrm{CO}_{3}{ }^{2-}$ ion by as little as 2 ppm of $\mathrm{FA}$ when the $\mathrm{HCO}_{3}$ - concentration does not exceed $250 \mathrm{ppm}$.

Mathew and Pillai [MATHEW] otudied the complexing of Pu with carbonate ion in the pregence of $220 \mathrm{mg} / \mathrm{L}$ of organic matter in seawater containing up to $96 \mathrm{mg} / \mathrm{L}\left(10^{-3} M\right)$ carbonate/bicarbonate. Their results are shown in Table 19. They found that the Pu solubilized (complexed) is more or less directly proportionsl to the carbonate added, but that solubilization of Pu is much higher if organic matter is added to the sea water. Furthermore, the results indicate that the amount of Pu solubilized vs. the amount of organic matter ins reased with increase in carbonate/bicarbonate concentration. Thus, in this particular experiment at least, the complexing of Pu with organic matter appears to actually be enhanced by the presence of carbonate ion.

Table 19. Influence of Carbonate, Bicarbonate, and Organic Matter on Solubilization of $\mathrm{Pu}$ in Filtered Seawater. [MATHEW].

\begin{tabular}{|c|c|c|c|}
\hline \multirow[b]{2}{*}{ Exper iment } & \multicolumn{3}{|c|}{ Soluble plutonium } \\
\hline & (dis/min per $100 \mathrm{~mL}$ ) & (M) & $(\mu \mathrm{g} \mathrm{Pu} / \mathrm{L})$ \\
\hline $\begin{array}{l}\text { Sea water witi low } \mathrm{CO}_{3}= \\
(3.6 \mathrm{mg} / \mathrm{L}) \\
\mathrm{pH}: 7.45\end{array}$ & 60 & $1.9 \times 10^{-11}$ & $4.4 \times 10^{-3}$ \\
\hline $\begin{array}{l}\text { Sea water with low } \mathrm{CO}_{3}= \\
\text { HCO } \\
\text { matter }\end{array}$ & 180 & $5.6 \times 10^{-11}$ & $13.1 \times 10^{-3}$ \\
\hline $\begin{array}{l}\text { Sea water with normal } \mathrm{CO}_{3}=\text {, } \\
\text { } \mathrm{HCO}_{3} \text { - concentration } \\
(24.6 \mathrm{mg} / \mathrm{L}) \\
\mathrm{pH}: 7.9\end{array}$ & 72 & $2.2 \times 10^{-11}$ & $5.3 \times 10^{-3}$ \\
\hline $\begin{array}{l}\text { Sea water with normal } \mathrm{CO}_{3}=\text {, } \\
\text { } \mathrm{HCO}_{3}-\text { concentration } \\
+20 \text { mg organic matter }\end{array}$ & 212 & $6.6 \times 10^{-11}$ & $15.5 \times 10^{-3}$ \\
\hline $\begin{array}{l}\text { Sea water with excess } \mathrm{CO}_{3}=\text {, } \\
\mathrm{HCO}_{3}-(96.36 \mathrm{mg} / \mathrm{L}) \\
\mathrm{PH}: 8.2\end{array}$ & 141 & $4.4 \times 10^{-11}$ & $10.3 \times 10^{-3}$ \\
\hline $\begin{array}{l}\text { Sea water with excess } \mathrm{CO}_{3}{ }^{2} \text {, } \\
\mathrm{HCO}_{3}-+20 \mathrm{mg} \text { organic } \\
\text { matter }\end{array}$ & 512 & $15.9 \times 10^{-11}$ & $37.3 \times 10^{-3}$ \\
\hline
\end{tabular}


Nash et al. [MASH-1981] investigated the reaction of hexavalent actinides with $\mathrm{HA}$ in aqueous carbonate and bicarbonate solutions. They report that the not only are effective reducing agents for hexavalent neptuniun and Flutonium, but also complex the (IV) and (VI) valence states strongly enough to prevent carbonate complexes. On the other hand, Wahlgren and Orlandini [WAHLGREN-1982] found that the high alkalinity in some North American lakes containing high DOC concentrations had little effect on Pu distribution coefficients, but caused a significant decrease in the distribution coefficients 0 ? U. They conclude that, when alkalinity is high and pH exceeds 7.5, alkalinity rather than DOC concentration appears to control the adsorption behavior of $\mathrm{U}$.

\section{Effects of Radionuclide Concentration}

Serne and Relyea [SERNE] report that, in contrast to the traditional assumption that the nuclide isotherm is linear (i.e., the distribution ratio is conatant with changes in nuclide concentration), WRIT studies found that adsorption of most nuclides (including Cs) exhibit nonlinear sorption isotherms for rock materials, even at extremely 1 ow nuclide concentration ranges $\left(10^{-} \underline{Y}_{\underline{Y}}\right.$ and lower). For example, in these studies Seitz et al. [SEITZ] observed a pronounced increase in sorption of $\mathrm{Cs}_{8}$ onto limestone with decreasing concentration of $\mathrm{Cs}_{\mathrm{i}}$ in solution within the concentration range of $\sim_{10^{-10}}$ to $10^{-2} \mathrm{M}$. A similar relationship of increasing distribution ratios with decreasing concentration of $\mathrm{Cs}$ with in the concentration range of $10^{-7}$ to $10^{-3} \mathrm{M}$ was observed by Torstenfeld et al. [TORSTENFELD] in studies of Cs sorption on Stripa granite. When clay minerals or weathered rocks with high clay content are the sorbing materials, more of the nuclides approach linear isotherms; however, the majority continue to exhibit nonlinearity. Thus, the WRIT studies suggest that, in most cases, distribution ratios increase (sorption increases) as the nuclide concentration decreases.

Studies of metal-organic complexing reported in Section III suggest a general trend or decreasing complexing ability with increasing metal ion concentration. This trcid was reported by Kerndorff and Schnitzer [KERNDORFF] as well as Ong et al. [ONG]; however, other investigators (e.g., Saar and Weber [SAAR-1979]) have observed variations in this trend depending upon the metal ion being studied.

The general trend of decreasing couplex stability with increasing metal ion concentration appears to hold also for radionuclide-organic complexing. Li et al. [LI] used dialysis techniques to examine the effects of $U$ (VI) and $U$ (IV) concentration on the interaction of these radionuclides with $20 \mathrm{gg} / \mathrm{L} \mathrm{HA}, \mathrm{FA}$, or TA (Fig. 18). A strong relationuhip between nuclide concentration and the degree of nuclide-organic complexing was observed. A nearly linear decrease in complexing (increase in free U(VI) ion concentration] with increasing total $U$ (VI) concentration at concentrations greater than about 5 to $10 \mathrm{gg}[U(V I)] / \mathrm{L}$ was eatablished for all three organic complexants. $A$ sinilar trend was observed for $U(I V)$ at concentrations greater than about 1 to $2 \mathrm{gg} / \mathrm{L}$. Means [MEAYS-1982B] exmined flocculation of $\mathrm{Th}, \mathrm{m}, \mathrm{U}$, and Pu in the presence of $\mathrm{HA}$ and FA at different nuclide concentrations. For experiments run at two different nuclide concentrations, Means determined that the removal of HA and FA by flocculation (of insoluble actinide-organic colloids) 
Increaced with increasing metal content of the solutions. This behavior auggesta that increase in nuclide concentracion causes a decrease in goluble nuclide-organic conplexactun-the same trend observed by $\mathrm{LI}$ et al. [LI].

The decreasing tendency to form soluble radionuclide-organic complexes with increasing radionuclide concentration indicates that, if the concentration of $\mathrm{HA}$ or FA in a solution is held constant, further addition of the radionuclide to the solution will decrease the capacity of the solution to form soluble radionuclide-organic complexes. Reducing the capacity of a solution to form soluble complexes with a radionuclide has the practical effect of increasing sorption of the rad lonuclide onto rock materials. On the other hand, the adsorption studies reported by Serne and Reylea [SERNE], which were conducted in the absence of DOC, show that radionuclide sorption onto rock materials generally decreases (mobility of the racionuclide increases) as the concentration of the radionuclide in solution Increases. Thus, in the presence of humic substances, the general tendency toward increased mobility of radionuclides caused by increased concentration of the radionuclides appears to be offset to some degree by the fact that increased nuclide concentration reduces soluble nuclide-organic complexes in the solution.

\section{Effects of Dissolved Organic Carbon Concentration}

Several Investigators have studied the effects of DOC concentration on complexing of radionuclides by organic substances. Most studies have established a strong sorrelation between increasing solubilization (cnmilexing) of radionuclides and increasing concentration of organic complexants. Nelson et al. [NELSON-1980] demonstrated that sorption of Pu onto suspended solids In lake waters varies inversely with the DOC content of the water within the approximate concentration range of 1 to $100 \mathrm{mg}(\mathrm{C}) / \mathrm{L}$. Wahlgren and orlandini [WAHLGREN-1982] reported a similar, essentially linear relationsh1p between sorption of $\mathrm{Pu}, \mathrm{Th}$, and $U$ and $\mathrm{DOC}$ concentration in lake waters, and orlandin1 [ORLANUINI] found the same Inverse relationship between Am and DOC concentration in lakes. Mar1nsky [MARINSKY] observed a 25-fold Increase in the ratio of bound (complexed) Eu(III) to free Eu(III) when the concentration of FA in experimental solutions was increased by only a factor of five.

Bogys and Seitz [BOGGS-1984A] studied the influence of different concentrations of $\mathrm{HA}$ and FA on sorption of $\mathrm{Am}$ and Np onto basalt. Batch partitioning experiments were carried out with synthetic groundwaters in which 1onic strength and nuclide concentration were held constant. In one experiment, $\mathrm{pH}$ was maintained at a constant value of 9.2 ; In other experiments, $\mathrm{pH}$ ranged from 8.8 to 9.9 depending upon the concentration of HA or FA added to the $\mathrm{g}$ roundwater. Temperature was maintalned constant at elther 22 or $90^{\circ} \mathrm{C}$. Experiments were conducted with groundwaters containing $0,1,10,20,100$, and $200 \mathrm{gg}(\mathrm{C}) / \mathrm{L}$ of HA or FA. The sclutions were spiked with Am or $\mathrm{Np}$ and allowed to equillbrate with crushed basalt for seven days. Distribution ratios were calculated based on the ratio of nuclide sorbed onto the basalt to muclide remaining in solution at the end of the experinent.

The results of the experiment with $\mathrm{HA}$ and $\mathrm{Am}$ at a fixed $\mathrm{pH}$ of 9.2 are sumarized In $81 \mathrm{~g}$. 24 , which shows a very strong Inverse relationship between distribution ratio (sorption) and the ceincentration of in organic 


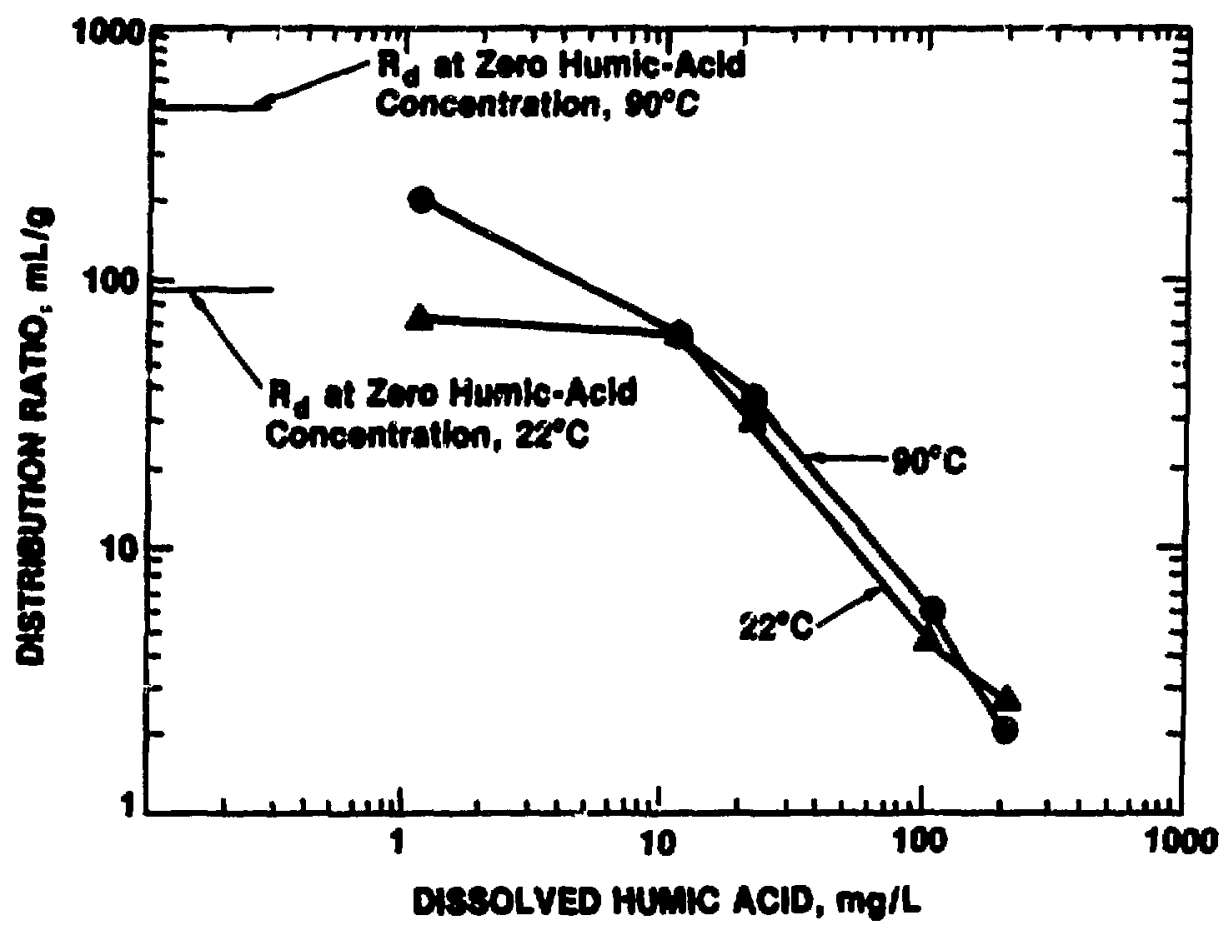

F18. 24. Distribution Ratios $\left(R_{d}\right)$ for Americium between Synthetic Groundwater and Granulated Pomona Basalt Reacted Seven Days in the Presence of Various Concentrations of Hunic Acid. Initial pH of solutions adjuated to 9.2 . [BOGGS-1984h].

carbon. This figure auggeets that solubilization of Am can be measurably lncreased by as little as 1 ppa DoC above zero level. At higher DoC concentrations, solubilization increased essentially linearly with fncreasing HA concentration within the range of 10 to $200 \mathrm{~ms}(\mathrm{C}) / \mathrm{L}$. Sinilar results were obtalned in experiments with both Am and Np in BA and is solutions in which pH ranged from $9.9(0 \mathrm{mg} / \mathrm{L}$ DOC) to $8.8(200 \mathrm{mg} / \mathrm{L}$ DOC). Figure 25 shows the results of experientes with $\mathrm{Np}$ and HA. In all experimente, a atrong trend of decreased eorption (increased complexetion) of the radionuclide with increasins concentration of th or FA was eatablished. 


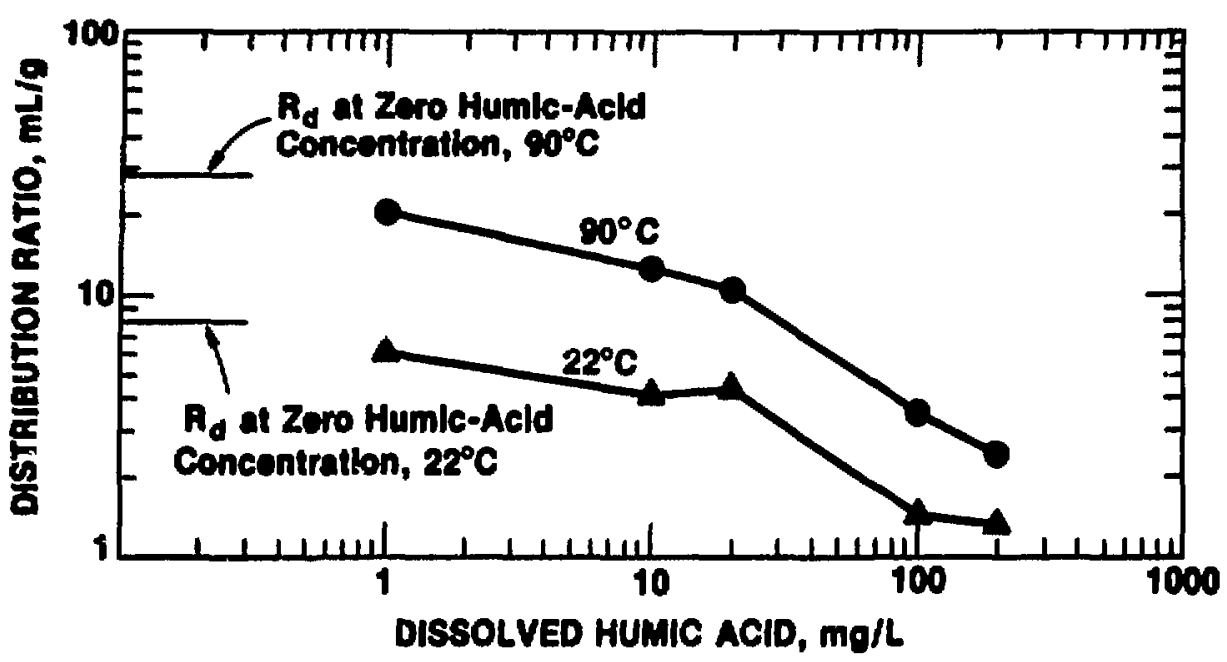

Fig. 25. Distribution Ratios $\left(R_{d}\right)$ for Neptunium between Synthetic Groundwater and Granulated Pomona Basalt Reacted Seven Days in the Presence of Various Csncentrations of Humic Acid. [BOGGS-1984A]. 


\section{v. SUMMARY AND CONCLUSIONS}

A. Distribution and Characterization of Dissolved Humic Substances in Natural Waters

Natural waters contain dissolved organic carbon (DOC) in concentrations ranging from as little as $0.1 \mathrm{mg} / \mathrm{L}$ in ocean water and unpolluted fresh water to more than $100 \mathrm{mg} / \mathrm{L}$ in some organic-rich lakes and swamps. A weighted world average of $5.75 \mathrm{mg} / \mathrm{L}$ DOC for streams has been reported. Groundwaters contain up to about $20 \mathrm{mg} / \mathrm{L} \mathrm{DOC}$; however, the average range of DOC values reported in one study of 100 groundwaters is $1.2 \mathrm{mg} / \mathrm{L}$.

Dissolved organic substances encompass wide range of compounds including humic substances, amino acids, fatty acids, phenols, sterols, carbohydrates, and porphyrins. Humic substances make up about 40 to $80 \%$ of the dissolved organics in surface waters. Groundwaters appear to contain somewhat less humic organic matter.

Humic compounds are poorly characterized, chemically and structurally complex, polyelectrolyte-like materials that range in molecular weight from a few hundred to several thousands. They can be subdivided into three fractions based on their solubility in acid and alkaline solutions: (1) humic acid (HA), which is soluble only in alkaline solutions; (2) fulvic acid (FA), which is soluble in both acid and base; and (3) humin, which is insoluble in both acid and base. Humic substances are composed predominantly of carbon, oxygen, hydrogen, and nitrogen, with small amounts of sulfur. These elements combine to form functional groups (structurally distinct arrangements of atoms) that play a dominant role in chemical reactions involving humic substances. The principal functional groups in humic materials are carboxyls, carbonyls, esters, ethers, alcoholic hydroxyls, phenolic hydroxyls, ketones, methoxyls, and quinones.

The dissolved humic substances (HA and FA) in surface waters are derived from soils where they originate by plant alteration, chemical polymerization, or microbial synthesis. The humic substances in groundwaters also appear to be derived mainly by leaching of humic materials from soils; however, some groundwater HA and FA may originate by leaching of fine particulate organic matter that was deposited concurrently with the sediments that make up the aquifer rock.

Humic substances can be studied and characterized by a wide variety of analytical wethode. Nondestructive analytical wethods include w and infrared opectrometry, nuclear magnetic resonance opectronetry, $X-r a y$ analysis, electron microscopy, viscosity messurements, surface tension measurements, nolecular wight measurements (particularly by gel filtration techniques), and electrometric titration. Destructive analytical techniques include various types of degradation (oxidat ive, reductive, hydrolytic, thermal, radiochemical, biological) as well as pyrolysis-gas chrowatography. Degradative methods particularly are used to study the structure of HA and FA. 


\section{Interaction of Humic Substances with Metals}

Humic substances can combine chemically with metal ions to form metalmate complexes. A metal complex is a chemical species that contains a metal om bonded to a greater number of ions or molecules than would be expected on simple valency considerations. Chelates are a special type of metalganic complex in which the ligands (the ions or molecules bonded or coornated with the metal ion) are bonded to the metal ion through two or more. $f$ ferent 1 igand atoms. The ligands thereby form part of heterocyclic rings which the metal is one of the members.

The tendency of metals to form complexes with humic substances in aqueous lutions can be measured by an empirically determined conditional stability nstant $\left(K^{\prime}\right)$ that is derived from the relationship

$$
K^{\prime}=\frac{[M L]}{[M][L]}
$$

are ML refers to bound metal (complexed with organic ligands), $M$ refers to se metal ions, $L$ refers to organic ligands, and the brackets indicate conitration. Conditional stability constants vary with the ionic strength of $\geq$ aqueous solution and, thus, differ from true thermodynamic stability conants, which are based on the activities of metals and ligands and are indeident of ionic strength. Thermodynamic stability constants for metal-humic aplexes commonly cannot be calculated owing to the fact that HA and FA do : have fixed chemical compositions, and activity-coefficient data for humic sstances are generally inadequate or unknown. Larger values of conditional bility constants indicate a greater tendency toward complex formation and sater stability of the complex or chelate.

In addition to forming soluble complexes with metals, humic materials can io interact with metal ions to forn colioids composed of water-insoluble :al humates. Humic substances have negative charges; therefore, they can readily coagulated by electrolytes to form colloids. In general, trivalent is are more effective in coagulating humic substances than divalent ions, I divalent ions are more effective than monovalent ions. The chemistry of loids is still poorly understood, however, and the overall importance of :al-humic colloid formation in natural waters remains to be established.

Several factors have been demonstrated to affect the formation and bility of metal-hamic complexes in natural waters. These factors include concentrations and types of metal ions and humic substances as well as ironmental variables such as $\mathrm{pH}$ and ionic strength. The effect of each these parameters is briefly summarized below.

\section{Type of Metal Ion}

Sowe metal ions are weskly bound to humic substances, whereas others : much more firmly bound. It is difficult to make generalizations about the perties of metal ions that affect bond strength, although it has been proled that bond atrength varies inversely with the ionic radius and the second lization potential of the metals. One empirical study determined that the 
comon metals can be broken down into three groups according to the relative strengths of their bonds with humic substances: (1) strong: $\mathrm{Fe}^{3+} \mathrm{Hg}^{2+}$; (2) intermediate: $\mathrm{Cu}^{2+}, \mathrm{Pb}^{2+}, \mathrm{Al}^{3+}$; and (3) weak: $\mathrm{Ni}^{2+}, \mathrm{Cr}^{3+}, \mathrm{Zn}^{2+}, \mathrm{Mn}^{2+}$, $\mathrm{Co}^{2+}, \mathrm{Cd}^{2+}, \mathrm{Mg}^{2+}, \mathrm{Ca}^{2+}$.

\section{Type of Organic Matter}

Data on the relative binding strengths of HA versus FA are few, although many investigators suggest that the latter binds metals more strongly than the former. By contrast, one study of the binding of copper by $H A$ and $F A$ reported the opposite trend. The binding capacities of HA and FA with copper were found to vary anong HA and FA from different sources; however, in all cases where the binding capacities of $\mathrm{HA}$ and FA from the same general environwent were compared, HA was a stronger binder of $\mathrm{Cu}^{2+}$ than FA.

\section{Metal and HA-FA Concentrations}

The effects of changes in metal or HA-FA concentration are conmonly expressed as a ratio; i.e., [M]/[HA] or [M]/[FA]. Most studies have demonstrated that decreases in these ratios cause an increase in the stability of netal-organic complexes. That is, an increase in the concentration of HA or FA or a decrease in metal concentration causes an increase in the tendency to form metal-humic complexes and in the stabilities of these complexes.

$$
\text { 4. } \mathrm{pH}
$$

With few exceptions, studies of $\mathrm{pH}$ have found general increase in stability of metal-humic complexes with increasing pH. Increasing complexation with increasing $\mathrm{pH}$ is apparently the result of decreasing competition between metal ions and $\mathrm{H}^{+}$ions for binding sites on the negatively charged organic substances.

\section{Ionic Strength}

Increase in ionic strength of aqueous solutions causes a decrease in the stability of metal-humic complexes. Metals that form strong corplexes with humic substances appear to be affected more strongly by changes in ionic trength than those that form weaker complexis. That is, the stability of strongly bonded netal-huic complexes decreases more rapidly with increasing ionic etrength than that of weakly bonded complexes. This trend of decreas ing stability with increasing ionic strength reflects the effects of increased competition by other cations in solution for binding sites on the humic aterials.

\section{Complexing of Radionuclides by Organic Subatances}

Hunic substances also form soluble and insoluble complexes with radionuclides, including the actinide elements. Radionuclides any interact with huic materials in the soil environment or in ourface vaters or groundwaters. In the soil environent, radionuclides can form either nobile soluble conplexes, or insoluble complexes that way reas in attached to soil particulates such as clay ninerals. They may also form "rediocolloids" that precipitate and remove radionuclides from solution. The relative inportance of the 
processes that form soluble versus insoluble complexes, which have opposing effects on radionuclide mobility, remains to be established. Studies of some radionuclides have shown tendency for the radionuclides to become fixed in the soils by adsorption to humic substances that are firmly bound to clay ninerals or other particulates in the solls. Studles of other radionuclides show Increased mobility of the radionuclides owing to complexing with soluble HA or FA.

Many radionuclides form strong, stable, soluble conplexes with dissolved HA and FA in surface waters and groundwaters. Under some conditlons, stable insoluble complexes (colloids) may also form. Stable soluble complexes appear more likely to form than colloids, given the low concentrations of radionuclides present in most natural waters; however, the conditions that favor formation of collolds over soluble complexes are poorly understood. A few available data suggest that colloid formation is favored by increasing radionuclide concentration and low $\mathrm{pH}$ values. Also, HA appears to cause flocculation and colloid formation more readily than FA. The tendency toward solloid formation also appears to vary with the type of radionuclide. For example, some preliminary data suggest that, at low $\mathrm{pH}$, Th and Am have a greater tendency to cause flocculation of $\mathrm{HA}$ and $\mathrm{FA}$ than $\mathrm{Pu}, \mathrm{Np}$, and $\mathrm{U}$.

Numerous studies have now established that the formation of soluble radionuclide-humic complexes is generally favored by increased concentrations of $\mathrm{HA}$ and FA. The oxidation state of actinide elements and the $\mathrm{pH}$ also have $a$ pronounced effect on complex formation. Other factors that affect the stability of radionuclide-organic complexes include radionuclide concentration, ionic strength, and temperature. The principal effects of these variables are summarized below.

\section{Oxidation State}

The oxidation state of the actinide elements, many of which exist In multiple oxidation states, appears to be one of the most important controls on their chemical behavior. The stable oxidation state of the enviroment is governed by the presence of oxidizing and reducing agents and complexing ligands. Organic substances act not only as complexants but also as reducing agents; thus, radionuclides are likely to exlot in their lower oxidation states in the presence of large concentrations of dissolved organic substances. In zeneral, the actinides appear to be more soluble in their higher oxidation atates than in their reduced forms. Actinide elements that have the same ixidation state tend to behave similarly chemicalily; e.g., the behavior of Pu(III) is similar to that of Am(III). The presence of dissolved humic substances in aqueous systems has two opposing tendencies on the mobility of the sctinide elements. On the one hand, humic substances bring about the reduction of actinides such as $\mathrm{Pu}(\mathrm{V})$ to $\mathrm{Pu}(\mathrm{IV})$, causing a decrease in solubility Ind mobility; however, competitive chelation caused by the Increased tendency to foration of soluble complexes in the presence of $\mathrm{HA}$ and FA acts in the spposite direction to increase mobility.

\section{2. 陡}

The complexing of actinides wh th $\mathrm{HA}$ and FA 18 strongly dependent upon $\mathrm{pH}$, because both the hydrolysis of the nuclides and the discociation of the acids are pH dependent. Also, pH affects the oxidation states of the 
actinides; i.e., in general, lower oxidation states are favored by acidic conditions. Most studies that have examined the effects of pH on radionuclideorganic complexing have found a general trend of increasing complex formation (solubilization of the radionuclide) with increasing $\mathrm{pH}$, although the trend is not linear. In general, neutral to basic $\mathrm{pH}$ values favor complexation and solubilization over acidic ph values. This trend appears to be opposite to that found in most studies of radionuclide sorption onto rock materials that have been carried out in solutions free of humic substances. These adsorption studies typically show that radionuclide adsorption onto rock materials increases (solubility decreases) as the pH increases, although this trend may not hold over the entire range of $\mathrm{pH}$ values. Thus, increasing $\mathrm{pH}$ appears to favor formation of soluble complexes of radionuclides in the presence of humic substances and decreased sorption onto solid phases, in contrast to increased sorption onto solid phases in the absence of humic substances.

\section{Temperature}

Studies ó radionuclide sorption onto rock materials in solutions free of organic complexants show, in general, that increase in temperature favors increased sorption onto the rock (decreased solubilization of the nuclide), although the exact effect depends upon the radionuclide involved and the temperature range. That is, sorption may not increase through all temperature ranges for a particular radionuclide, and may not increase at all for some radionuclides. Then dissolved humic substances are added to solutions at a given temperature, the general effect is to increase solubilization and decrease sorption. Preliminary data suggest that if temperature is then increased, a general trend of decreasing solubilization (increasing sorption) is observed, though the effects vary with different radionuclides and with in different temperature ranges. Thus, increased sorption of radionuclides onto rock materials at higher temperatures occurs both in solutions containing organic complexants and in those free of such complexants, although the presence of organic substances decreases sorption in all temperature ranges and the effects of temperature on sorption appear to be less severe in solutions with high concentrations of organics than in those with lower concentrations. It is difficult to conclude from these sorption studies whether increasing temperature does or does not increase the stability of radionuclide-organic complexes. Experimental results need to be recast in terms of conditional stability constants that are calculated for experimental runs made over a range of temperaturcs and where all other solution and environmental parameters are held constant.

\section{Ionic Strength}

Only a few studies have examined the effects of ionic strength on radionuclide-organic complexing. One well-documented study of Eu binding by FA demonstrated a significant decrease in binding of Eu with increasing ionic strength of NaCl solutions with in the range of 0.05 to $0.30 \mathrm{M}$. Presumably, ionic strength affects other radionuclides in a similar manner. Thus, preliminary studies suggest that the stability of radionuclide-organic complexes, like that of trace metal-organic complexes, decreases in the presence of increasing concentrations of competing cations. 
Inorganic ligands ouch $\mathrm{as} \mathrm{HCO}_{3}{ }^{-}$and $\mathrm{SO}_{4}{ }^{2-}$ may also affect

radionuclide-organic complexing by competing with organic ligands for avallable nuclide ions. In the alkaline groundwater enviroment, carbonate is the most likely inorganic ligand to interact with radionuclides. Some available data suggest that the relative bond strength of radionuclide-humic complexes and radionuclide- $\mathrm{CO}_{3}{ }^{2-}$ complexes varies with the source of the humic material and the $\mathrm{pH}$. In one study, it was found that Eu can be complexed more strongly at pH 8 by as 1 ittle as 2 ppm FA than by $\mathrm{CO}_{3}{ }^{2-}$, when the $\mathrm{HCO}_{3}$ concentration does not exceed $250 \mathrm{ppm}$. In another study of Pu complexing in seawater, the complexing of $\mathrm{Pu}$ with $20 \mathrm{mg} / \mathrm{L} \mathrm{DOC}$ appeared actually to be enhanced by the presence of carbonate ion. In the other hand, a study of radionuclide-organic complexing in a high-alkalinity lake demonstrated that Pu complexing with the DOC of the lake water was little affected by high alkalinity, but that the complexing behavior of $U$ appeared to be controlled by alkalinity rather than DOC concentration. Obviously, the effects on radionuclide-organic complexes caused by the presence of Inorganic ligands depend upon the type of radionuclide and the $\mathrm{pH}$-and probably other factors as well. Too few data are available to draw a more definite conclusion.

\section{Radionuclide Concentration}

A general trend of decreasing complex stability with increasing radionuclide concentration has been observed in most studies of radionuclideorganic complexing. This is the same trend reported in most studies of trace metal-organic complexing. This tendency indicates that if HA or FA concentration in a solution is held constant, further addition of radionuclide to the solution will decrease the capacity of the solution to form soluble radionuclide-organic complexes.

\section{Humic and Fulvic Acld Concentration}

It has now been clearly established that HA and FA have a solubilizing effect on most radionuclides as a result of forming stable, soluble complexes with the radjonuclides. Concentrations of dissolved humlc materlals as low as $1 \mathrm{mg}(\mathrm{C}) / \mathrm{L}$ have been shown to have a measurable effect on solubilization. Several studies have established that complexation increases with increasing concentration of HA or FA, in some cases almost linearly. Most experimental studies of radionuclide complexing by humic materials have been carried out using purified HA or FA extracted from soils. The process of extraction and purification removes most to the naturally complexed metal Ions (such as Fe) from these humic materials, malking them much more receptive to complexing with radionuclides than the indigenous humic substances dissolved in surface waters and groundwaters. There is a need now to carry out more definitive studies on radionuclide complexing by these indigenous humic materials, particularly the humic substances in deep ground ters that are 1ikely to be subjected to the greatest impact from radlonuclides escaping from deep radioactive-4aste repositorles. Succeeding studies will have to examine the effects on complexing of small changes in the concentration of indigenous DOC within the limited range of about 1 to $10 \mathrm{mg} / \mathrm{L}$, which are likely to be e.countered in deep groundwaters. 
REFERENCES

\section{ALLARD-1979}

B. Allard and G. W. Beall, Sorption of Americium on Geologic Media,

J. Environ. Sci. Health $114(6): 507-518$ (1979).

\section{ALLARD-1993}

B. Allard and J. Rydberg, Behavior of Plutonium in Natural Waters, in

W. T. Carnall and G. R. Choppin (eds.), Plutonium Chemistry, American Chemical Society, Washington, DC, Pp. 275-296 (1983).

\section{BALRGH}

J. C. Balogh and D. F. Grigal, Soil Chromatographic Movement of Technetium-99 through Selected Minnesota Soils, Soil Sci. 130:278-282 (1980).

\section{BARNES}

H. L. Barnes, Geochemistry of Hydrothermal Ore Deposits, 2nd Ed., John Wiley \& Sons, Inc., New York (1979).

BELL

C. F. Be11, Principles and Applications of Metal Chelation, Clarendon Press, Oxford, 149 pp. (1977).

BERTHA

E. L. Bertha and G. R. Choppin, Interaction of Humic and Fulvic Acids with Eu(III) and Am(III), J. Inorg. Nuc1. Chem. 40:655-658 (1978).

BOGGS-1984A

S. Boggs, Jr., and M. G. Seitz, The Influence of Dissolved Organic Substances in Groundwater on Sorption Behavior of Americium and Neptunium, Argonne National Laboratory, ANL-83-84 (1984).

BOCGS-1984B

S. Bogga, Jr., N. U. Sturchio, and M. G. Seitz, Trace-Element Transport in Lithic Material by luid Flow, in M. J. Steindler, Fuel Cycle Prograns Quarterly Progress Report, Jul.y-September 1983, Argonne National Laboratory, ANL-83-88 (1984).

BOGGS-1985

S. Bogge, Jr., D. L. Livermore, and M. G. Seitz, Humic Macromolecules in

Natural Watere, Rev. Macromol. Chem. Phys. C25(4):599-657 (1985).

BONDIETTI-1975

E. A. Bondietti, S. A. Reynulds, and M. H. Shanks, Interaction of Plutoniu with Complexing Substances in Soils and Natural Waters, in Transuranic Nuclides in the Environent, International Atomic Energy Agency, IARA-SY-199/51, pp. 273-287 (1975).

BOKLIETTI-1979

E. A. Dondietti and C. W. Francis, Geoloric Migration Potentials of Technetiu-99 and Neptuniu-237, science 203:1337-1340 (1979). 
BONDIETTI-1980

E. A. Bondietti and T. Tamura, Physicochemical Associations of Plutonium and Other Actinides in Soils, in W. C. Hanson (ed.), Transuranic Elements in the Environment, Technical Information Center, U. S. Department of Energy, PP. 145-164 (1980).

BONDIETTI-1981

E. A. Bondiet $\mathrm{t}$, The Influence of Geochemical Variables on Long-Lived Radionuclide Migration and Risk Assessment, Proceedings of the Symposium on Uncertainties Associated with the Regulation of the Geologic Disposal of High-Level Radioactive Waste, U.S. Nuclear Kegulatory Commission, NUREG/CP-0022, CONF-810372, 13 pP. (1981).

BRESNAHAN

W. T. Bresnahan, C. I. Gra.at, and J. H. Weber, Stability Constants for the Complexation of Copper(II) Ions with Water and Soil Fulvic Acids Measured by an Ion-Selective Electrode, Anal. Chem. 50:1675-1679 (1978).

SAROTHERS

W. W. Carothers and Y. K. Kharaka, Aliphatic Acid Anions in 0il-Field Waters - Implications for Origin of Natural Gas, Am. Assoc. Pet. Geol. Bu11. 62:2441-2453(1978).

CHABEREK

S. Chaberek and A. E. Martell, Organic Sequestering Agents, John Wiley \& Sons, Inc., New York, 616 pp. (1959).

CHEBOTINA

M. Y. Chebotina, Influence of Plant Extracts on the Mobility of Iron 59 and Cobalt 60 in Soil under Conditions of Dynamic Laboratory Experiments, Sov. Radiochem. 13:756-759 (1971).

CHOPPIN-1978

G. R. Choppin and L. Kullberg, Protonation Thermodynamics of Humic Acid,

J. Inorg. Nuc 1. Chem. 40:651-654 (1978).

CHC PPIN-1980

G. R. Choppin, Binding of Actinides by Humic Acid, Thalassia Jugosl., $16: 243-247(1980)$.

CHOPPIN-1 $981 \mathrm{~A}$

G. R. Choppin and K. L. Nash, Eissociation Kinetics of Thorium and Humic Acid, J. Inorg. Nuc 1 . Chem. 43:357-359 (1981).

CHOPlIY-1981 B

G. R. Choppin and P. M. Shanbhag, Binding of Calcium by Humic Acid,

J. Inorg. Nuc 1. Chem. 43:921-922 (1981).

\section{CHOPPIN-1983}

G. R. Choppin, Aspects of Plutonium Solution Chemistry, in $W$. T. Carnall and G. R. Choppin (eds.), Plutonium Chemistry, American Chemical Society, Hashington, DC, pp. 213-230 (1983). 
CHRISTMAN-1983A

R. F. Christman and E. T. Gjessing (eds.), Aquatic and Terrestrial Humic Naterials, Ann Arbor Science Publishers, Ann Arbor, 538 pp. (1983).

CHRISTMAN-1 983B

R. F. Christman and E. T. Gjessing, Priorities in Humic Regearch, in

R. F. Christman and E. T. Gjessing (eds.), Aquatic and Terrestrial Humic Materials, Ann Arbor Science Publishers, Ann Arbor, pp. 517-528 (1983).

\section{CLAYTON-1981}

J. R. Clayton, Jr., T. H. Sibley, and W. R. Schell, Diatribution Coefficients for Radionuclides in Aquatic Environments, U.S. Nuclear Regulatory Commission, NUREG/CR-1853, Vol. 1, 30 pp. (1981).

CLAYTON-1982

J. R. Clayton, Jr., T. H. Sibley, and W. R. Schell, Effects of Selected Organic Compounds on Radionuclide Adsorption to Sediments in Freshwater Systems, Bull. Environ. Contam. Toxicol. 28:409-415 (1982).

\section{CLEVELAND-1976}

J. M. Cleveland and T. F. Rees, Investigation of Solubilization of Plutonium and Americium in Soil by Natural Humic Compounds, Environ. Sci. Technol. 10:802-806 (1976).

CLEVELAND-1981

J. M. Cleveland and T. F. Rees, Characterization of Plutonium in Maxey Flats Radioactive Trench Leachates, Science 212:1506-1509 (1981).

\section{CZYSCINSRI}

R. S. Czyscinski and M. Rinsley, Stability of Organo-Radionuclide Complexes in Anoxic Disposal Trench Environments, in K. S. Czyscinski, R. F. Pietrzak, and A. J. Weiss (eds.), Evaluation of Isotope Migration - Land Burial: Water Chemistry at Commercially Operated Low-Level Radioactive Waste Disposal Sites, Quarterly Progress Report, April-June 1981, U.S. Nuc lear Regulatory Commisoion, NUREG/CR-2192, Brookhaven National Laboratory, BNL-NUREG-51409, 26 pp. (1981).

\section{DAKLMAN}

R. C. Dahlman, R. A. Bondietti, and D. Eyman, Biological Pathways and Chenical Behavior of Plutonium and Other Act inides in the Environment, in A. M. Friedman (ed.), Actinides in the Enviroment, American Chenical Society, Washington, DC, PP. 47-80 (1976).

De HAMY

H. De Haan, Use of Ultraviolet Spectroscopy, Gel Filtration, Pyrolyoie/ Maes Spectrometry and Nubers of Benzonte-Metabolizing Bacteria in the Study of Huification and Degradation of Aquatic Organic Matter, in R. F. Chrietsan and E. T. Gjessing (eds.), Aquatic and Terrestrial Humic Materiale, Ann Arbor Science Publiohera, Ann Arbor, pp. 155-182 (1983). 
DEMPSEY

B. A. Dewpsey and C. R. O'Mella, Proton and Calcium Complexation of Four Fulvic Acid Fractions, in R. F. Christman and E. T. Gjessing (eds.), Aquatic and Terrestrial Humic Materlal, Ann Arbor Sclence Publishers, Ann Arbor, pp. 219-238 (1983).

DORMAAR

J. F. Dormaar, Can. J. So11 Sc1. 52:67-77 (1972).

FAULKNER

D. J. Faulkner et al., In E. D. Goldberg (ed.), Dahlem Konferenzen, Berlin, 623 pp. (1975).

FELBECK

G. T. Felbeck, Chemical and Biological Characteristics of Humic Matter, in A. D. McLaren and J. Skiyins (eds.), Soll Blochem1stry, Vol. 2, Marcel Dekker, Inc., New York, pp. 36-59 (1971).

\section{GJESS ING}

E. T. Gjessing, Physical and Chemical Characteristics of Aquatic Humis, Ann Arbor Sclence Publishers, Ann Arbor, 120 pp. (1976).

\section{GRIGOROPOULOS}

S. G. Grigoropoulos and J. W. Smith, Trace Organics in Subsurface Waters,

in S. J. Faust and J. V. Hunter (eds.), Organic Compounds In Aquatic

Environments, Marcel Dekker, Inc., New York, pp. 95-118 (1971).

\section{GUSTAFSON}

R. L. Gustafson and J. Paleos, Interactions Responsible for the Selectlve Adsorption of Organics on Organic Surfaces, in S. J. Faus: and J.V. Hunter (eds.), Organic Compounds in Aquatic Environments, Marcel Dekker, Inc., New York, pp. 213-238 (1971).

GUY

R. D. Guy and C. L. Chakrabart1, Studies of Metal organic Interactions In Model Systems Pertaining to Natural Waters, Can. J. Chem. 54:2600-2611 (1976).

\section{HARVEY}

G. R. Harvey, D. $\Lambda$. Boran, and J. M. Tokar, The Structure of Marine

Fulvic and Humlc Ac1ds, Mar. Chem. 12:119-132 (1983).

HuYes

M. H. B. Hayes and R. S. Swlft, The Chemistry of Soil Organic Collolds,

in D. J. Greenland and M. H. B. Hayes (eds.), The Chemistry of Soil

Constituents, John Wiley Sons, New York, pp. 179-321 (197k).

\section{HIRATA}

S. Hirata, Stablity Constants for Complexes of Transition-Metal Ions With Fulvic and Humic Ac1ds in Sedimente Measured by Gel Filtration, Talanta 28:809-815 (1981). 
HOUGHTON

R. P. Houghton, Metal Complexes in Organic Chemistry, Cambridge

University Press, Cambridge, 308 pp. (1979).

\section{IRVIKG}

H. Irving and J. P. Willians, The Stability of Transition-Metal

Complexes, J. Chem. Soc., p. 3192 (1953).

\section{ISHIWATARI}

R. Iohiwatari, Chemical Nature of Sedimentary Humic Acids: Discussion,

in D. Povoledo and H. L. Golterman (eds.), Humic Substances, Their

Structure and Function in the Biosphere, Centre for Agricultural

Publishing and iocumentation, Wageningen, pp. 87-108 (1973).

KERNDORFF

H. Kerndorff and M. Schnitzer, Sorption of Metals on Humic Acid,

Geoch im. Cosmoch im. Acta 44:1701-1708 (1980).

RIM

J. I. Kim, G. Buckau, F. Baumgärtner, H. C. Moon, and D. Lux, Colloid

Generation and the Actinide Migration in Goreleben Groundwaters, in

Scientific Basis for Nuclear Waste Management, North-Holland,

New York (1984).

LANDA

E. R. Landa, L. Thorvig, and R. G. Gast, Effect of Selective Dissolution, Electrolytes, Aeration, and Sterilization on Technetium-99 Sorption by Soils, J. Environ. Quel. 6:181-187 (1977).

\section{LANGFORD}

C. H. Langford, D. S. Gamble, A. W. Underdown, and S. Lee, Interaction of Metal Ions with a Weil Characterized Fulvic Acid, in R. F. Christman and E. T. Gjessing (eds.), Aquatic and Terrestrial Humic Materials, Ann Arbor Science Publishers, Ann Arbor, pp. 219-238 (1983).

\section{LEENHEER-1974}

J. A. Leenheer, R. L. Malcolm, P. W. McKinley, and L. A. Eccles,

Occurrence of Dissolved Organic Carbon in Selected Groundwater Sampl as

in the United States, J. Res. U.S. Geol. Surv. 2:361-369 (1974).

\section{LEENHEEK 1982}

J. A. Leenheer and J. C. Bagby, Organic Solutes in Ground Water at the Idaho National Engineering Laboratory, U.S. Geol. Surv. Water-Resour. Invest., 82-15, 39 pp. (1982).

LI

W. C. Li, D. M. Victor, and C. L. Chakrabarti, Effect of pH and Uranive Concentration on Interaction of Uraniv(VI) and Uraniu(IV) with Orranic Eigands in Aqueous Solutions, Anal Chen. 32:520-523 (1960).

LIAO

W. Liso, R. F. Chrietman, J. D. Johncon, D. S. Millington, and

J. R. Hass, Structural Characterisation of Aquatic Huaic Material,

Environ. Sci. Technol. 16:403-410 (1982). 
MALCOLM

R. L. Malcolm and W. H. Durum, Organic Carbon and Nitrogen Concentrations and Annual Organic Carbon hoad of SIx Selected RIvers of the United States, U. S. Geol. Surv., Water-Supply Pap. 1817-F, 20 PP. (1976).

MANTOURA-1975

R. F. C. Mantoura and J. P. Rliey, The Use of Gel Filtration in the Study of Metal binding by Humic Aclds and Related Compounds, Anal. Chim. Acta 78:193-200 (1975).

MANTOURA-1978

R. F. C. Nantoura, A. Dickson, and J. P. R1l6y, Complexation of Metals with Humic Naterials in Natural Waters, Estaur. Coast . Mar. ScI. 6:387-408 (1978).

MARINSKY

J. A. Marinsky, The Complexation of Eu(III) by Fulvic AcId, SKBF/KBS

Teknisk Rapport 83-14, 63 pp. (1983).

MARTELL-1952

A. E. Martell and M. Calvin, Chemistry of the Metal Chelate Compounds, Prentice-Hall, Inc., New York (1952).

MARTELL-1 971

A. E. Martell, Principles of Complex Formation, in S. J. Faust and J. V. Hunter (eds.), Organic Compounds in Aquatic Enviroments, Marcel lekker, Inc., New York, pp. 239-263 (1971).

MATHEW

E. Mathew and K. C. Pillai, study of Chemical speciation of Plutonium in Sea Water-Sediment System, in Techniques for Identifying Transuranic Speciation In Aquatic Enviroments, International Atomic Energy Agency, pp. $195-207$ (1981).

MEANS-1978

J. L. Means, D. A. Crerar, and J. O. Duguid, Migration of Radioactive Waste: Radionuclide Mobilization by Complexing Agents, Science 200:1477-1481 (1978).

MEAS-1982A

J. L. Means, The Organic Geochemistry of Deep Groundwaters, Battelle columbus Laboratortes, ONWI-268, 22 Pp. (1982).

MTANS-1982B

J. L. Heans, The Importance of Organic Compounds in cround Water as Radionuclide Mobilizing Agents, Battelle Columbus Laboratories, OWI I -348, 28 pp. (1982).

NEANS -1983

J. L. Means, A. S. Maest, and D. A. Crerar, The Oryanic Chemistry of Deep Ground Haters and Radionuclide Partitioning Experiments under Bydrothermal Condit 1one, Battelle Colubue Laboratories, ONHI-448, $75 \mathrm{pp} \cdot(1983)$. 
MELLOR

D. P. Hellor, Historical Background and Pundanental Concepts [of chelating agente and aetal chelates], in F. P. Dwyer and D. P. Mellor (eds.), Chelating Agente and Metal Chelates, Academ1c Press, New York, pp. 1-50 (1964).

MEYBECK

M. Meybeck, R1ver Traneport of Organic Carbon to the Ocean, In Carbon Dioxide Effects Research and Assessment Program: Flux of Organic Carbon by Rivere to the Ocean, prepared by the Committee on Flux of Organic Carbon to the Ocean (G. E. Likens, Ch.), Div. of Blological Sclences, National Research Counc1, , U. S. Dept. of Energy, Offlce of Energy Research, Washing ton, DC, CONF-8009140, 219 pp. (1981).

MORTENSEN

J. L. Mortensen, Complexing of Metals by So11 Organic Matter, So11 Sc1. Soc. Proc. 33: 179-186 (1963).

NASH-1980

K. L. Nash and G. R. Choppin, Interaction of Humic and Fulvic Acide with Th(IV), J. Inorg. Nucl. hem. 42:1045-1050 (1980).

NASH-1981

K. L. Nash, S. Fried, A. M. Friedman, and J. C. Sullivan, Redox Behavior, Complexing, and Adsorption of Hexavalent Actinides by Humic Acid and Selected Clays, Environ. Sci. Technol. 15:834-837 (1981).

NELSON-1980

D. M. Neleon, J. 0. Karttunen, K. A. Orlandin1, and R. P. Larson, Influence of Dissolved Organic Carbon on Sorption of Plutonium to Natural Sediments, in R. E. Rowland and W. R. Penrose (eds.), Radlological and Environmental Research Division Annual Report, Argonne National Laboratory, ANL-80-115, Part III, pp. 19-25 (1980).

NELSON-1982

D. M. Nelson, J. O. Karttunen, and P. Nehlhoff, Influence of Colloldal Dissolved Organic Carbon (DOC) on the Sorption of Plutonium on Natural Sedinente, in R. E. Rowland and W. R. Penrose (eds.), Radiological and Environmental Research Division Annual Report, Ecology, Argonne National Laboratory, ANL-81-85, Part III, pp. 48-52 (1982).

\section{NISHITA}

H. Nishte and R. Mo Haug, The Effect of Fulvic and Hunlc Actde and Inorganic Phage of Soll on the Sorption and Extractability of 239 Pu(IV), So11 Sc1. 128:291-296 (1979).

OLOFSSON

U. Olofason and B. Allard, Conplexing of Actinides vith Maturally Occurrin: Oryanic substances - Literature Survey, SKBF/KBS Tekn 1ek Repport 83-09, 27 pp. (1983). 
ONG

H. L. Ong, V. E. Swanson, and R. E. Bisque, Natural Organic Acids as Agents of Chemical Weathering, U. S. Geol. Surv. Prof. Pap. 700-C, PP. 130-137 (1970).

ORLANDINI

K. A. Orlandini, Observations on the Behavior of Americium in Natural Waters, in R. E. Rowland and W. R. Penrose (eds.), Radiological and Environmental Research Division Annual Report, Ecology, Argonne National Laboratory, ANL-81-85, Part III, PP. 53-56 (1982).

PERDUE-1 $983 \mathrm{~A}$

E. M. Perdue and C. R. Lytle, A Critical Examination of Metal-Ligand Complexation Models: Application to Defining Multiligand Mixtures, in R. F. Christman and E. T. Gjessing (eds.), Aquatic and Terrestrial humic Materials, Ann Arbor Science Publishers, Ann Arbor, pp. 295-314 (1983).

PERDUE-1983B

E. M. Perdue, Chemical Modeling of Metal Complexation by Humic Substances, Trans. Am. Geophys. Union 64:249, abstract (1983).

\section{PIERCE}

R. H. Pierce and G. T. Felbeck, Jr., A Comparison of Three Methods of Extracting Organic Matter from Soils and Marine Sediments, in D. Povoledo and H. L. Golterman (eds.), Humic Substances, Their Structure and Function in the Biosphere, Centre for Agricultural Publishing and Documentation, Wageningen, pp. 217-232 (1973).

PLECHANOV

N. Plechanov, B. Josefsson, D. Dyrssen, and $\mathrm{K}$. Lundquist, Investigations on Humic Substances in Natural Waters, in R. F. Christman and E. T. Gjessing (eds.), Aquatic and Terrestrial Humic Materials, Ann Arbor Science Publishers, Ann Arbor, pp. 387-405 (1983).

\section{RAINVILLE}

D. P. Rainville and J. H. Weber, Complexing Capacity of Soil Fulvic Acid for $\mathrm{Cu}(\mathrm{II}), \mathrm{Cd}(\mathrm{II}), \mathrm{Mn}(\mathrm{II}), \mathrm{Ni}(\mathrm{II})$, and $\mathrm{Zn}$ (II) Measured by Dialysis Titration: A Model Based on Soil Fulvic Acid Aggregation, Can. J. Chem. 60:1-5 (1982).

RASHID-1 969

M. A. Rashid and L. H. King, Molecular Weight Distribution Measurements on Humic and Fulvic Acid Fractions from Marine Clays on the Scotian Shelf, Geoch im. Cosmoch im. Acta 33:147-151 (1969).

RASHID-1970

M. A. Rashid and L. H. King, Major Oxygen-Containing Functional Groups Present in Humic and Fulvic Acid Fractions Isolated from Contrasting Marine Environments, Geoch im. Cosmochim. Acta 34:193-201 (1970).

\section{RASHID-1971}

M. A. Rashid and L. H. King, Chemical Characterization of Fractionated Huic Acids Associated with Marine Sedinente, Chen. Geol. 1:37-43 (1971). 
REUTER-1977

J. H. Reuter and E. M. Perdue, Importance of Heavy Metal-Organic Matter Interactions in Natural Waters, Geoch im. Cosmoch im. Acta 41:325-334 (1977).

REUTER-1983

J. H. Reuter, M. Ghosal, E. S. K. Chian, and M. Giabbai, Oxidative Degradation Studies on Aquatic Humic Substances, in R. F. Christman and E. T. Gjessing (eds.), Aquatic and Terrestrial Humic Materials, Ann Arbor Science Publishers, Ann Arbor, pp. 107-126 (1983).

ROBINSON

L. R. Robinson, J. T. Connor, and R. S. Engelbrecht, Organic Matter in

Illinois Groundwaters, Am. Water Works Assoc. J. 59:227-236 (1967).

ROSELL

R. A. Rosell, A. M. Miglierina, and L. Q. DeNevilla, Stability Constants

of Some Complexes of Argentine Humic Acids and Micronutrients, in

International Atomic Energy Agency (eds.), IAEA, Vienna, pp. 15-21

(1977).

ROSSOTTI

F. J. C. Rossotti and H. Rossotti, The Determination of Stability

Constants, McGraw-Hill Book Co., Inc., New York, 425 pp. (1961).

RYAN

D. K. Ryan and J. H. Weber, Fluorescence Quenching Titration for Determination of Complexing Capacities and Stability Constants of Fulvic Acid, Anal. Chem. 54:986-990 (1982).

SAAR-1979

R. A. Saar and J. H. Weber, Complexation of Cadmium(II) with Water-and Soil-Derived Fulvic Acids: Effects of pH and Fulvic Acid Concentration, Can. J. Chem. 57:1263-1268 (1979).

SAAR-1980

R. A. Saar and J. H. Weber, Lead(II) Complexation by Fulvic Acid: How It Differs from Fulvic Acid Complexation of Copper(II) and Cadmium(II), Geochim. Cosmoch im. Acta 44:1381-1384 (1980).

\section{SALTER}

P. F. Salter, L. L. Ames, and J. E. McGarrah, The Sorption Behavior of Selected Radionuclides on Columbia River Basalts, Rockwell Hanford Operations, RHO-BWI-LD-48, p. 38 (1981).

\section{SAXBY}

J. D. Saxby, The Significance of Organic Matter in Ore Genesis, in R. H. Wolf (ed.), Handbook of Stratabound Stratifore Ore Deposits, Vol. 2, Chapter 5, pp. 111-133, Elsevier Sci. Pub1. Co., New York (1976).

SCATCHARD-1949

G. Scatchard, The Attraction of Proteins for Sall Nolecules and Ions, Ann. NY Acad. Sci. 51:660-672 (1949). 
SCATCLARD-1956

G. Scatchard, J. S. Coleman, and A. L. Shen, Physical Chemistry of Protein Solutions. VII. The Binding of Some Small Anions to Serum Albumin, J. A. Chen. Soc. 79:12-20 (1956).

\section{SCANITZER-1969}

M. Schnitzer, Reactions between Fulvic Acid, a Soil Humic Compound, and Inorganic Soil Congtituents, Soil Sci. Soc. Am. Proc. 3j:75 (1969).

\section{SCHNITZER-1970}

M. Schnitzer and E. H. Hansen, Organo-Metallic Interactions in Soils: 8. An Evaluation of Methods for the Determination of Stability Constants of Metal-Fulvic Acid Complexes, Soil Sci. 109:333-340 (1970).

SCHNITZER-1972

M. Schnitzer and S. U. Khan, Humic Substances in the Environment, Marcel Dekker, Inc., 327 pp. (1972).

\section{SCHNITZER-1978}

M. Schnitzer and S. U. Khan (eds.), Soil Organic Matter, Developments in Soil Science 8, Elsevier Sci. Pub1. Co., New York, 319 pp. (1978).

SEITZ

M. G. Seitz et al., Transport of Radionuclides in Geologic Media: Annual Report October 1978 to September 1979, in J. F. Reylea (ed.), Task 4 Third Contractor Information Meeting, Pacific Northwest Laboratory, Richland, WA, PNL-SA-8571, Vo1. 1, PF. 77-154 (1980).

SERNE

R. J. Serne and J. F. Reylea, The Status of Radionuclide SorptionDesorption Studies Performed by the WRIT Program, Pacific Northwest Laboratory, PNL-3997, 83 Pp. (1982).

\section{SHANBHAG}

P. M. Shanbhag and G. R. Choppin, Binding of Uranyl by Humic Acid,

J. Inorg. Nuc 1. Chem. 43:3369-3372 (1981).

\section{SHCHEBETKOVSKII}

N. Shchebetkovskii and A. A. Bochkov, Interaction of Plutonium with

Natural Humus Substances, Radiokhimiya 17:952-956 (1975).

\section{SHEPPARD-1979}

J. C. Sheppard, M. J. Campbell, and J. A. Kittrick, Retention of Neptunium, Americium, and Curium by Diffusible Soil Particles, Environ. Sei. Technol. 13:680-684 (1979).

\section{SHEPPARD-1980}

J. C. Sheppard, M. J. Campbe11, T. Chang, and J. A. Kittrick, Retention of Radionuclides by Mobile Humic Compounds in Soil Particles, Environ. Sci. Technol. 14:1349-1353 (1980). 
SHEPPARD-1983

J. C. Sheppard and J. A. Kittrick, Factors Influencing the Transport of Actinides in the Groundwater Environnent, U.S. Dept. Of Energy, DOE/EV/73012-3, 41 Pp. (1983).

SIMPSON

R. M. Simpson, The Separation of Organic Chemicals from Water, Rohm and Haas, Philadelphia, 28 pp. (1972).

SOHN

M. L. Sohn and M. C. Hughes, Metal Ion Complex Formation Constants of Some Sedimentary Humic Acida with $\mathrm{Zn}$ (II), $\mathrm{Cu}$ (II) and Cd(II), Geochim. Cosmoch im. Acta 45:2393-2399 (1981).

STEVENSON-1976

F. J. Stevenson, Binding of Metal Ions by Humic Acids, in J. O. Nriagu (ed.), Envi ronmental Biogeochemistry, Vol. 2, Ann Arbor Science Publishers, Ann Arbor, Pp. 519-540 (1976).

STEVENSON-1977

F. J. Stevenson, Nature of Divalent Transition Metal Complexes of Humic Acids as Revealed by a Modified Potentiometric Titration Method, Soil Sci. 123:10-17 (1977).

STUE RMER

D. H. Stuermer and J. R. Payne, Investigations of Seawater and Terrestrial Substances with Carbon-13 and Proton Nuclear Magnetic Resonance, Geochim. Cosmoch im. Acta 40:1109-1114 (1976).

STUMM

W. Stumm and J. J. Morgan, Aquatic Chemistry, 2nd Ed., Wiley-Interscience, New York, 766 pp. (1981).

SWANSON

J. L. Swanson, Effect of Organic Complexants on the Mobility of Low-Level Waste Radionuclides in Soils, in Richland ANS Waste Meeting, April 198?, Vol. IV, 13 PP. (1982).

TARAMATSU

T. Takamatsu and T. Yoshida, Determination of Stability Constants of Metal-Humic Acid Complexes by Potentiometric Titration and Ion-Selective Electrodes, Soil sci. 125:377-386 (1978).

TKURMAN-1979

E. M. Thurman, Isolation, Characterization, and Geochemical Significance of Humic Substances from Ground Water, unpublished Ph.D. thesis, University of Colorado, 210 pp. (1979).

\section{THURMAN-1983}

E. M. Thurman and R. L. Malcolm, Structural Study of Heric Substances: New Approeches and Methode, in R. F. Chrietwen and E. T. Gjessing (eds.), Aquatic and Terrestrial kumic Materials, Ann Arbor Science Publishers, Ann Arbor, pp. 1-24 (1983). 
TORSTENFELD

B. Torstenfeld, K. Andersson, and B. Allard, Sorption of Strontium and Cesium on Rocks and Minerals, Chem. Geol. 36:123-137 (1982).

TRUITT-1981A

R. E. Truitt and J. H. Weber, Copper(II)- and Cadmium(II)-Binding Abilities of Some New Hampshire Freshwaters Determined by Dialysis Titration, Environ. Sci. Technol. 15:1204-1208 (1981).

TRUITT-1981B

R. E. Truitt and J. H. Weber, Determination of Complexing Capacity of Fulvic Acid for Copper(II) and Cadmium(II) by Dialysis Titration, Anal. Chem. 53:337-342 (1981).

VAN DIJK

H. Van Dijk, Cation Binding of Humic Acids, Geoderma 5:53-67 (1971).

WAHLGREN-1976

M. A. Wahlgren, D. M. Nelson, and K. A. Orlandini, Study of the Behavior of Transuranics and Possible Chemical Homologues in Lake Michigan Water and Biota, in Transuranic Nuclides in the Environment, Symposium Proceedings, San Francisco, 1975, STI/PUB/410, International Atomic Energy Agency, $1=$ ina, PP. 9-24 (1976).

WAHLGREN-1982

M. A. Wahlgren and K. A. Or landini, Comparison of the Geochemical

Behavior of Plutonium, Thorium and Uranium in Selected North American Lakes, in Envi ronmental Migration of Long-Lived Radionuclides,

International Atomic Energy Agency, Vienna, pp. 757-774 (1982).

WALTON

H. F. Walton, Chelation, Sci. Am., pp. 68-76 (June 1953).

WATTERS-1980

R. L. Watters, D. N. Edgington, T. E. Hakonson, W. C. Hanson, M. H. Smith,

F. W. Whicker, and R. E. Wildung, Synthesis of the Research Literature

[of transuranic elements], in W. C. Hanson (ed.), Transuranic Elements

in the Environment, Technical Information Center, U. S. Dept. of Energy, pp. 1-44 (1980).

\section{WATTERS -1983}

R. L. Watters, Aquatic Chemistry of Plutonium, in W. T. Carnall and

G. R. Choppin (eds.), Plutonium Chemistry, American Chemical Society, Wash ington, DC, pp. 297-316 (1983).

\section{WEISS}

A. J. Weiss, K. S. Czyscinski, and R. F. Pietrzak, Trench Water-Soil Chemistry and Interactions at the Maxey Flats Site-II, in L. J. Rirby (ed.), Radionuclide Distributions and Migration Mechanisms at Shallow Land Burial Sites, U. S. Nuclear Regulatory Commission, NUREG/CR-2383, pp. IV-1 - IV-23 (1981). 


\section{WIGGINS}

D. J. Wiggins and J. A. Franz, Mobility of Organic Complexes of Some Non-TRU Fission and Activation Products: A Selective Review, Pacific Northwest Laboratory, PNL-2607, 39 pp. (1978).

\section{WILLIAMS}

P. M. Williams, The Distribution and Cycling of Organic Matter in the Ocean, in S. J. Faust and J. V. Hunter (eds.), Organic Compounds in Aquatic Environments, Marcel Dekker, Inc., New York, pp. 145-163 (1971). ZUNINO

H. Zunino and J. P. Martin, Metal-Binding Organic Macromolecules in Soil: 2. Characterization of the Maximum Binding Ability of the Macromolecules, Soil Sci. 123:188-202 (1977). 
Distribution for ANL-84-78

\section{Interna1:}

J. K. Bates

J. Bogner

R. L. Breyne

F. A. Cafasso

A. M. Friedman

D. W. Green

D. R. Hamrin

J. E. Harmolr
W. Harrison

C. E. Johnson

R. B. Keener

D. M. Nelson

P. A. Nelson

W. R. Penrose

G. W. Reed

N. F. Sather

F. Schreiner
M. G. Seitz (15)

V. C. Stamoudis

M. J. Steindler

N. C. Sturchio

ANL Patent Dept. ANL Contract File

ANL Libraries (2)

TIS Files (6)

\section{Externa1:}

DOE-TIC, for distribution per UC-70 (309)

Manager, Chicago Operations Office, DOE

Chemical Technology Division Review Committee Members:

S. Baron, Brookhaven National Lab.

R. Winston, U. Chicago

R. G. Wymer, Oak Ridge National Lab.

D. H. Alexander, Office of Geologic Repository Deployment, USDOE

R. Barletta, Brookhaven National Lab.

J. W. Bennett, Office of Civilian Radioactive Waste Management, USDOE

N. J. Beskid, Battelle Memorial Inst., Argonne, Ill.

G. W. Bird, Atomic Energy of Canada Ltd., Pinawa

S. Boggs, Jr., U. Oregon (10)

D. J. Bradley, Battelle Pacific Northwest Lab.

D. Clark, Battelle Memorial Inst., Columbus

J. Cleveland, U. S. Geological Survey, Lakewood, Colo.

E. F. Conti, Office of Nuclear Regulatory Research, USNRC

$F$. R. Cook, Office of Nuclear Material Safety and Safeguards, USNRC

R. G. Dosch, Sandia National Labs., Albuquerque

T. Early, Rocksell Hanford Operations

B. R. Erdal, Los Alamos National Lab.

R. Ewing, U. New Mexico

D. Fortrey, Sandia National Labs., Albuquerque

D. E. Gordon, Savannah River Lab.

A. B. Gureghian, Battelle Memorial Inst., Argonne, Ill.

P. Helmke, U. Wisconsin-Madison

T. Hunter, Sandia ivational Labs., Albuquerque

D. Isherwood, Lawrence Livermore National Lab.

K. S. Kim, Office of Nuclear Regulatory Research, USNRC

J. Kircher, Battelle Memorial Inst., Columbus

G. A. Kolstad, Office of Energy Research, USDOE

L. W. rake, U. Texas, Austin

S. Lambert, Sandia National Labs., Albuquerque

D. Livermore, U. Oregun (5)

T. P. Longo, Office of Civilian Radioactive Wagte Management, USDOE

J. L. Means, Battelle Memorial Inst., Columbus

J. B. Mendel, Battelle Pacific Northwest Lab.

C. Noronha, Battelle Meworial Inst., Argonne, I11.

E. J. Nowak, Sandia National Labs., Albuquerque

v. Oversby, Laurence Livermore National Lab. 
M. J. Swith, Rockwell Hanford Operations

R. D. Walton, Jr., Office of Defense Waste and Byproducts Management, USDOE

D. F. Weill, Office of Energy Research, USDOE

P. A. Witherspoon, U. Callfornia, Berkeley

E. L. Zebroski, Electric Power Research Inst., Palo Alto 